\title{
THE HOP
}

AND TTS CONSTITUENTS. 


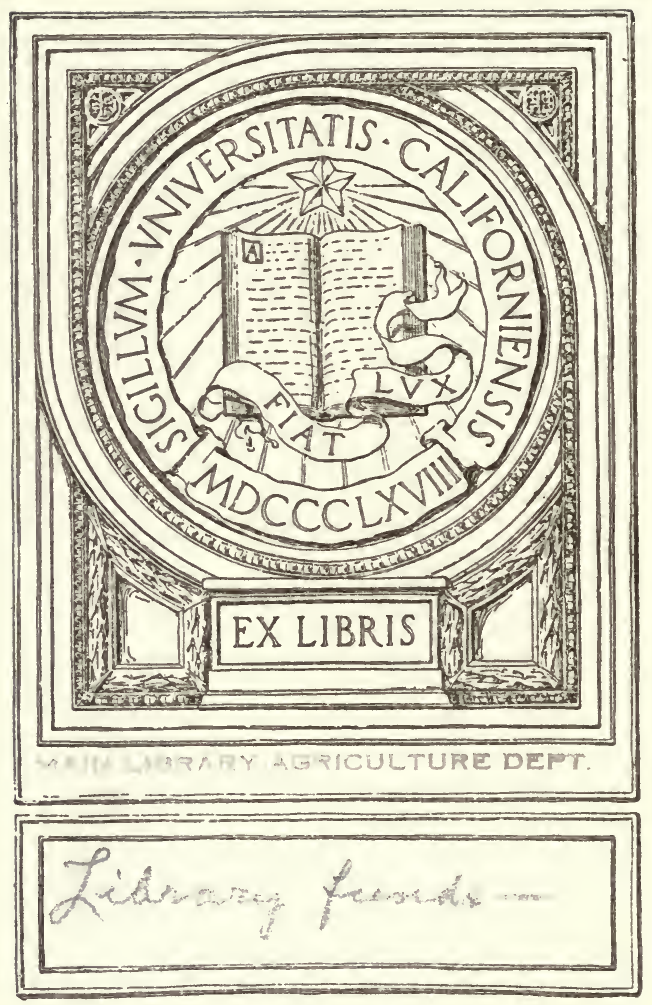






\section{THE HOP}

AND ITS CONSTITUENTS. 




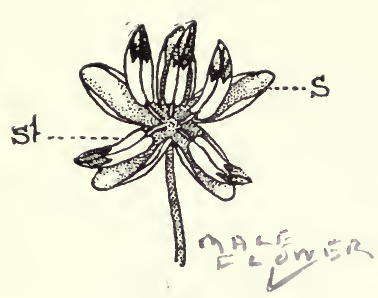

t.

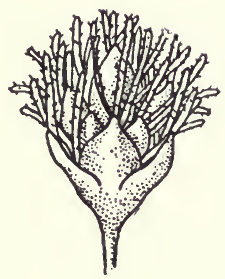

4.

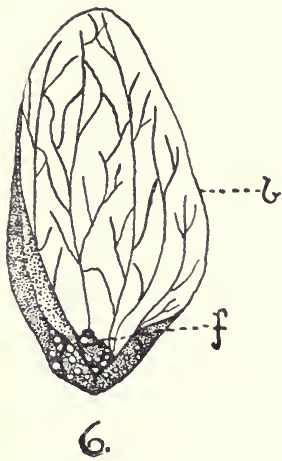

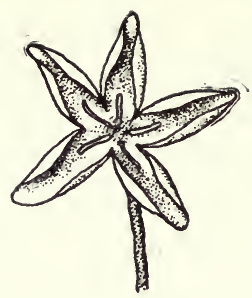

2.
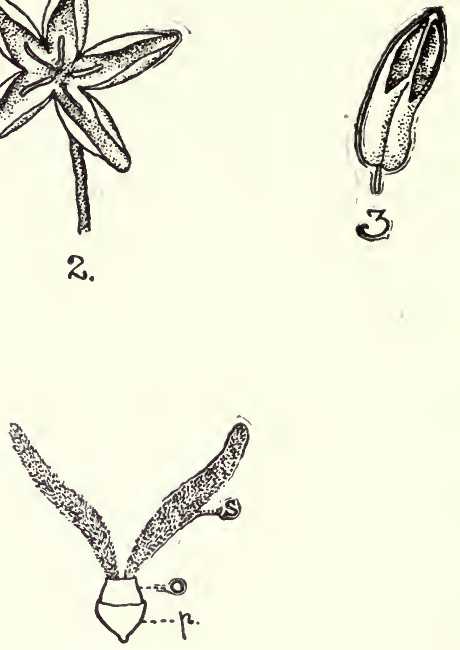

5.

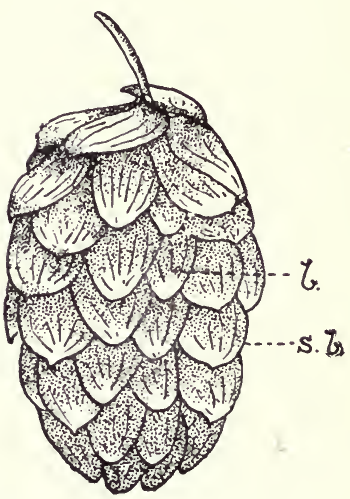

7.

FIG. I.

I. - A male hop. flower. \$ Perianth (sepal) st stamen.

.- Eeriánth of male flower with anthers removed; the fine short filaments are visible.

3. - A stam sn shcxing the dehissence of the anther.

7. - A young fernale inforescence (a hop "in burr") showing the stigmas ("brush").

5.-A complete female flower. $p$ The cup-shaped perianth; $o$ ovary; $s$ stigma.

6.-A bracteole $(b)$ surrounding the ripe fruit (" seed ") $f$.

7.-A ripe hop showing the stipular bracts $(s b)$ and bracteoles $(b)$.

$$
(\mathrm{I}-6 \times 3,7 \text { natural size.) }
$$




\section{THE HOP}

AND ITS CONSTITUENTS.

A MONOGRAPH ON THE HOP PLANT

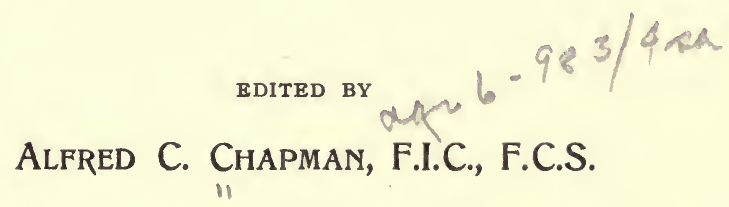

FIVE SHILLINGS NET.

LONDON :

THE BREWING TRADE REVIEW,

I 3 LITTLE TRINITY LANE, UPPER THAMES STREET. 
$\because \because \quad \vdots \because \vdots \vdots \vdots \vdots$

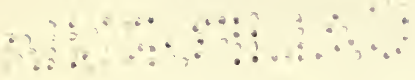

$$
\begin{aligned}
& \text { SB295 } \\
& \text { H } 6 C 5
\end{aligned}
$$

.MIV LIOKARY.AGRICULTURE DEF I 


\section{INTRODUCTORY.}

Nearly a century has elapsed since the constituents of the hop cone first attracted the attention of Chemists, and the fact that we are only now beginning to understand the principal chemical characters of some of those constituents and the rôles they play in the brewing process, is in itself the strongest evidence of the magnitude of the difficulties which have been encountered. Seeing that the constituents in question (resins, bitter principles, essential oil, tannin, \&c.) are among the most complicated substances with which the Chemist has to deal, it is not surprising that the older investigators were, as a rule, very wide of the mark, and that many of the earlier statements were hopelessly incorrect. During the past decade a number of Chemists have devoted attention to the investigation of the more important hop constituents, with the result that a great deal of definite information has been gained and many of the old errors cleared away. Nor has the knowledge thus acquired been merely of scientific interest, for it has thrown much light on the part played by the hop in the manufacture of our national beverage, and has already found industrial application to the great advantage both of the hop-growing and of the brewing industries. That there is much that is still doubtful and obscure is unfortunately true, but the rapid progress which has been made during recent years justifies the hope that before very long the existing gaps in our knowledge will be filled. About a year ago the Management of the Brewing Trade Review conceived the idea of publishing a series of articles dealing with the Chemistry and Natural History of the Hop Plant, each article to be written as far as possible by someone possessing special knowledge of the particular 


\section{INTRODUCTORY.}

portion of the subject entrusted to him. These articles having duly appeared in the pages of the Brewing Trade Review, it was suggested that it would be an advantage to many who are directly or indirectly interested in the hop plant if a more permanent and more easily accessible form were given to them. This little monograph-the outcome of the above suggestion-is therefore primarily intended to indicate to those who may be interested in the subject the present state of our knowledge in regard to the more important constituents of hops; the articles coming, with one or two exceptions, from the pens of the investigators themselves. Whilst, therefore, it does not aspire to be regarded as a text-book it is hoped that this little work may have a sphere of usefulness as an appendix or supplement to more systematic treatises.

ALFRED C. CHAPMAN.

London, October, 1905. 



\section{TABLE OF CONTENTS.}

PAGE

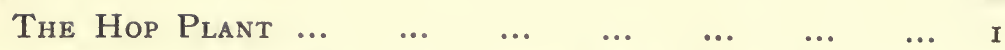

Professor John Percival, M.A., F.L.S.

The Physical Characteristics of a Good Hop $\ldots . \quad \ldots$ io Professor John Percival, M.A., F.L.S.

Fertilization and Cross-Fertilization of the Hop $\quad \ldots$ i 7 Albert Howard, M.A., F.L.S.

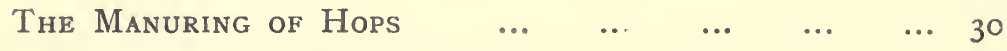

Bernard Dyer, D.Sc., F.I.C.

$\begin{array}{llllllll}\text { The Cold Storage of Hops } & \ldots & \ldots & \ldots & \ldots & \ldots & 5^{I}\end{array}$

Lawrence Briant, F.C.S., F.R.M.S.

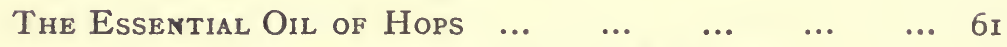
Alfred C. Chapman, F.I.C., F.C.S.

The Bitter Substances and Resins of Hops $\ldots . \quad \ldots \quad 70$ Dr. Georg Barth.

$\begin{array}{lllllllllll}\text { Hop Alkaloids } & \ldots & \ldots & \ldots & \ldots & \ldots & \ldots & \ldots & 89\end{array}$

Philip Schidrowitz, Ph.D., F.C.S.

$\begin{array}{llllll}\text { The Part Played by Hop Tannin in Brewing } & \ldots & \ldots & 92\end{array}$ 


\section{THE HOP PLANT.}

By Prof. John Percival, M.A., F.L.S.

$T^{H E}$ hop belongs to a small family or order of plants-the Cannabaceæ-which includes hemp. It possesses certain affinities with the stinging-nettles and the elms, and is sometimes classed with these.

Two distinct species or kinds of hops are known, viz., the Japanese Hop (Humulus japonicus Zieb. et Zucc.), and the Common Hop (Humulus lupulus L.). The former plant is indigenous in China, Japan and the neighbouring islands. It is a perennial like the Common Hop, more delicate in its bine and foliage, and used in this country as a climbing annual for covering arbours and trellis work. For brewing purposes it is of no value as the "cones" or hops are devoid of lupulin.

The Common Hop is a native wild plant met with throughout Europe and Western Asia, and is no doubt indigenous in the southern parts of the British Islands.

The date of its first use in beer is unknown, but records are met with of cultivated hop-gardens as far back as the gth century in France and Germany. Imported hops were used in England by Dutch brewers of beer as early as the time of Richard III., and hop-gardens were in existence in Norfolk in 1533 or earlier. 
It was not, however, until the reign of Edward VI. that the cultivation of the crop was seriously taken in hand. From I 549 to 1553, Dutch experts were employed by the Government to teach the business of hop growing to the English farmers. In an Act of the Privy Council, February I8th, I549, a warrant was issued for the payment of $£$ III for "charges in bringing over certain hopsetters," and in the two following years payments were made for wages to one Peter de Wolfe and his workmen for planting hops.

The hop plant has its reproductive organs-its stamens and carpels containing the seed-on different individual plants. We thus have male plants and female plants distinct from each other. Occasionally sports arise with the male and female flowers present on the same individual, but these are abnormal uncommon forms.

It will be useful to describe the various parts of the plant in order, beginning with the seedling.

Seedlings are very easily produced although they are generally destroyed when very young by the hoeing and constant cultivation which goes on in the spring and summer in all well-managed gardens. The young plants have two narrow cotyledons or seedleaves not unlike those of a mangel, the subsequent young foliage leaves being heart-shaped with serrated edges somewhat similar to those of a stinging-nettle.

The primary root of a young hop soon branches and produces secondary roots which strike deep down into the ground, finding their way along openings in the soil and through crevices into the rocky substratum below.

The complete system of roots below ground is very extensive, thick roots descend almost vertically to considerable depths, and the plant, when fully established, is more or less independent of surface droughts in consequence.

At the same time a vast number of smaller roots live in the upper regions of the soil and increase enormously in quantity wherever there is good tilth favouring development. About midsummer, and later, these delicate fibrous roots or "shank" are evident in all well-tilled hop gardens, especially where the land is 
heavily manured. As their function is to absorb water and other food materials, it is bad policy to destroy them, as is frequently done by some growers, unless for the express purpose of checking growth and favouring early ripening of the crop.

The stems of the hop plant which come above ground are known as "bines." They are hollow and arise from buds on the rhizome or root stock below ground.

These bines vary in colour, some being reddish and others streaked or spotted with red blotches; some are pale green. The early common hops in this country have reddish bines, while the choicer and later varieties generally have green stems.

Hop bines wind from left to right round any neighbouring support which is available, or scramble over hedges, being to some extent assisted in the process and prevented from slipping down the supports by rough short prickles on the stem and ribs of the leaves.

In the ordinary course of things the stems of the plant die down in autumn completely, except a small portion of each which lies below ground. These underground pieces of stem, which bear two or three opposite groups of buds, thicken and become filled with stored food for the development of bines in the following season. They are generally cut off in spring when the plants are "dressed" and used as "sets" for propagating the crop.

The leaves of the plant are opposite each other on the bine. They vary considerably in shape; some are simple cordate leaves, others are larger and palmately divided into three or five lobes.

The flowers of the hop are very simple in structure. The staminate or male flowers are about a quarter of an inch in diameter, and consist of five green sepals with five stamens from which are shed large quantities of pollen. Hundreds of these flowers are produced on each male plant, where they grow in clusters on lateral branches.

The female flowers are also simple in character, consisting of a cup-shaped corolla with a round ovary containing one seed. From 
the top of the ovary arise two long stigmas known as the "brush" of the hop. Each female flower is very small, nuch smaller than that of the male plant. Several of them grow together in structures, somewhat resembling fir-cones and technically termed "strobiles." These are the "hops" of commerce for which the plant is cultivated.

When young, or in the "burr" stage of growth, the stigmas of the female flowers are conspicuous, and readily accessible to the pollen which is carried about by the wind.

Subsequently growth takes place, the "brush" falls, and the leafy chaffy bracts of the strobile or cone develop.

The structure of a fully-developed "hop" is depicted in Fig. B, No. I, p. I2.

A hairy axis or "strig " runs down the centre of the cone, and upon it are four rows of small leafy bracts. In reality these are pairs of stipules of leaves whose green blades usually remain undeveloped. Just above each pair of these bracts short branches grow out from the central axis, and upon each branch are produced four female flowers surrounded by bracts. The bases of the latter curl round the female flowers, and partially envelope the ripe fruit or "seed."

It is upon the corolla and bracts of the hop cone that the lupulin glands are produced as described on page II.

The distance apart of the branches on the central axis of the cone and the shape of the bracts greatly assist in distinguishing the different varieties of hops. In the coarse common kinds the branches are some distance from each other, whereas in the finer kinds they are closer together. The choicest English kinds of hops have bracts with rounded tips, those of the poorer varieties being more pointed.

After the pollen has been carried to the stigmas of a female flower, it germinates and ultimately fertilises the seed in the ovary. 
The ovary develops into a small round nut (called by growers the "hop seed") which, when ripe, is purplish in colour and contains a single true seed. If fertilisation does not occur, which is generally the case where male plants are not allowed in a garden, the nut remains small and shrivelled.

The regularity and size of the bracts of the hop are dependent largely upon the fertilisation of the seed. Where the seed is unfertilised the bract associated with it does not grow out or develop so well as where the pollen does its work. Irregular lop-sided "hops" frequently result from want of a proper number of male plants in the garden. The brewer, however, generally objects to many well-developed seeds in hop samples.

\section{ENGLISH VARIETIES OF HOPS.}

The hop plant is one which shows great variability of character. Seedlings are very rarely similar to the parents from which they are derived. They not only vary in their outward botanical features, such as shape and size of hop and colour of bine, but also in their physiological characters, some being early, others late, while certain seedlings are hardy, and others more delicate and liable to suffer from frost, disease and adverse soil conditions.

To obtain new sorts, the raising of seedlings is the most satisfactory method, although the process needs much patience and is slow in its results. Of course, when once a good seedling is obtained, it is easily propagated and kept pure by cuttings and sets in the ordinary manner.

Although in this country a considerable number of varieties are known and cultivated, some six or seven varieties only are grown on an extensive scale, and these are sufficient to meet the requirements of the brewer and grower alike if properly managed.

It is not necessary here to describe the characters of all the kinds, some of the leading varieties, however, must be briefly referred to. 
For convenience of description it is best to divide them into early, mid-season or main crop, and late varieties respectively.

I.-The early sorts as a rule possess red bines, yield a comparatively small crop and the quality is generally inferior. They are, however, useful to the grower in so far as they provide work for the pickers, and tend to extend the season over a longer period than would be the case if main crop varieties only were cultivated.

The following are the chief early sorts grown in England :-

(i.) Prolifics.-This variety possesses red, rough bines, which do not reach a great height, the hops themselves being large and pointed. The petals are coarse and thick and when ripe are poor in colour and coarse flavoured. It is a variety grown only in localities where the best kinds do not thrive satisfactorily.

The Meopham is a coarse, large, loose hop, somewhat similar to the Prolific.

The Henham's Jones' Hop is somewhat better than either of the above, though difficult to meet with true to name.

(ii.) The Bramling Hop, in a sense, plays a similar rôle in good hop districts, to that played by the Prolifics in poorer soils. It is a good early sort, reddish in bine with hops of medium size. The latter are a lengthened oval shape, roundish in section, and of good flavour and aroma.

The Bramling seeds freely, and male plants make their appearance in gardens of this variety more frequently than is the case with any other kind with which I am acquainted. The fact that these male plants appear chiefly at intervals of two years, after the garden is cleared of them suggests that they are seedlings and not sports.

Amos' Eavly Bird is a good variety, very similar in its character to the Bramling.

Another early variety known as White's Eavly Hop has a pale green bine, it is inferior in flavour to any of those 


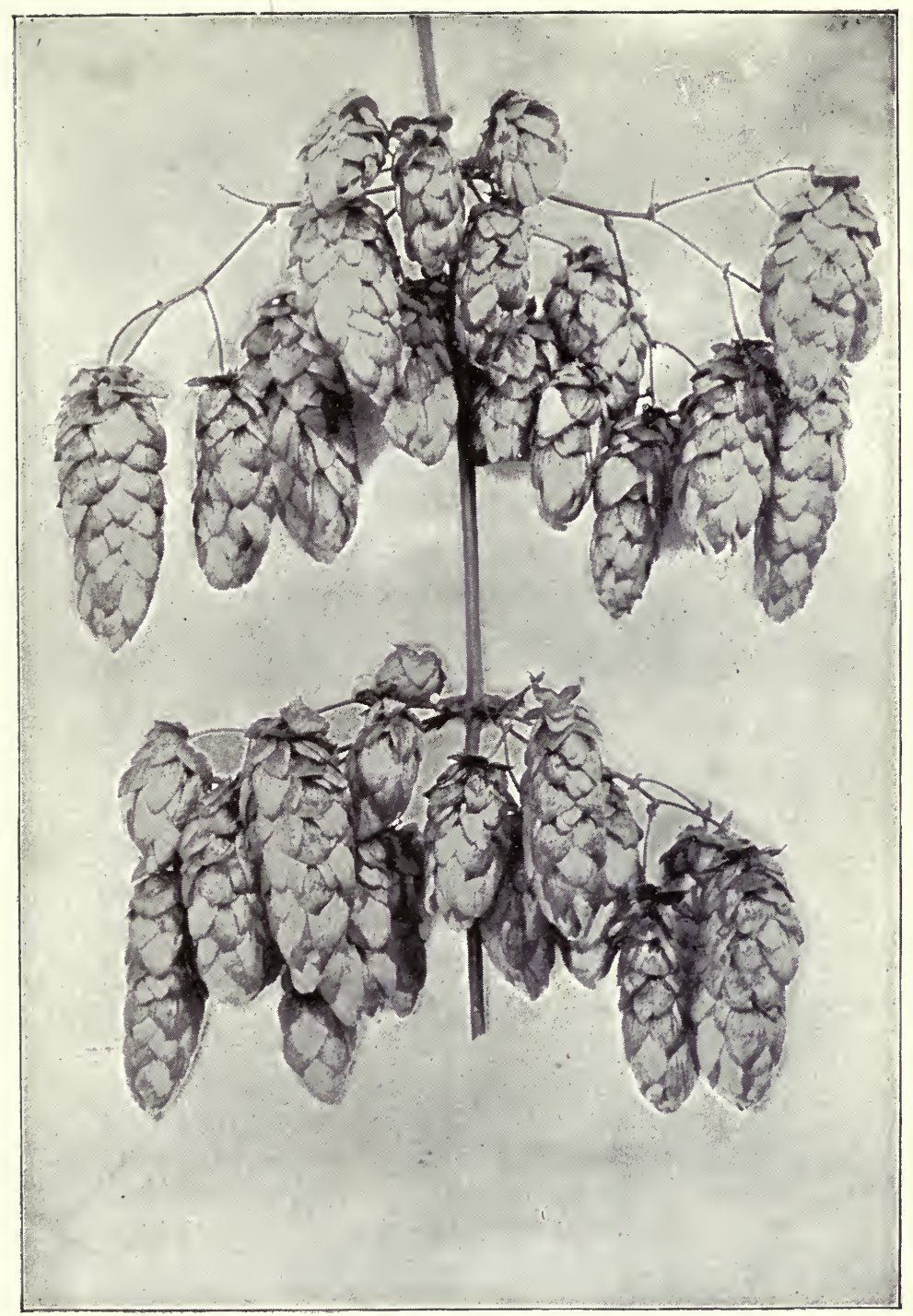

Prolific Hop. 



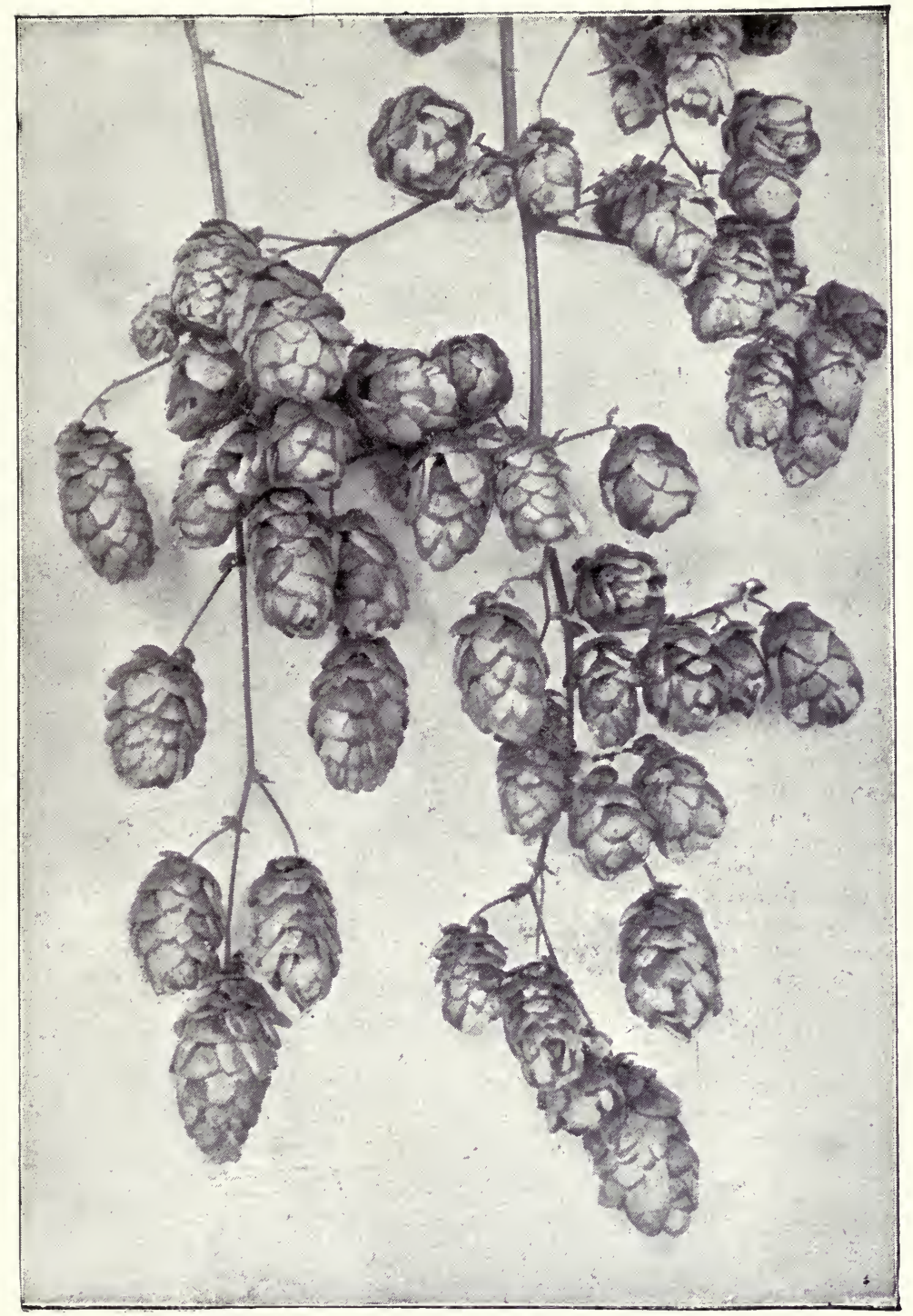

Bramling HoP. 




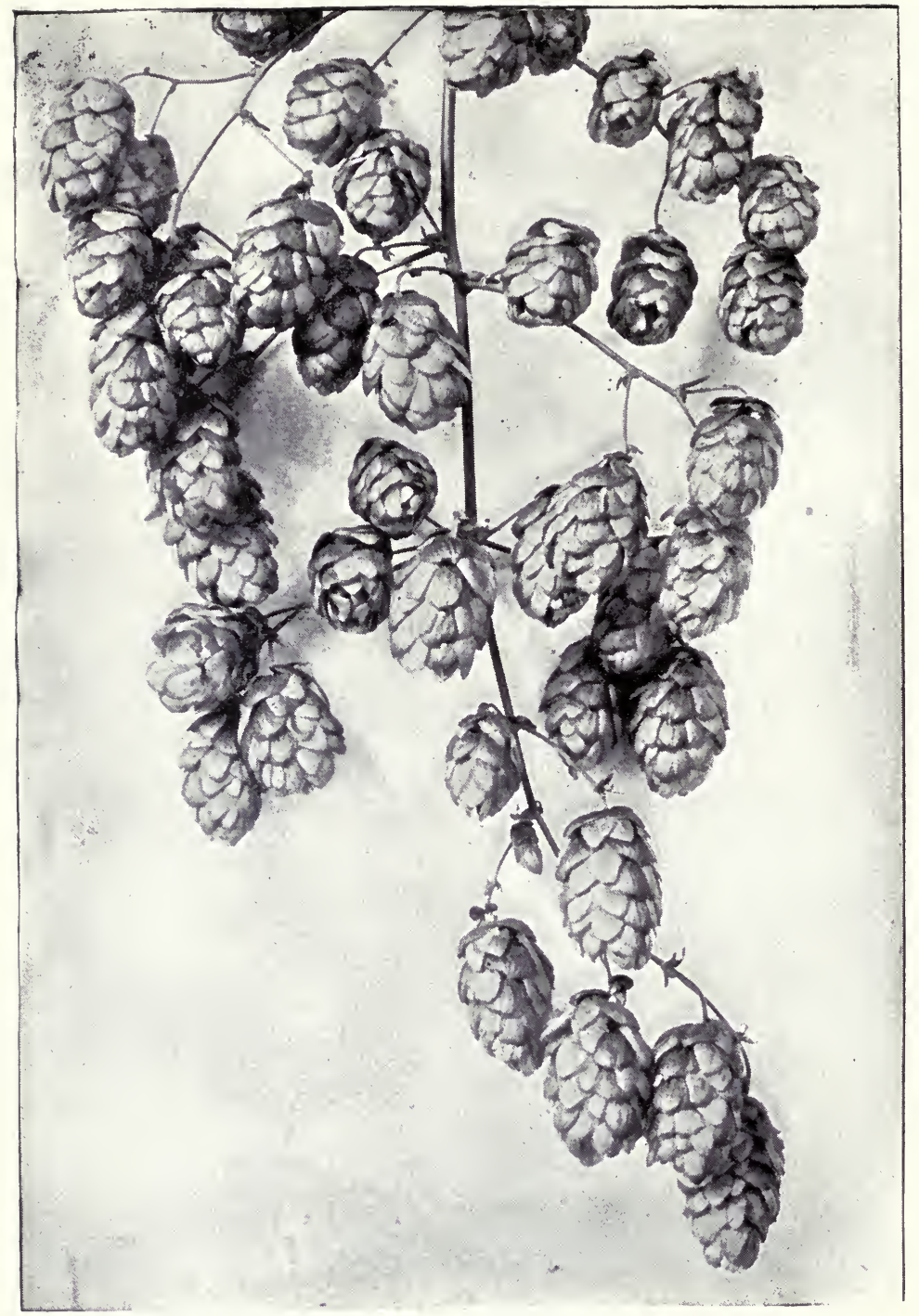

Canterbury Whitebine Hop. 



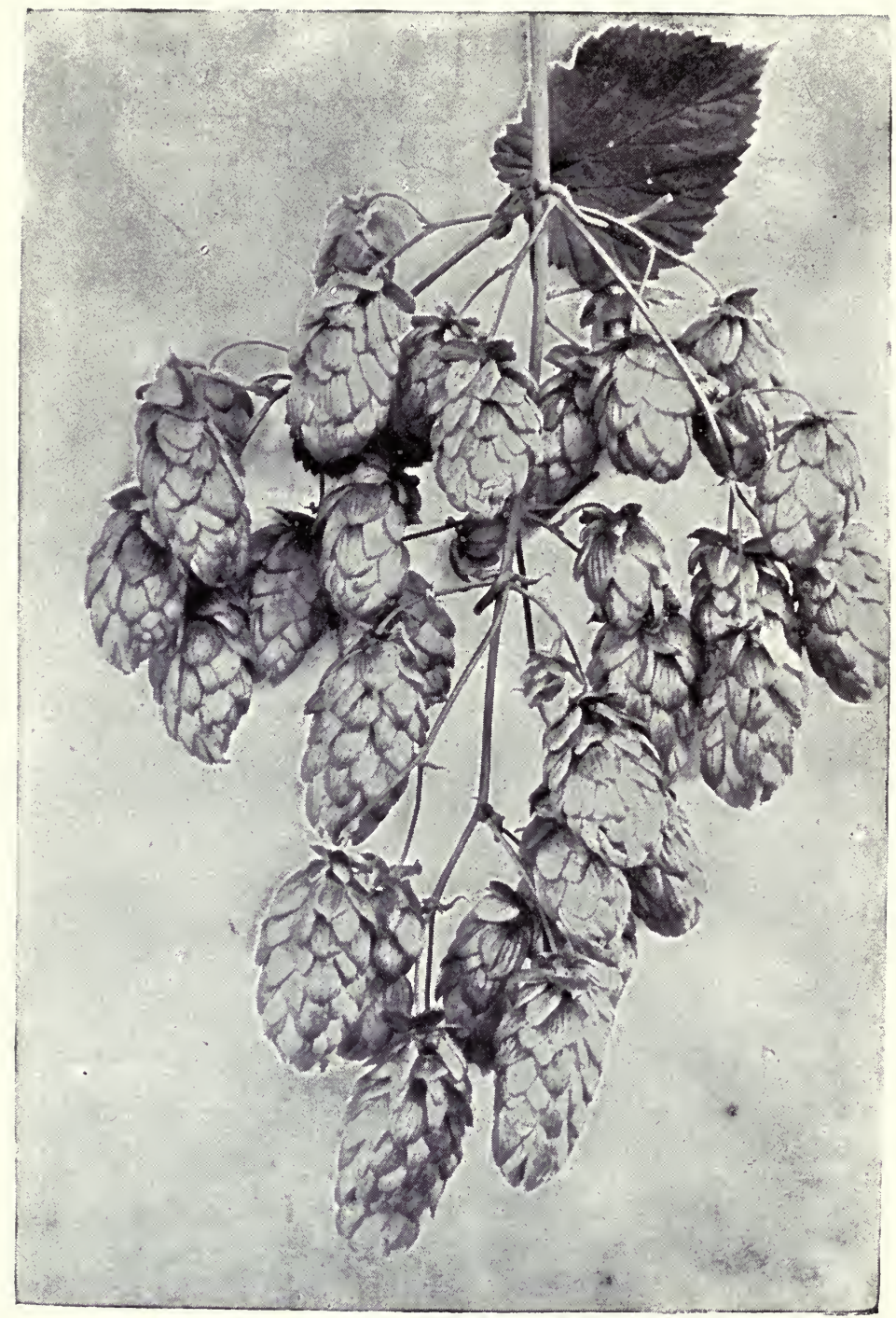

FUGGLE'S HoP. 
already mentioned, but is a shy cropper and only suited to deep soils in warm sheltered localities.

II.-The mid-season or main crop varieties, as the name implies, are sorts more extensively cultivated.

(i.) In the less favoured districts with damp, stiffish soils, or where the climate is against the production of the finest quality, Fuggle's Hop is a variety extensively grown, and its cultivation is spreading.

It is a heavy cropper, hardy, with a green bine. The hops are somewhat large, square in section, pointed at the tip, with thickish petals. The basal petals of the "cone" are dirty green in colour. The hops are rich in lupulin, but their aroma is second rate.

For use in the copper this variety is as good as any, and, when well managed, gives a remunerative yield to the grower.

(ii.) The main crop sorts cultivated in the best hop-growing districts are the Canterbury, Farnham, and Mathon varieties, with the true Golding hop.

These are similar to each other in many respects, and in all probability are genetically related.

The Canterbury, Farnham and Mathon hops all have pale green or "white" bines, which grow to a great height if allowed.

The Canterbury whitebine is largely grown in East Kent, the Farnham hop around the town of this name in Surrey, while the Mathon is the Worcestershire and Herefordshire representative of this class.

The cones are of medium size, oval in shape, those of the Farnham hop being the least of the trio, the Mathon perhaps the largest, although there is not much difference in size. All have thin pale golden petals, rich in lupulin, and the flavour and aroma are all that is desired. 
On account of their delicate constitution they cannot be grown profitably except in the most favoured districts where soil and climate are suitable.

The Cobbs' Hop is a main crop variety of recent introduction. It is hardier than the Canterbury type with thin pale petals.

It is an excellent cropper where the climate and land are satisfactory, but it is generally not rich in lupulin.

The "Golding" Hop resembles the Canterbury and Farnham types. It is often confused with these, and gardens supposed to be pure usually contain both Goldings and Canterbury Whitebines.

The true Golding hop has slightly larger cones not so clustered together as the Canterbury sort, and the bine is not so tall and is more speckled with red blotches and streaks.

III.-There are comparatively few really Late varieties.

The latest of all is the Colegate Hop. The cones are long and narrow, square in section, with thin pale greenish-yellow "petals." They are poor in lupulin, and have a disagreeable aroma.

The plant has green bines, crops heavily, and is readily distinguished from all other cultivated sorts by the roughness of its branches and leaf ribs, as well as by the deeper serrations on the edges of the leaves.

The Colegate hop is thoroughly hardy and adapted for growth on the damp heavy soils of the Weald and other similar districts.

Bates' Brewer Hop is another late sort of distinct habit and character of cone. It has dark green bines. The cones resemble those of the Bramling variety with a good lupulin content, but the aroma is not first-class. In certain districts it crops well, whereas in others the yield is disappointing. 


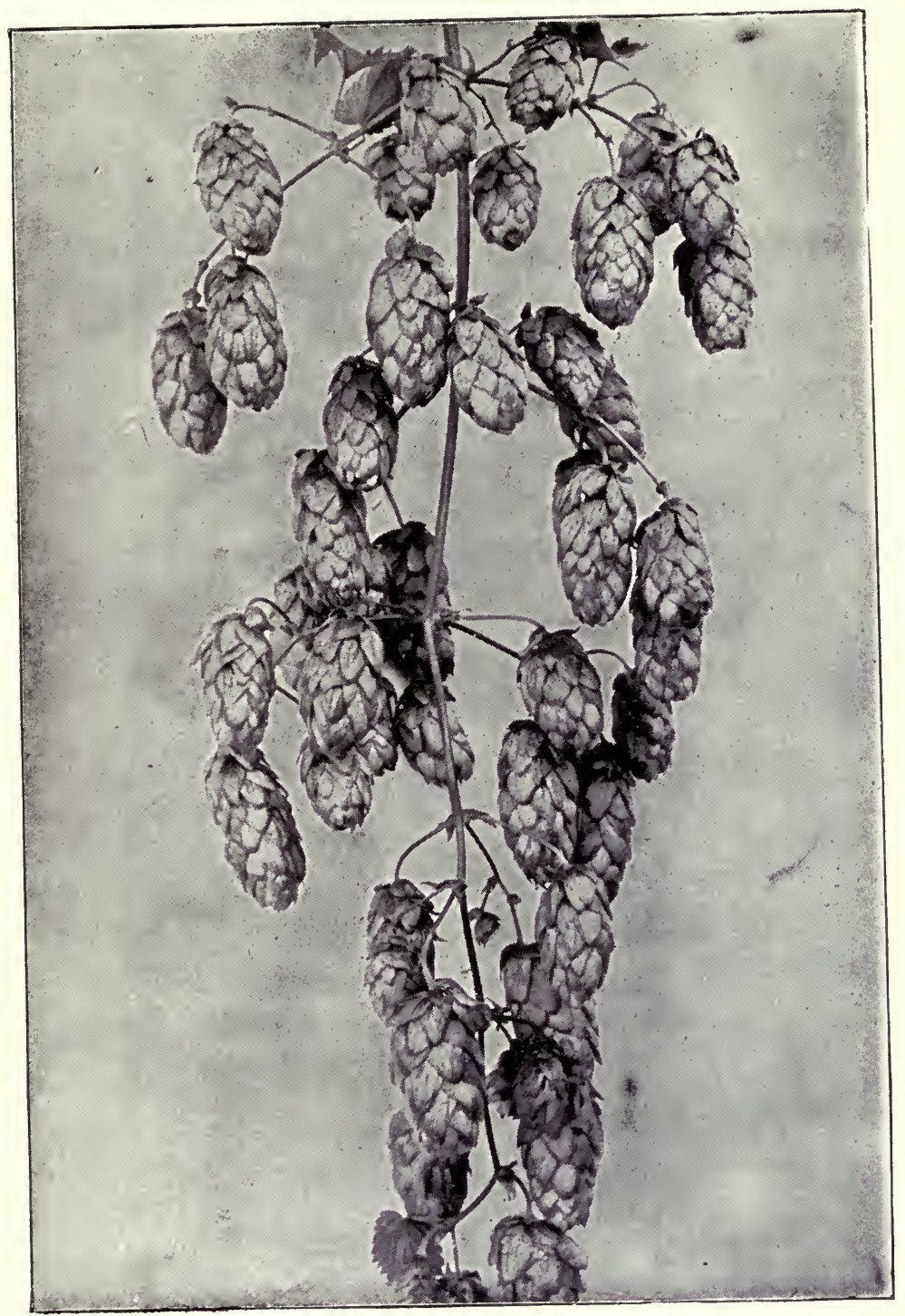

Colegate's Hop. 

The Grape Hops are a group of late hops closely resembling each other. They all possess green bines, on which the cones grow in dense clusters. Each cone is long, square in section, and pointed. When well grown, they are of fine colour, though inclined to be too green for the factor's fancy; the aroma is usually good. 


\section{THE PHYSICAL CHARACTERISTICS OF A GOOD HOP.}

By Professor John Percival, M.A., F.L.S.

THE value of the various materials used in almost all the larger industries can be, and generally is, very accurately estimated where efficiency and economy are considered. The brewer has found in the chemist a valuable assistant in the determination of the value of many of the materials utilised in his industry. Nevertheless, it is noteworthy that at present no certain and accurate chemical method of estimating the intrinsic brewing value of a sample of hops has been established.

Not until many more investigations have been made by the brewer's chemist into the function of the hop and its constituents in the brewing processes, will the more or less conventional system of estimating the usefulness of a hop be superseded.

The relative value of samples of hops, however, may be determined by certain physical characteristics which I propose to deal with in the present communication. There is no need to enter into a discussion of the various chemical constituents of the hops which affect the quality of beer; it is sufficient to observe that the most important of these are contained in the "lupulin glands," and it is for these " lupulin glands" that the brewer should more particularly pay his money when buying hops.

These structures (sometimes spoken of as hop-meal, hop-flour, pollen, or "condition") originate as outgrowths on the small corolla surrounding the "seed," and on the bracts or "petals" of the hop cone. 
By the end of July or early in August the glands appear as small cup-shaped structures, which become more and more filled with oily, resinous contents as the season advances (Fig. A). The oily material

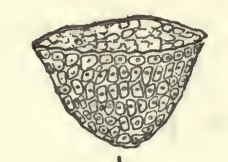

1.

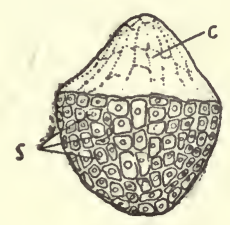

3
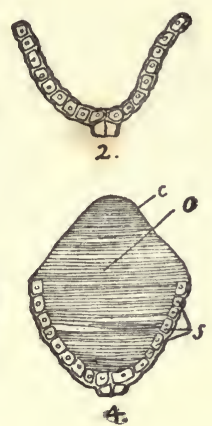

* FIG. A.

I-Young lupulin gland. 2-Section of the same. 3-Fully ripe gland. 4-Section of the same.

is for a time transparent, of a clear golden-yellow colour resembling amber varnish; but when the glands are dead ripe the contents become turbid or opaque, and look very much like particles of "flowers" of sulphur.

Hops are generally picked unripe, and even if allowed to ripen the glands on being subjected to the drying process become transparent again, so that in commercial samples they are always transparent.

The characteristic aroma of hops, the preserving effect they have when added to beer, and the peculiar bitter taste which they impart to the latter, are almost entirely due to the nature of the contents of these glands. The aroma is chiefly due to a volatile essential oil, while the preservative effect and bitter taste are associated with various resinous substances dissolved in the oil.

* The illustrations to this article are taken from the author's text book on Agricultural Botany, by the kind permission of the publishers, Messrs. Duckworth \& Co., Covent Garden. 
On examining a hop it will be observed that there are two different kinds of bracts or "petals " arranged on an axis (or " strig," as it is called in Kent) which is branched as in Fig. B, 2. One of these

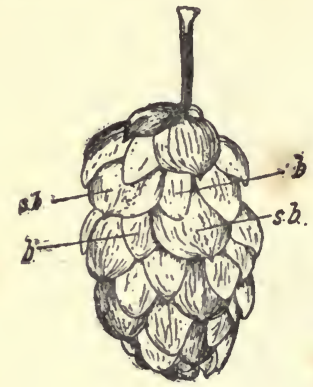

I.

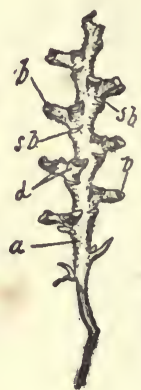

2.

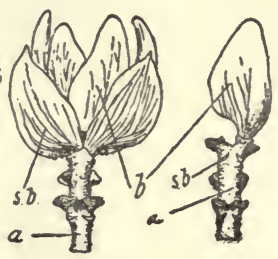

3.

4 .

FIG. B.

I-Fully grown hop cone: $s b$. seedless bract or "petal"; $b$. seed-bearing "petal." 2-Hop axis or "strig." 3 and 4 -Pieces of strig and petals as in $I$.

kinds of bract $(b)$ has the fruit or "seed " of the hop attached to it, while the other is seedless $(s b)$. The seed-bearing bracts always have a larger or smaller number of glands present on their outer surfaces ; but it is only in the better class of hops that lupulin glands are met with on the seedless "petals." On the corolla surrounding the "seed" they are very abundant. It is owing to the recognised importance of these structures that some brewers have begun to show a decided preference for whole hops. The glands are very easily broken or rubbed off the petals, and considerable quantities are lost during the process of drying and bagging, as may be seen on examining the floor of the kiln and other parts of the hop oast. Not only are many lost when the hops are broken up, but rough treatment is liable to rupture the glands and set free the resinous contents, which are rapidly acted on deleteriously by the air, and converted into a less valuable form than when preserved in unbroken glands. Broken hops do not retain their preservative power and aroma so long as whole ones.

It would, therefore, be to the interest of the brewer to lay much more stress upon whole hops than he does at present, and at the same 
time very extensively modify his more or less fanciful views upon delicacy of colour of hop samples.

Growers not unfrequently find it more to their pecuniary interest to deliberately break up their produce after drying, so as to expose more of the clean interior of the hop, especially when the crop has become more or less weathered and discoloured on the outside.

Whatever the intrinsic merit of the hop may be, a discoloured exterior reduces its value in the eyes of the authorities who act for the brewers, very much more than does the defect of brokenness of sample; this the grower knows by experience, and cannot be blamed for acting upon the knowledge until the value of a whole sample is more appreciated. The presence of many loose "strigs " and broken bracts are sufficient indication of a badly mutilated growth, and should be carefully allowed for in estimating the value of samples.

A microscopic examination of the glands of the hop helps us readily to distinguish good from bad hops. Their colour and form are different in good fresh samples from those of old or damaged ones, In fresh well-managed hops the glands are a pale golden yellow colour, with slightly wrinkled surfaces, and oily contents which readily ooze out when pressed on a microscopic slide or rubbed on paper. With age they become more wrinkled and darker in colour, assuming finally a deep, reddish, orange colour; in samples dried at too high a temperature similar changes in shape and colour are noticeable. The resinous substances present in the glands lose much of their oily sticky character, after being kept a considerable time. Good fresh samples of individual hops if rich in lupulin stick together, and only slowly open out again when pressed tightly in the hand, although as. a whole a properly dried sample is very elastic and springy when pressed.

A good hop should show the smallest amount possible of material not lupulin. Hence the size and thickness of the "strig," petals, and seeds should be reduced to a minimum, and only the smallest leaves of the hop plant should be permissible in commercial samples. The petals should be arranged at very close intervals along the "strig" or axis of the cone, and the axis should be fine and slender. Varieties. 
differ very considerably in these respects. Some sorts have from 20 to 25 per cent. more petals than others for the same length of strig.

Fully developed "seeds" should be few in number, for apart from their increasing the weight of ineffective brewing material, they are said to impart an objectionable flavour to beer.

There is no room in the present article to deal with the smaller botanical distinctions between the many varieties of hops in the market. It is, however, useful to point out that those of the best quality which combine both richness in lupulin and excellence of aroma and flavour possess thin, smooth bracts with slender veins. Moreover the colour is more uniform all over such hops, both seedbearing and seedless bracts being similar in tint; even the smaller bracts at the base are of good colour. Hops of inferior quality, especially so far as aroma is concerned, have coarse, stiff bracts, with prominent strong veins, which are not so much branched as in good varieties. The bracts are also more corrugated or wrinkled than those of good hops. The shape of the "petals" or bracts of the hop appear to be associated with quality. Among the English varieties those of the best quality have broad bracts with rounded tips (Fig. C, 3 and 4). The bracts of the poorer varieties are long and

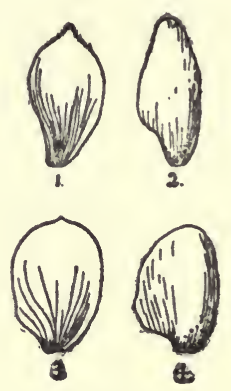

FIG. C.

I and 2-Seedless and seed-bearing petals of a poor English hop.

3 and ${ }_{4}$-The same of a good hop.

narrow, and more or less pointed at the tip (Fig. C, I and 2). The colour is generally darker than that of good hops, the petals at the 
base of the cone being frequently a dirty green tint, and somewhat twisted instead of flat.

In estimating the brewing value of a sample, the size of the cone is sometimes a good index of quality. The amount of lupulin on a hop "petal" does not increase proportionately with an increase in the area or size of the latter. In addition it should be observed that the best hops are chiefly of medium size, both large and small-coned varieties are usually poor in lupulin.

Among Continental hops, however, some of the smaller-coned sorts are especially rich in lupulin, but among English varieties this is not the case.

For the finest pale ales, flavour and colour are both important characters to be taken into account in deciding between good and bad samples of hops. Of flavour there is no definite measurable standard of comparison, but the inferior varieties possess a garlic or onion-like odour, which in some cases is very marked. Samples which have been damaged in the drying process have a gingerbread or sweet odour.

The delicate aroma of good hops, or the taints of poor or damaged ones, is most readily detected after rubbing some of the sample in the hand. Mustiness, due to damp packing, can be detected in a similar manner. Old hops, stored in the ordinary way, soon lose some of their fine aroma, and after a time develop a disagreeable cheese-like odour. Cold-stored hops preserve their good qualities for a longer period, but after removal from the store must be used immediately or they deteriorate rapidly. Except for dry-hopping, the aroma of the hop is of comparatively small account, nevertheless, it must be carefully observed that objectionable taints are often indicative of deterioration of other qualities of more serious import. However, where preservative effect is chiefly aimed at, hops of inferior aroma may be as useful, or more so, than those of better aroma, for they are frequently exceptionally rich in lupulin, and whatever imperfect aroma they possess is boiled off from the copper

At the present time English hops are subjected to the fumes of burning sulphur when they are being dried, and the process bleaches 
and otherwise alters their natural tint. Probably the process is illegal, but it is nevertheless practised throughout the country as a matter of course, and I venture to say unsulphured or unbleached samples would not sell so readily or so well as sulphured ones. This is the reverse of what holds on the Continent of Europe. Sulphured hops there (except when prepared for the foreign market) are more difficult to dispose of, and the fact of their being sulphured is looked upon as evidence that the samples were faulty in some respect.

It is possible that the sulphuring process may be of real use in preventing the resins and oil from oxidation, or in destroying colouring matter which might affect pale ales deleteriously. It is however practised, and the process was originally adopted for the purpose of giving a fictitious colour to the sample. Strongly sulphured hops, especially when picked very green, possess a colour which is attractive in some way to the brewers or their purchasing agents, and growers have frequently been advised by authorities in the Borough to sulphur more extensively during the drying. Brewers should judge their samples of hops more on the lines previously suggested, and keep the question of colour in the background. In fact, exceptionally clean, pale and delicate-looking samples I should suspect as being unripe or belonging to a " silvery" wilding race with few lupulin glands in them, and not until I was satisfied as to the quantity, maturity, and full development of these glands should I be inclined to purchase.

The colour of the small green leaves of the hop in commercial samples is useful as a guide to good or bad drying. In samples properly dried they are of a fresh, lively green, similar to a healthy leaf freshly picked; in coddled or burnt hops they are a dirty brownish or olive-green 


\title{
FERTILISATION AND CROSS-FERTILISATION OF THE HOP.
}

\author{
By Albert Howard, M.A., F.L.S. \\ (Botanist to the South-Eastern Agricultural College, Wye, Kent).
}

SPECIALLY CONTRIBUTED.

I.-The Influence of Fertilisation on the Development of THE Hop.

$\mathrm{I}^{\mathrm{N}}$ general the hop is dioecious, i.e., the male and female flowers are borne on different plants. Sometimes, however, in gardens of the Bramling variety, hills are met with from which bines arise bearing both male and female flowers. Such monœcious plants are rare.

The Male Flowers.-The inflorescences bearing the male flowers are much branched cymose panicles, arising either from the axils of the main stem or from the axils of the lateral shoots.

Each flower is about a quarter of an inch in diameter, and consists of a five-leaved sepaloid perianth, opposite which are five stamens with short filaments and long anthers, which liberate their pollen by longitudinal dehiscence (I, 2, 3, Frontispiece).*

* The illustrations in this article appeared in a recent Bolletin issued by the South-Eastern Agricultural College, Wye, to whom we are indebted for permission to reproduce. 
The Female Flowers. - The female flowers occur in definite inflorescences (strobiloid spikes), which are borne on branches arising directly from the leaf axils of the main stem itself, or from the axils of the leaves upon lateral shoots produced by the main stem. These inflorescences give rise to the hops of commerce.

Each female flower is very minute and consists of a cup-shaped perianth, partially surrounding the superior ovary, which contains a single ovule, and which is surmounted by two long stigmas covered with elongated papillæ (4, 5, Frontispiece). At this stage (as a rule early in July) the hops are said to be "in burr." After the stigmas or "brush" of the young hops drop off there is a rapid growth of the bracts of the strobile, giving rise to the fir cone shape of the mature inflorescence $(7$, Frontispiece). The bines are now said to be "in hop."

During the "growing out" period, which usually lasts about five weeks, it will be observed that there are two very distinct kinds of bracts in the strobile. At the four corners of the hop occur the seedless stipular bracts ( 7 , Frontispiece), which are further distinguished by their greenish colour, the limited development of lupulin glands and their acuminate apex. On the flat sides the rounded, bright yellow, seed-bearing bracteoles $*(6,7$, Frontispiece) occur in pairs.

While carrying out the various cross-fertilisation experiments, described in the second part of this paper, during the past summer, it was noticed that the young hops which were not pollinated, and which served as check experiments or controls, always remained in burr for a much longer period (often more than a week) than those which were pollinated. On the other hand, it was found that when the young hops were artificially pollinated, the brush turned brown and withered in three or four days and then fell off. The dying away of the stigmas was at once followed by the growth in size of the young hops. In a word, the pollinated hops started to grow

* The stipular bracts and bracteoles of the hop are spoken of as "petals" by the hop growers in Kent. 



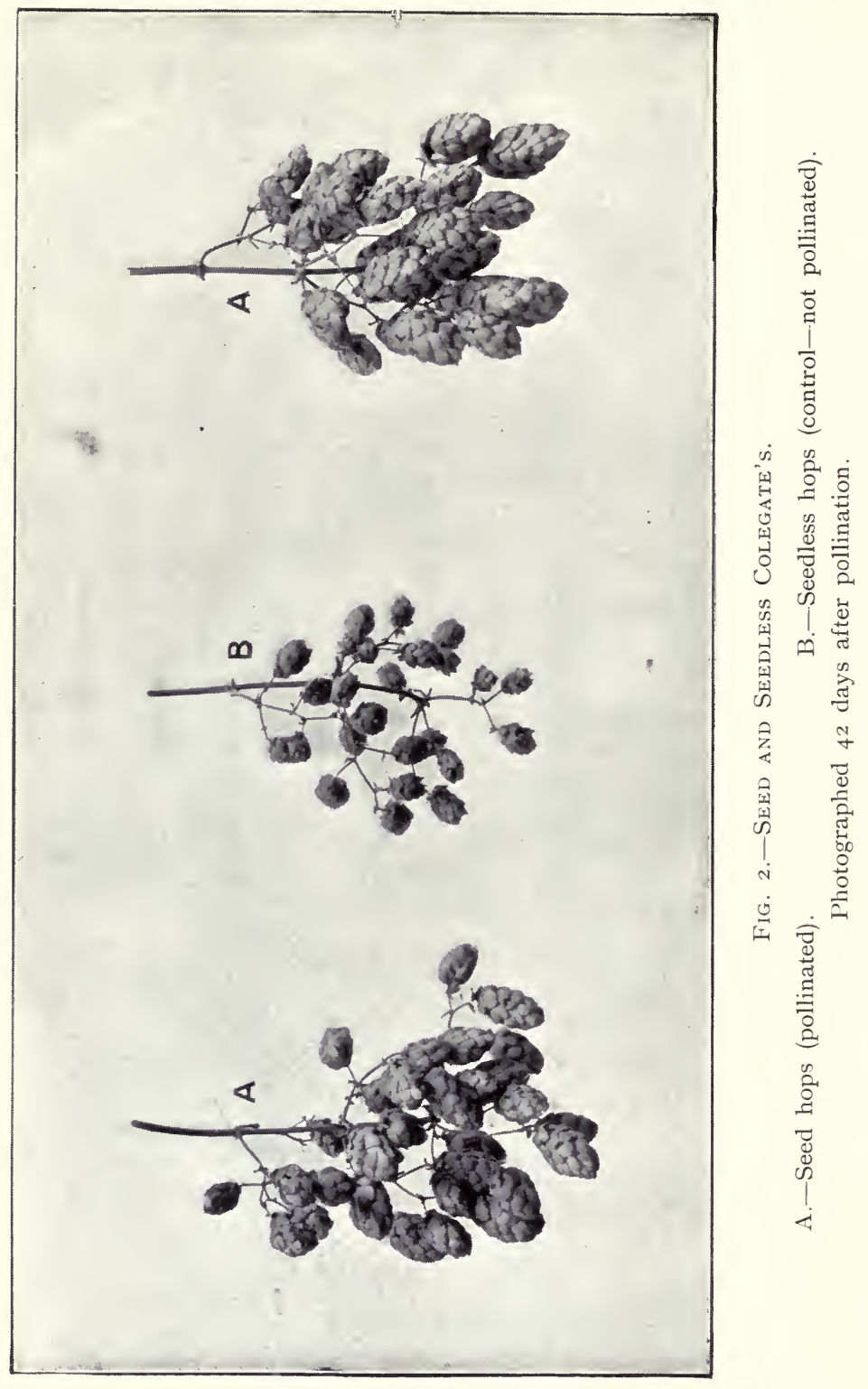


out at once, while those which had not received pollen did not develop immediately, but waited, as it were, for this process to take place. Thus as the pollinated hops began growth a week to ten days before the controls, it became a matter of great interest to follow the subsequent development of both.

It was found that the non-pollinated hops never recovered their lost ground. They turned out at picking time to be small, green and unripe, and compared very unfavourably with the well-grown, bright yellow and ripe pollinated hops. The difference between the two sets was so great in all respects that they would never have been taken for hops of one variety, much less for hops growing on the same bine and on opposite pairs of laterals. While the controls were very small and green, the pollinated hops only differed from the normal hops on the same bine in being rather more symmetrical and better developed specimens with the free ends well closed in.

The differences between the two sets of hops at picking time may be seen in Fig. 2. The control hops are in the centre, the bunches on either side having been pollinated. Fig. 2 represents three bunches of COLEGATE's hops from the same bine and developed from laterals of nearly equal strength. The control bunch in the centre is quite seedless, while the pollinated bunches on either side are well seeded.

A further point of some interest was noted when the experimental hops were picked. It was found that the controls, which, in all cases, turned out to be seedless, were attacked by " mould "Sphavotheca Humuli (D.C.) Burr.-to a much greater extent than the seed hops which had been pollinated. Indeed these latter were singularly free from this parasite. Fertilisation, therefore, seemed not only to stimulate the growth, to hasten ripening, and to improve the colour, but also to increase the mould-resisting power of the hop itself.

The behaviour of the experimental hops suggested the desirability of extended observations in hop gardens to determine, if 
possible, whether the above results, arrived at under somewhat artificial conditions, are borne out in actual practice.

In the first place, a very large number of nearly ripe hops were examined in order to determine to what extent seed production takes place. No well-grown hops weve seen without seeds. Further, it was found possible to count the seeds in any hop by observing the size of the bracteoles. When seeds have set, the bracteoles are much larger and brighter yellow than those which only bear rudimentary seeds. In Fig. 3, bracteoles with (A), and without (B) fully developed seeds are shown. In all cases those with mature seeds are larger than those with rudimentary seeds. The hops on the right and left (C) represent extremes of well-grown-out seed hops. The two hops (E) are seedless hops from a control bunch, while (D) represents a hop from a pollinated bunch. The difference in size of the bracteoles with and without perfect seeds is well seen in the large hop on the left (C).

Since the stigmas at the stalk-end of the hop are ready for pollen first, after which those towards the free end become successively receptive, a considerable period elapses between the beginning and end of pollination in any particular hop. In view of the scarcity of males in many gardens at the present time, it appeared probable, therefore, that hops would be found seedless at the base, fertile at the free end and vice vers $A$. A search showed that this was the case. In a garden near Wye which contained only three male hills in fourteen acres, numerous hops were found seedless and small at the base, but fertile and enlarged at the free end. Others were found seedless and constricted in the centre only. Fig. 4 illustrates this point.

It was next noticed that fully developed seed hops and badly grown out, unripe, seedless hops were often to be found on the same bine. In such cases, pollen was probably abundant when the earliest hops on the bine were in burr, but was not available when the later hops were ready for pollination. Hence, in order to obtain all the hops on a bine in a well-grown-out condition pollen must be available during the whole burr period.

Evidence on the subject of the special liability of seedless hops. to mould attacks was now sought in the field. It will be remembered 


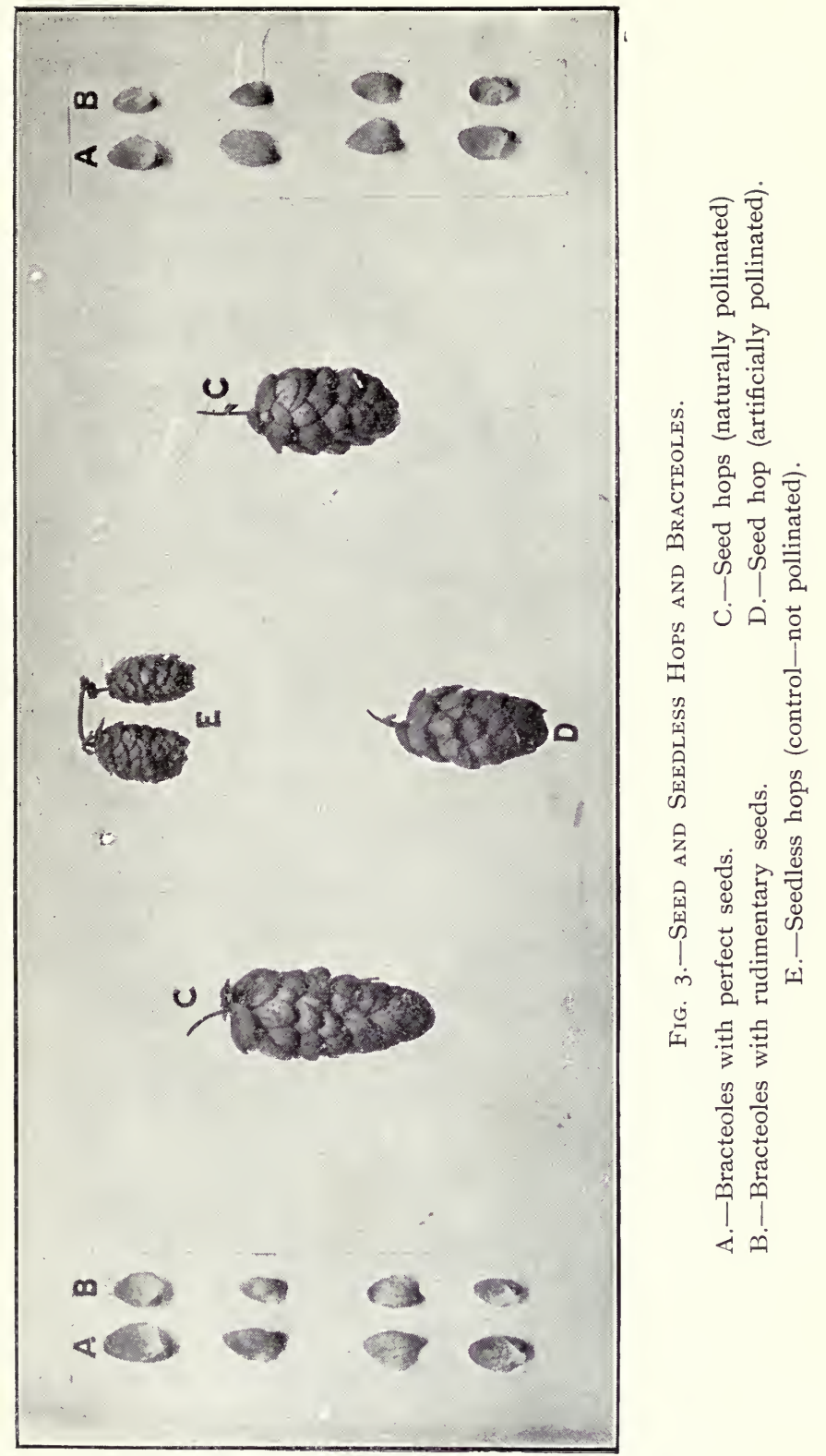

Page 20. 



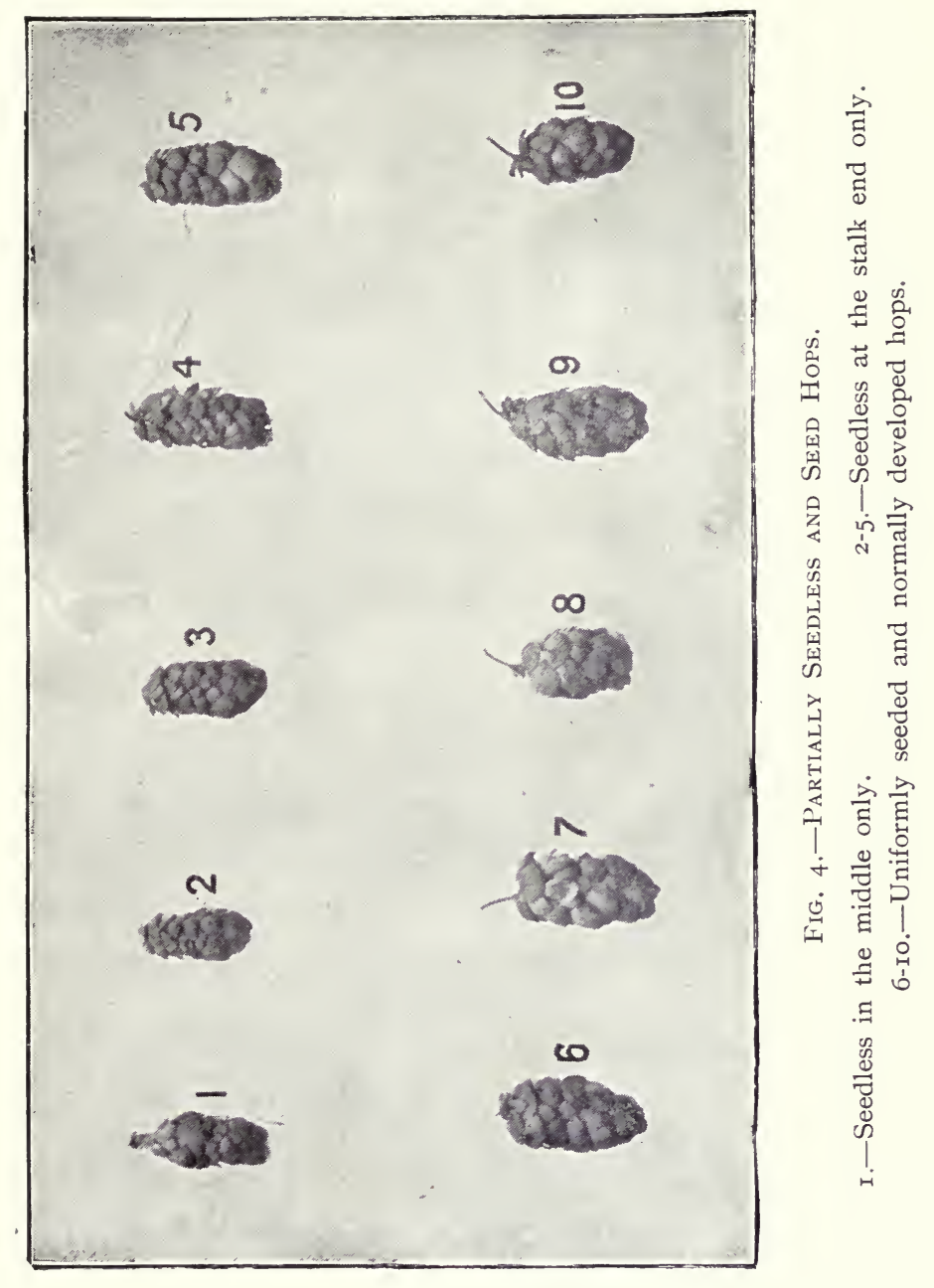






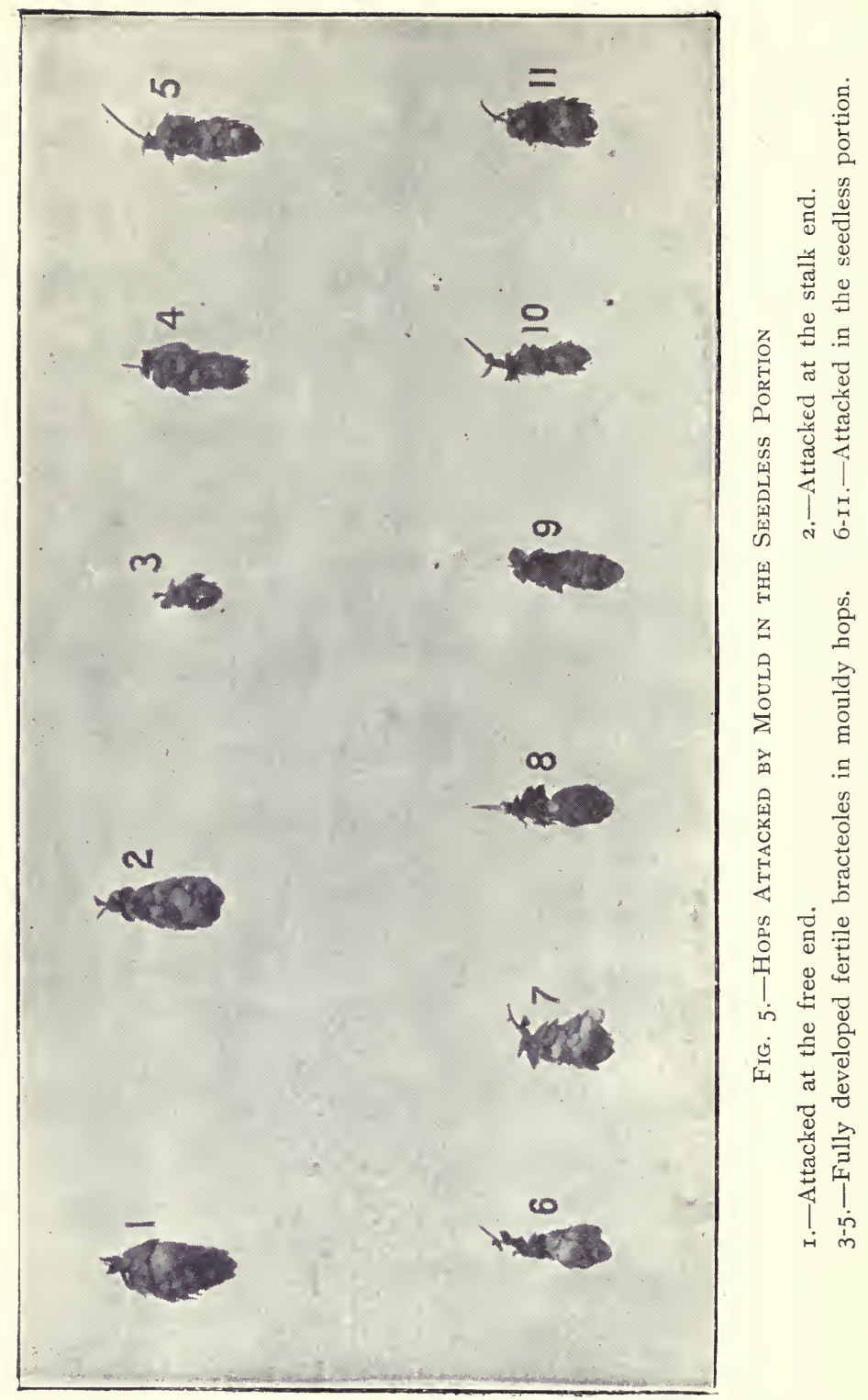

Page 21. 
that in the cross-fertilisation experiments it was noticed that the seedless hops in the control bunches were attacked by mould to a much greater extent than the seed hops on the same bine. Accordingly a large number of half-seedless hops were examined to see whether the mould did more damage on the seedless part than on the seeded portion. This was found to be the case. The seedless portions were usually completely destroyed, while the fertile portions grew out almost normally (Fig. 5). Further, in hops which contained only one or two fertile bracteoles it was constantly seen that these structures were hardly affected, while the rest of the hop was destroyed (3-5, Fig. 5).

The above experiments and observations all point to the necessity of fertilisation in the production of well-grown hops of the desired colour. On the other hand, the absence of fertilisation leads to small, green, unripe hops, particularly liable to total destruction by mould. As is well known, it is during the burr stage that hops are most liable to damage by mould. This seems, apart from climatic considerations, due to two main causes. In the first place, the feathery stigmas arrest the mould spores as they blow past, and also tend to keep the atmosphere around the spores moist and so assist in their germination. Secondly, unless pollination takes place as soon as the stigmas are receptive, there seems to be a pause in development, during which the hop waits for the process to take place. It would appear, therefore, that any arrest of growth at this period is particularly dangerous, and everything should be done to rapidly carry the young hops through this critical phase.

It seems difficult, therefore, to escape the conclusion that, under the conditions obtaining in Kent, the growth of seed hops rather than seedless hops should be aimed at. Before, however, any special recommendations are made on such an important subject as this, it is proposed to carry out further investigations during the coming summer on the lines indicated below. The present paper is put forward merely as a contribution to the subject.

The advantages of growing seed hops seem to be the following :

I. Large, heavy, brightly-coloured and well-grown-out specimens. 
2. Early ripening.

3. Increased mould-resisting power.

The disadvantages, on the other hand, would appear to be :

I. The space taken up and the trouble involved in growing suitable males for the various gardens. It is evident that unless the males shed their pollen when the females are in burr, they are useless as far as the particular garden in which they are growing is concerned. There seems to be quite as much variation in the time of ripening among male hops as there is among the females Further, it appears that a good many of the males met with in hop gardens ripen too early and shed most of their pollen before the surrounding hops are in burr. Some trouble, therefore, would have to be taken to select and grow male hops which would correspond to the full burr period of the various varieties grown in the sontheastern districts of England. Probably, suitable males could either be raised from seeds or obtained from other countries, such as the United States or Germany. Steps are being taken to obtain and test foreign male plants.

2. The possible difference in brewing value between seed and seedless hops. It is said that II 6 lbs. of German seed hops are equal, in this respect, to roo lbs. of seedless hops. Next season, it is proposed to estimate the total resins present in equal weights of seedless and seed hops of the more important varieties grown in Kent. With regard to this point, however, it might be mentioned that, in all the cases examined this year, it was found that the lupulin glands of the seedless hops were not so ripe at picking time as those in the seed hops on the same bine. This difference in ripeness, therefore, may lead to some difficulty in carrying out and in interpreting the results of the proposed experiments.

3. The possibility of the more rapid exhaustion of the hills through the more frequent formation of perfect seeds. In order to throw light on this point, an analysis of hop seeds (Early Bird Bramlings) has been made by Mr. F. T. HоLвRоoк. The results 
are given in the following table, together with the figures relating to the whole hop :-

Analyses showing the fertilising constituents contained in hops and seeds, stated in parts per Ioo of the air-dried materials as taken from the pocket.

\begin{tabular}{|c|c|c|c|c|c|c|}
\hline & & Ash. & Nitrogen. & $\begin{array}{l}\text { Potash } \\
\left(\mathrm{K}_{2} \mathrm{O}\right)\end{array}$ & $\begin{array}{c}\text { Phosphoric } \\
\text { Acid } \\
\left(\mathrm{P}_{2} \mathrm{O}_{5}\right)\end{array}$ & $\begin{array}{r}\text { Lime } \\
(\mathrm{CaO})\end{array}$ \\
\hline Whole hops.. & . & $6 \cdot 33$ & $3 \cdot 22$ & 2.45 & $I \cdot I 8$ & I.06 \\
\hline Seeds .. & .. & 6.53 & $4^{\cdot 64}$ & $I \cdot 39$ & $2 \cdot 33$ & 46 \\
\hline
\end{tabular}

It will be seen that the seeds are the richer in nitrogen, and phosphoric acid. In view, however, of the liberal manner in which hops are manured, it is hardly likely that increased seed production will either exhaust the soil or weaken the plant.

Reviewing the whole question it would appear that the advantages are distinctly in favour of seed hops.

The opinions of several leading Kentish hop-growers were now sought on this question of the value of male plants. The views obtained differed widely. Many regard the males as useless and have them grubbed after picking time. Others, especially in East and Mid Kent, consider that a few males are useful, and improve the general welfare of the gardens.

Mr. W. H. Hammond, of Canterbury, in a very interesting letter dated Oct. I7, I904, sums up his experiences as follows :-

"With regard to male hops in our gardens in East Kent, I have all my life understood from growers that they thought it an advantage to have a few male plants scattered about. My father, who was a large planter in the Petham Valley for 60 years or more; always grew a few males.

"The perfect seeds for one thing help to make weight, and our English brewers do not object to them, but apart from that many men seem, in the past, to have had an idea that it was better for the general welfare of the gardens if there were a few males present. 
"I can recollect talking this matter over more than 30 years ago with the late Mr. S. J. SANKey, of South Hill, Hastingleigh, when he instanced the case of a garden at Hastingleigh Court Lodge Farm, which had always been a good one and had always had a considerable number of male plants in it, but at one time a fresh tenant came who thought them useless, and destroyed them all, after that the garden moulded, went to the bad, and was soon grubbed.

"Personally, I have always thought it best to keep a few male plants in my own garden."

Mr. H. O. Hubble, of Hunton, Maidstone, writes:-

"I consider that the influence of the male hop in a hop plantation is decidedly a matter worthy of further experiments on your part, especially because the results you have already obtained seem conclusively to prove what some growers in Mid Kent have for many years believed, as the result of observation only.

" I cannot pose as an 'experienced grower,' but I have often noticed that the female hops in close proximity to a 'seeder'* come into hop earlier, are larger and more mature, in fact are generally more 'complete,' if I may so put it, than those which are not so situated.

"The rule does not, of course, always hold good, but that, you have explained, is because the male hop has come to maturity either too early or too late for ' pollination' to take place.

"Your statement that a 'pollinated' hop is better able to resist mould is extremely interesting and valuable, and the fact that 'pollinated hops' always contain seeds is surely a weighty argument in favour of the preservation of the male plant.

" My uncle, a grower of long experience, has always insisted on the value of the male plants, and would always have some of them planted about each garden, and there are other large growers in this district who think and act in the same way."-(Letter, Nov. $4^{\text {th }}$, I904.)

* In Kent, male hops are often spoken of as " seeders." 
Turning now to the literature of the subject the greatest diversity of opinion is found. The German investigators seem to agree on this question, and regard male hops as useless or even harmful. It is said that male plants are not allowed in Spält under a heavy penalty. The hops from this district, however, are not seedless, so that the efforts made in striving after a seedless hop are not altogether successful.

The American growers, on the contrary, think that imperfect fertilisation is a frequent cause of light weight hops of inferior quality. A leading Oregon grower relates his experience as follows :-

"This complaint of the Germans of seeds in American hops was first heard in I882, when hops were so high, and caused some growers on this coast to grub out and destroy all their male vines. The result was that their hops did not mature well. They were large, green, light, feathery things, with neither colour nor strength, and dealers would not handle them. I have seen this experiment tried in Southern Oregon with the same result. I planted a yard myself once without being able to get male roots, and my hops were poor, lean things, until I obtained the male plants and got them to grow vigorously, when my hops became of good colour when ripe, with plenty of strength, and I heard no more complaints of poorly matured or lean hops. I am now fully convinced that hops, like many other plants, require fertilising from the bloom, and, as none but the male hop bear any pollen, it is necessary to have a sufficient number of these in a hop yard, so that the flowers of each vine may be fertilised. And brewers, if they expect a good, solid, bright-coloured, well-matured hop, well filled with lupulin, must expect also to see the hop well filled with good, large, purple seed. If they do not wish seed they cannot expect lupulin. Germany may produce good hops without seed, but it cannot be done here, at least such has been my observation and experience. Therefore my advice is to let the male hop alone, and if in a season of high prices a few brewers complain of extra weight in the seed, pay no attention, but go ahead." (From The Hop: Its Culture and Cure, by H. Myrick.) 
Interesting references to the value of the male plant are to be found in the older writings on hops in this country. Thus in the account of the hop crop in Wilson's Our Farm Crops, published in I859, it is stated :-

"Care should be taken that the cuttings from the male plants should be kept distinct from those from the female plants, otherwise they are likely to be irregularly distributed, instead of having them dispersed at given regular distances over the ground."

"Respecting these distances, and indeed the function and value of the male plants altogether, a difference of opinion appears to exist with practical men. Some growers plant and retain every tenth or up to every fifteenth hill with male plants; others distribute them with less regard to regularity throughout the ground. Again, another plan recommended is to keep the male plants on the outside, so that the pollen may be carried over the ground by whichever wind may blow, while there are some growers who search for the unproductive male plants at the time of flowering and at once extirpate them as useless incumbrances of the soil."

It seems, therefore, that the practice in England with regard to this question has undergone some change in recent years. Fewer males seem to be grown than formerly. This idea is confirmed by a recent paper by Mr. D. G. FAIRCHILD, on " Hop Culture in Europe," presented to the 53rd annual meeting of the American Association for the Advancement of Science, held recently at St. Louis. The author remarks on the fact that in America male hops are numerous, while in Europe the male plants are hardly tolerated in the hop field.

It is clear, therefore, that the subject is well worthy of independent investigation, and the directions in which further work is desirable seem to be as follows:-

I. The effect of pollination and its absence in gardens which are particularly liable to mould at the present time. It is well known that, other things being equal, mould is most prevalent where the air is still, and where the hops are "housed in." In such situations there is also the smallest chance of pollination, and it is 
possible that the lack of pollen may partly account for the damage done by mould.

2. The effect of pollination in gardens where the hops do not usually grow out well.

3. The influence of temperature and moisture on the liberation of pollen and the spread of mould. Generally speaking, damp, cold weather favours mould and also checks the liberation of pollen.

4. The possible relation between the percentage of seed and the total crop. Fertilisation seems to stimulate the growing out of the hop, and its absence has the reverse effect.

5. The comparison of the brewing value of seedless and seed hops. The determination of the total resins seems to be the best: way of arriving at an opinion on this point.

6. Comparative infection experiments with mould on seed and seedless hops.

7. The influence of pollen from different males on the development of particular varieties.

8. The effect of various washes on hops when in burr. Possibly fertilisation may be interfered with or even prevented when hops. are sprayed at this stage.

9. The influence of seed formation on the "thickness" of the sample as taken from the pocket.

I0. The effect of fertilisation on the compactness or "density" of the hop.

II. The effect of premature pollination on the development of the hop.

I2. The selection of seedling and foreign male plants to suit the time of flowering of the various Kentish varieties.

As far as possible these lines of enquiry will be followed up. during the coming year. 


\section{II.-The Production of New Varieties of}

Cross-Fertilisation.

A consideration of the possible lines of investigation by which science may be applied to the hop industry, points to the conclusion that the systematic production of new varieties of the hop from seeds offers the greatest likelihood of success and also promises the largest increase in the crop. It is probable that the variety of hop is of more importance than the soil or manurial treatment.

Of the many varieties grown in Kent at the present time, two only-Bennett's Early Seedling and Fuggle's-are known with certainty to have arisen from seed. It appears that, on many occasions, hop seeds have been grown, but the resulting plants have varied considerably, and therefore doubt has been thrown on the possibility of improving the hop in this direction. In all these cases, however, no attempt seems to have been made to control the fertilisation, and only seedlings arising through chance pollination have been raised. The field of hop breeding is therefore open.

During the past year, various English and German female plants have been crossed with widely different males, and 23 sets of seeds have been obtained for growth next spring.

In the first instance, the characters of the seedling hops will be carefully compared with those of the parents, and an attempt will be made to see how these characters resemble and differ from those of the parents. Secondly, any promising new forms will be propagated under ordinary conditions and their value tested. Possibly some of the seedling males thus produced may be useful in making further crosses, and for propagation for use in hop gardens.

The method adopted in crossing varieties of the hop was as follows:-The laterals selected were cut back as soon as the burr was just visible, and placed in thin, white, tough paper bags which were tied on with fine wire. The bunches shown in Fig. 2 are examples of laterals which have been bagged in this way. About eight days after the bags are placed in position, the burr is usually 
ready for pollination. This operation is carried out by removing the bag and dusting the young hops with the flowers of the male plant selected for the cross; as soon as this is completed the bag is once more placed in position. In order to check the results, a large number of controls are used-bunches which are not pollinated-so as to determine whether the laterals have been bagged in time, and whether pollination took place before the beginning of the experiments. In no single instance did the control bunches contain seeds at picking time, thereby proving that the method employed was a reliable one. As a rule, the bags were removed a fortnight after pollination, when it was found that the crossed hops had already grown out considerably, while the controls had only just shed their brush. At this point it was sometimes found necessary to spray the experimental hops with soft soap, so as to rid them of lice which had increased in large numbers on the sheltered laterals. At picking time, the crossed hops were removed and the controls examined. The seeds were picked out, after the bunches had wilted in the air a few days, and placed in canvas bags for storage during winter.

These experiments naturally involved the examination of a very large number of male hops. It was found that there is the greatest variation in the vegetative characters of these plants. The colour of the bine varies from a bright red to a very distinct green and there is a wide range in the texture and shape of the leaves and the time of ripening of the flowers. In some cases the males were seen to be very liable to mould, both as regards the leaves and flowers.

The female varieties crossed during the present year were Fuggle's, Old Canterbury Whitebines, Amos's Early Bird Bramling, Cobb's, Colegate's, Wild hops with good aroma, and Saaz (Nos. I and 2 in the College Garden). The males employed varied considerably in their characters. 


\title{
THE MANURING OF HOPS.
}

\author{
By Bernard Dyer, D.Sc., F.I.C.
}

THE manuring of hops has received during the last ten or twelve years more systematic attention than has been devoted to the subject at any time previously. Experiments have been made with various manures at various centres under the auspices of the Agricultural College at Wye, and at the same time a systematic and continuous series of experiments has been carried out under the direction of the present writer on the farm of Mr. F. W. E. Shriveli, at Golden Green, Hadlow, Tonbridge.

Furthermore, in pursuance of the line of investigation marked out in our Hadlow experiments, similar experiments on an extensive scale have been carried out simultaneously during several years at no less than twenty-one farms or stations by members of the German Society of Hop-growers (Deutsche Hopfenbauverein), under the direction of Prof. WAGNER, of Weihenstephan.

In all of these experiments the influence of manuring on the quality as well as the yield of hops has been taken into account.

Although hop-growers have never been backward in spending money on manure for their gardens, there can be little doubt that a great deal of the manuring practised until recent years has been very unscientific. Hops, like most luxuriantly growing plants, are very responsive to applications of nitrogenous manure. Repeated observation of this fact formerly led to the very general overlooking of the fact that the hop crop is in equal need of other manurial constituents like phosphates and potash. Thus, while our hop farmers used a great abundance of essentially nitrogenous manures-e.g., wool dust, shoddy, 
hoofs and horns, skin clippings, waste feathers, rape dust, and the like - they comparatively rarely applied phosphates, except in the form of fish guano, rape cake, and purchased dung, in which manures phosphates may be considered as existing in quite insufficient proportion to form a practical balance to the nitrogen present. The application of potash, too, was neglected in a great number of gardens where it might have done good.

These mistakes are now being generally recognised. Professor HaLl, the late Principal of Wye College, and present Director of the Rothamsted Agricultural Experiment Station, in a summary which he has recently written of the hop manuring experiments carried out under his auspices, points out that the general conclusion so far arrived at is "that the hop plant is one which shows no special requirements in one direction or another, but is an all round feeder." It is not comparable with the Swede, '" which shows a special dependence on a free supply of phosphates," or with potatoes, "which particularly need plenty of potash." The hop "requires what may be termed a normal mixture of all the elements of plant food."

Doubtless many soils on which hops are grown are of great natural fertility and rich in mineral plant food; and even to-day there are, no doubt, soils independent of any special application of phosphates or potash or both. But there must be a great many gardens the mineral resources of which have been too heavily taxed in the past by almost exclusive nitrogenous manuring.

It is also to be remembered that the average crops grown to-day are usually greatly in excess of those grown in earlier times. This is no doubt attributable to improved general knowledge on the subject of the prevention and mitigation of the ravages of the green fly, red spider and mildew, and to the availability of improved appliances, for coping with these pests. Obviously an increased output should be accompanied by increased manuring, if the productivity of the soil is to be maintained.

Although the Wye College experiments, to which allusion has already been made, show that different soils vary in their mineral requirements in relation to hop growing, and that probably in no 
particular case can it be ascertained, without experimental investigation or a chemical analysis of the soil, how far phosphates and potash are really needed, it would nevertheless be a safe rule for hop farmers to make a point of supplying their hops with an abundance of phosphates as well as with nitrogen, no matter whether they use dung or not. Phosphatic manures are, happily, inexpensive, and the cost of even a heavy dressing is so small an item in the unfortunately large total expenditure which the production of a crop of hops involves, that it seems scarcely worth while to seek to economise by withholding phosphates where there is any chance of their being useful.

On soils containing a fair quantity of carbonate of lime, half a ton per acre of superphosphate or of vitriolised bones may safely be used as an annual application without the slightest risk of doing harm; while on soils in which there is a scarcity of carbonate of lime the place of superphosphate or vitriolised bones may be taken by a like dressing of basic slag or of phosphatic Peruvian guano, or of precipitated phosphate made by neutralising superphosphate with lime-a form of phosphate which is now purchasable commercially under the name of "basic superphosphate."

On light soils, finely-ground bonemeal, in quantities of not less than half a ton per acre, also makes a good phosphatic dressing, and at the same time supplies some nitrogen ; while a very good phosphatic manure for light soils poor in lime may also be made by mixing superphosphate and fine bonemeal in equal proportions, and using an annual dressing of not less than half a ton of the mixture per acre.

In gardens where the application of phosphates has been neglected and where the land is also poor in lime, any of the above-mentioned dressings (basic slag, guano, bonemeal, or " basic" superphosphate) might probably be advantageously increased in the first season to I 5 cwt. per acre.

Large dressings of ordinary acid superphosphate should not be used-or only rarely-on soils containing little or no carbonate of lime. Whether this is the case may be roughly ascertained by mixing a few ounces of soil with water and then pouring on some hydrochloric ("muriatic") acid. If there is no distinct effervescence, 
poverty in lime is indicated, and the phosphatic manure to be used should be chosen accordingly. In doubtful cases an analytical examination of the soil is desirable.

A special application of potash salts is probably less necessary as a rule than one of phosphates, and no doubt on a great many soils, especially where dung has been freely used, potash salts need not be applied at all. But where dung is not freely used it is probably safer, in the writer's opinion, in most seasons and on most soils, to give a dressing of potash salts, unless experience or investigation of the soil has distinctly indicated that the natural supply of available potash is sufficient. On many soils the aid of potash salts should on no account be dispensed with, and their moderate and proper use is in no case likely to do harm.

The repeated application of kainit year after year is not to be recommended, on account of the large quantities of salt and of magnesium chloride contained in this form of potash salts, in addition to the sulphate of potash, for which it is chiefly useful. For regular application, a dressing of from I cwt. to 2 cwt. per acre of sulphate of potash is probably better than kainit, but every now and again a variation may be made by applying 5 or 6 cwt. of kainit per acre.

In the case of many hop gardens which have been under long cultivation, much good is no doubt to be derived from an occasional dressing of lime, which should be applied in the winter in a finely ground state so as to be well distributed.

There is practically no chance of injuring either the quality or the yield of the hop crop by an over-supply of phosphates or by any ordinary application of potash salts. Given a sufficiency of these, however, both the quality and the quantity of the crop are capable of being largely influenced both by the nature and by the quantity of the manure used to supply the nitrogen, and also by the time of its application.

The nitrogenous manures used for hops in former days to supplement home-made dung, were chiefly of the organic kind. Homemade dung, while a most valuable adjunct to hop farming, can never be more than an adjunct, owing to the necessarily limited quantities 
which can be produced on the farm. Town dung, however, has for a great many years formed a favourite manure with hop farmers. This, although it contains also a good deal of phosphates, may essentially be regarded as a nitrogenous organic manure. Wool waste, or shoddy, containing 5 or 6 per cent. of nitrogen, is sometimes used by hop growers to the extent of as much as two tons per acre, while fish guano, containing about 8 per cent. of nitrogen, is often used to the extent of a ton per acre, as is also rape dust. Slowly acting manures like hoofs and horns-containing about I4 per cent. of nitrogen-are also applied by the ton. Peruvian guano of the old-fashioned type, essentially rich in ammonia, and forming a very readily available nitrogenous manure, was also a favourite application for hops, and such limited quantities of rich guano, both Peruvian and African, as are still imported, are largely used in the hop districts.

In more recent years sulphate of ammonia and nitrate of soda, which differ from organic manures in being much more rapidly available, have been coming into use for hop growing as adjuncts to the more slowly acting manures, over which they present, by their more rapid availability, certain advantages.

Manures in which the nitrogen exists in the form of animal or vegetable matter have to become decomposed before they can be of any use to the crop, their nitrogen being converted first into the form of ammonia, which again has to undergo natural conversion into nitrates within the body of the soil before it becomes available as a plant food. In these respects organic manures resemble the natural organic matters of the soil.

These successive processes of fermentation and nitrificationespecially the latter-only take place during fairly warm weather, and when the hop plant begins its growth the nitrogen it takes up may be said to be mainly derived less from the organic manures which have been applied during the winter and spring than from the unused nitrates formed in the soil during the previous summer and autumn by the decomposition and nitrification of manure applied earlier. It is not until the bine is well advanced in growth that the nitrogenous 
organic manures applied for the current season can be generally regarded as coming into active play.

If the winter should have happened to be a wet one, the nitrates formed during the previous year have probably been washed away to such an extent that the plant in its earlier stages of the season's growth may be suffering for lack of readily available nitrogen, despite the recent application of organic manures which have not yet assumed an active condition; and this state of things is still more likely to occur if, in addition to a wet winter, there should happen to be a late or cold spring. In such circumstances as these much assistance may be rendered by a dressing of nitrate of soda, which the first shower of rain renders immediately available for the use of the plant.

This special utility of nitrate of soda in hop manuring has been overlooked until recent years. Indeed, this particular manure-which, as need scarcely be observed, has long been in general and extensive use for ordinary farm crops-was for a long time regarded with an unfriendly eye both by hop growers and by hop consumers as being likely to produce a rank growth of bine at the expense of quality, and even quantity of crop. This view was no doubt partly based on the experience of those who had applied nitrate of soda without a sufficient quantity of mineral manures (phosphates and potash salts); but more especially, perhaps, on the experience of those who erred by applying nitrate of soda too late in the season. Formerly, indeed, when the hop grower did have recourse to nitrate of soda it was as an application late in the season to stimulate a backward plant. Such late applications, no doubt, may have the effect of rapid feeding and consequent stimulation of the bine; but, unfortunately, they are likely to have the result of unduly delaying the ripening period, and often of causing the hops to ripen unequally, and any hop grower of experience knows that late and unequal ripening are seldom consistent with excellence of quality.

Of late years, however, owing largely to the interest which has been taken, not only by hop growers but also by factors, merchants and brewers, in the results of the experiments about to be briefly described, the general attitude towards nitrate of soda bas been greatly modified. To the knowledge of the present writer nitrate of 
soda is now regularly used by some of our largest and most successful hop growers, both on light and on heavy land ; but it is applied comparatively early in the season, when the soil is likely to be naturally most deficient in nitrates, thus placing a supply of readily available nitrogen at the disposal of the plant when it begins its active growth. There can be little doubt that nitrate thus used is better calculated to lay the foundation of a good crop than if the application is delayed, as in older practice, until those months when the soil is actively producing nitrates from other sources.

The hop growing experiments of Mr. Shrivell and the present writer have been mainly directed to ascertaining the limits within which nitrate can be most economically and safely used. It has been necessary for this purpose to make the experiments as direct and simple as possible, and, therefore, on a number of the plots nitrate of soda-in conjunction with phosphates and potash salts-has been used for a number of years as the sole source of nitrogen. In this way annual applications of nitrate of soda have been made varying from 2 cwt. up to as much as ro cwt. per acre.

Before, however, going on to describe the results it is as well to explain that the exclusion of other nitrogenous manures on these plots is merely due to the exigencies of the experimental conditions. Neither of us supposes that any hop grower would use year after year, as we are using on some of our plots, nothing but phosphates, potash salts, and nitrate of soda. As has been pointed out elsewhere, miscellaneous feeding is good for soils and good for crops, and the best results are probably to be obtained by varying the source of manure from time to time, using nitrate of soda as a supplement to dung and the various other nitrogenous manures which have been already referred to in the course of these notes.

Furthermore, in order to keep the experiments at Hadlow as free from complication as possible and within the scope of practical management, no systematic attempt has been made to compare the results obtained on the nitrated plots with those obtainable by the use of miscellaneous nitrogenous manures; but there is, side by side with the purely chemically manured plots, for purposes of general comparison, a trial plot manured every year solely with London 
dung; and incidentally it has been also possible to institute a comparison between the yields of the various plots and that of the remaining portion of the garden, which in different seasons has been manured in various ways.

The Hadlow experiments were begun in 1894 , on a new plantation of Fuggles hops made in old hop ground on the weald clay. A series of parallel plots were permanently marked out, each plot being one-sixth of an acre in area and containing four rows of hills. During the first season all the plots were limed and dunged. On six of the plots no dung has since been applied, but phosphates have been abundantly furnished every year, sometimes in the form of superphosphate and sometimes in the form of basic slag; and potash has also been annually given, sometimes as kainit, sometimes as muriate of potash, and more recently as sulphate of potash.

One plot has, year after year, received the " mineral" manures only, without any application whatever of nitrogenous manure, while on five other plots the phosphates and potash salts have been supplemented by nitrate of soda in quantities varying from $2 \mathrm{cwt}$. per acre up to Io cwt. per acre. The larger quantities of nitrate of soda have been applied in successive dressings of 2 cwt. per acre each.

Adjoining these six plots is another plot which year by year is dressed with London dung only, without any concentrated manures.

In the first year of cropping-I895-no dressings of nitrate of soda were applied until May, and the latest dressings went on as late as August. The summer was a dry one, and most of the nitrate failed to produce any effect, there being a crop of from I I to I $3 \mathrm{cwt}$. of hops per acre without any consistent differences between the plots.

In the next year-1896-the application of nitrate was begun earlier-namely, in February; the dressings on the more heavily manured plots were finished in June. The results were better, but nitrate in excess of $2 \mathrm{cwt}$. per acre seemed to be of little additional use, although 2 cwt. per acre-in conjunction, of course, with phosphates and potash salts-gave a very satisfactory increase. 
FUGGLES HOPS,

\begin{tabular}{|c|c|c|c|}
\hline Plot. & Annual Manuring per Acre. & $\begin{array}{l}\text { Annual } \\
\text { Cost of } \\
\text { Manure } \\
\text { per Acre }\end{array}$ & I896. \\
\hline A & *Phosphates and Potash $\quad$.. $\quad$.. & $\underset{2}{£}$ s. & $\begin{array}{l}\text { cwt. } \\
\mathrm{r}_{3} \frac{1}{2}\end{array}$ \\
\hline B & Phosphates, Potash and 2 cwt. Nitrate of Soda & 3 Io 0 & $16 \frac{1}{2}$ \\
\hline $\mathrm{C}$ & 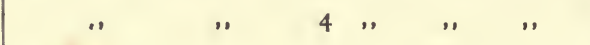 & 4100 & $r 6 \frac{1}{2}$ \\
\hline $\mathrm{D}$ & $6 \quad, \quad$, & 5 I0 0 & I5 $5 \frac{7}{4}$ \\
\hline $\mathbf{E}$ & $\begin{array}{lllll}n & 8 & & & \end{array}$ & 6 10 0 & I5 \\
\hline $\mathbf{F}$ & " $\quad$, 10 ,,$"$, & 7 Io 0 & $15 \frac{3}{4}$ \\
\hline $\mathrm{X}$ & 30 loads ( ${ }_{5}$ tons) London Dung $\quad \ldots \quad \ldots$ & 600 & 13 \\
\hline $\mathrm{S}$ & $\begin{array}{l}\text { Rest of Field-I } 5 \text { cwt. Basic Slag, } \frac{1}{2} \text { ton Fish } \\
\text { Guano in autumn, } \frac{1}{3} \text { ton Fish Guano in } \\
\text { spring, and } 4 \text { cwt. Nitrate of Soda }\end{array}$ & 9170 & $\cdots$ \\
\hline $\mathrm{S}$ & $\begin{array}{l}\text { Rest of Field-20 loads Dung, } 6 \text { cwt. Super- } \\
\text { phosphate and } 6 \text { cwt. Nitrate of Soda } .\end{array}$ & 7 I 8 & $\cdots$ \\
\hline $\mathrm{S}$ & $\begin{array}{l}\text { Rest of Field }-20 \text { loads Dung (mixed horse } \\
\text { and cattle), } 6 \text { cwt. Superphosphate, and } \\
3 \text { cwt. Nitrate of Soda } . . \quad \ldots\end{array}$ & $68 \mathrm{c}$ & $\cdots$ \\
\hline S & $\begin{array}{l}\text { Rest of Field-6 cwt. Superphosphate and } \\
3 \text { cwt. Nitrate of Soda } \\
\begin{array}{llll} & \ldots & \ldots\end{array}\end{array}$ & $28 \mathrm{c}$ & $\cdots$ \\
\hline $\mathrm{S}$ & 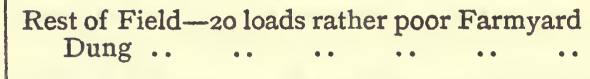 & 400 & $\cdots$ \\
\hline $\mathrm{S}$ & $\begin{array}{l}\text { Rest of Field-20 loads Farm Dung, } 8 \mathrm{cwt} \text {. } \\
\text { Phosphatic Guano, } 3 \mathrm{cwt} \text {. Nitrate of Soda }\end{array}$ & 7 I8 & - \\
\hline \multirow[t]{2}{*}{$\mathrm{S}$} & $\begin{array}{l}\text { Rest of Field-6 cwt. Superphosphate, I cwt. } \\
\text { Sulphate of Potash, } 3 \text { cwt. Nitrate of Soda }\end{array}$ & $3 I \mathrm{C}$ & $\because$ \\
\hline & $\begin{array}{l}\text { Total Rainfall for Year } \\
\text { Rainfall from January to end of September }\end{array}$ & & $\begin{array}{l}\text { in. } \\
24^{\circ} 19 \\
15 \% 72\end{array}$ \\
\hline
\end{tabular}

* $8 \mathrm{cwt}$. Superphosphate and $2 \mathrm{cwt}$. Muriate of Potash in 1896 ; ro cwt. Basic Slag in 1898; 10 cwt. Basic Slag and $5 \mathrm{cwt}$. Kainit in 1899; 10 cwt. Superphosphate and Igor; Io cwt. Basic Slag and $2 \mathrm{cwt}$. Sulphate of Potash in 1902; 10 cwt. Superphosphate 
1896-1904.

Weight of Kiln-dried Hops per Acre.

\begin{tabular}{|c|c|c|c|c|c|c|c|c|}
\hline I 897. & I898. & I899. & I900. & Igor. & I902. & 1903. & I904. & $\begin{array}{l}\text { Average } \\
\text { of nine } \\
\text { years. }\end{array}$ \\
\hline $\begin{array}{l}\text { cwt. } \\
7 \frac{1}{2}\end{array}$ & $\begin{array}{c}\text { cwt. } \\
81\end{array}$ & $\begin{array}{c}\text { cwt. } \\
201\end{array}$ & $\begin{array}{c}\text { cwt. } \\
8\end{array}$ & $\begin{array}{c}\text { cwt. } \\
\text { I } 9 \frac{1}{2}\end{array}$ & $\begin{array}{c}\text { cwt. } \\
\text { I21 }\end{array}$ & $\begin{array}{l}\text { cwt. } \\
9 \frac{1}{2}\end{array}$ & $\begin{array}{c}\text { cwt. } \\
6 \frac{3}{4}\end{array}$ & $\begin{array}{l}\text { cwt. } \\
\text { II } \frac{1}{2}\end{array}$ \\
\hline $9 \frac{1}{4}$ & IO $\frac{1}{4}$ & $22 \frac{1}{4}$ & $9 \frac{3}{4}$ & $23 \frac{3}{4}$ & $14 \frac{1}{2}$ & 12 & $9 \frac{1}{2}$ & $I_{41}$ \\
\hline I2 & $12 \frac{1}{2}$ & 23 & II & 25 & $15 \frac{3}{2}$ & I3 & $12 \frac{1}{2}$ & I5 \\
\hline 13 & I3 & $22 \frac{1}{2}$ & IO $\frac{1}{3}$ & 241 & I51 & $12 \frac{3}{4}$ & I 2 & I $5 \frac{1}{2}$ \\
\hline $13 \frac{1}{2}$ & I 51 & $23 \frac{1}{2}$ & II & $25 \frac{3}{4}$ & I61 & I 51 & 121 & $1 \sigma_{\frac{1}{2}}$ \\
\hline 13 & I5 & $24 \frac{1}{2}$ & IO $\frac{1}{2}$ & 25 & I5t & I5t & I 2 & I61. \\
\hline 8 & $9 \frac{3}{4}$ & $24 \frac{1}{2}$ & 103 & 264 & I6 & 13亲 & II & $14 \frac{3}{4}$ \\
\hline .. & $13 \frac{1}{4}$ & .. & .. & $\cdots$ & .. & .. & .. & .. \\
\hline .. & .. & $24 \frac{1}{2}$ & .. & .. & .. & .. & .. & .. \\
\hline . & .. & .. & $\operatorname{II} \frac{1}{2}$ & . & .. & .. & . & .. \\
\hline .. & •. & .. & $\cdot \cdot$ & 264 & . & •. & . & . \\
\hline . & •. & •. & . & .. & 161 & . & . & $\cdot$ \\
\hline .. & .. & .. & •. & .. & .. & 134 & .. & .. \\
\hline .. & .. & .. & .. & .. & .. & .. & II & .. \\
\hline $\begin{array}{l}\text { in. } \\
23^{\circ} 05 \\
18^{\prime} .12\end{array}$ & $\begin{array}{l}\text { in. } \\
\text { I8.25 } \\
\text { I0.73 }\end{array}$ & $\begin{array}{l}\text { in. } \\
24 \cdot 64 \\
\text { I6.89 }\end{array}$ & $\begin{array}{l}\text { in. } \\
26.60 \\
18.80\end{array}$ & $\begin{array}{c}\text { in. } \\
20 \cdot 26 \\
13 \cdot 26\end{array}$ & $\begin{array}{l}\text { in. } \\
2 \mathrm{I} \cdot 44 \\
\mathrm{I} 5 \cdot 60\end{array}$ & $\begin{array}{l}\text { in. } \\
36 \cdot 18 \\
26 \cdot 47\end{array}$ & $\begin{array}{l}\text { in. } \\
23 \cdot 10 \\
\text { I6. } 55\end{array}$ & $\begin{array}{l}\text { in. } \\
2419 \\
16.90\end{array}$ \\
\hline
\end{tabular}

and 2 cwt. Sulphate of Potash in $1897 ; 8 \mathrm{cwt}$. Superphosphate and $\mathrm{r}$ cwt. Sulphate of Potash $2 \mathrm{cwt}$. Sulphate of Potash in Igoo; 1o cwt. Superphosphate and $2 \mathrm{cwt}$. Sulphate of Potash in and $2 \mathrm{cwt}$. Sulphate of Potash in rgo3; ro cwt. Basic Slag and $4 \mathrm{cwt}$. Kainit in I904. 
In 1897 nitrate dressing began in February, but was completed by the end of May. The results obtained from the larger quantities of nitrate were much more satisfactory.

In 1898 the first dressing of nitrate was put on earlier stillnamely, in the third week in January, and the last dressing towards the middle of May, and the results were yet more marked. In I899 the dressing began at the beginning of January, finishing in April; and in 1900, and since, the first application of nitrate has been in January, when each nitrated plot has received $2 \mathrm{cwt}$. of nitrate per acre, four of the plots receiving a further 2 cwt. per acre in February three a still further $2 \mathrm{cwt}$. per acre in March, two a yet further $2 \mathrm{cwt}$. per acre in April, and one plot a finaldressing of $2 \mathrm{cwt}$. per acre in May.

The results for each year from 1896 to 1904 , together with the average of the nine years, are here given for each plot, in terms of weight of kiln-dried hops per acre, as well as the manures used, calculated per acre, and their cost.

In the following table is shown the increase in hops obtained by the use of the varying quantities of nitrate of soda on the chemically manured plots, in excess of the yield of Plot A, to which phosphates and potash salts only have been applied :-

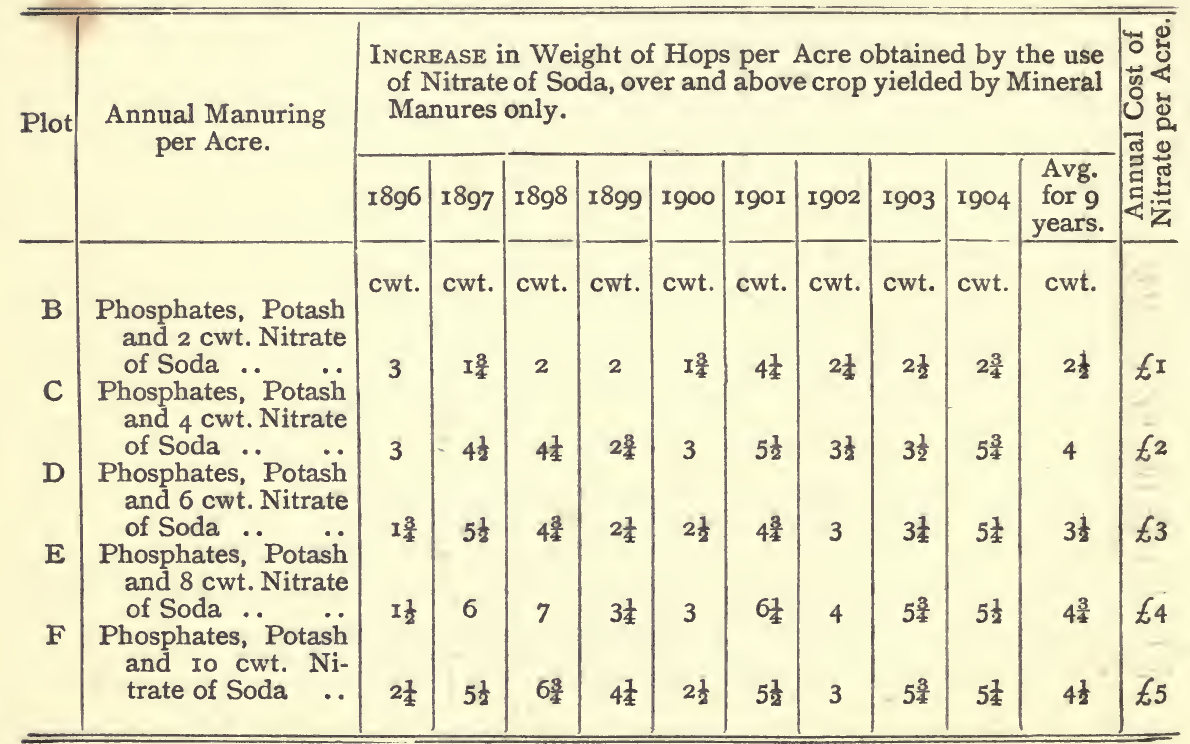


In the earlier seasons no critical examination was made as to the comparative quality of the hops from the several plots; but in 1898 , and since, the hops from each plot have, after drying, been packed separately, and duplicate sets of samples from the growth of each plot, drawn in the ordinary way as for market purposes, have been subjected to the ordeal of chemical examination as well as that of examination by market experts.

One of the sets of samples each year has been submitted to Mr. Alfred C. Chapman, F.I.C., for the determination of total resin and "soft" resin. Mr. Chapman has at the same time been asked to "place" the samples in order of merit, and, during the last six years, he has also been asked to state what he considered to be the money value of the samples to the brewer, having regard to the market conditions of the moment and to the general quality of Fuggles hops during the particular season. In kindly acceding to this request, $\mathrm{Mr}$. Chapman has taken into account the physical properties of the hopssuch as aroma, condition of strobiles, freedom from disease, colour, \&c.-considering all these points together with the resin percentages.

Duplicate samples have also been each year submitted to a firm of experienced hop factors, and, in later years, not only to a firm of factors, but (independently) to a firm of hop merchants also. These gentlemen have been good enough to place the samples in their order of merit and (in most cases) to put on each its current market value on the day of examination.

It should be stated that all the samples-both those submitted to Mr. Chapman and those submitted to the factors and merchants-have each year been marked with casual cipher numbers bearing no relation to the alphabetical letters by which the experimental plots are distinguished, so that in every case the valuation has been made without any knowledge of the mode of manuring corresponding to any particular sample. Indeed, on several occasions other samples than those grown on the plots have been included in the set of samples submitted for valuation.

The percentages of total and " soft resin" found by Mr. CHAPMAN are shown in the following table :- 
FUGGLES HOPS-ANALYSES BY

\begin{tabular}{|c|c|c|c|c|c|c|}
\hline \multirow{2}{*}{ Plot } & \multirow{2}{*}{ Annual Manuring per Acre. } & \multicolumn{2}{|c|}{ r8g8. } & \multicolumn{2}{|c|}{ I899. } & \multirow{2}{*}{$\begin{array}{r}\text { rgoo } \\
\text { Total } \\
\text { Resin. }\end{array}$} \\
\hline & & $\begin{array}{l}\text { Total } \\
\text { Resin. }\end{array}$ & $\begin{array}{l}\text { Soft } \\
\text { Resin. }\end{array}$ & $\begin{array}{l}\text { Total } \\
\text { Resin. }\end{array}$ & $\begin{array}{l}\text { Soft } \\
\text { Resin. }\end{array}$ & \\
\hline A & Phosphates and Potash $\quad$. & $\begin{array}{l}\text { Per cent. } \\
\text { I } 4 .{ }^{\prime} 5\end{array}$ & $\begin{array}{c}\text { Per cent } \\
9.2 I\end{array}$ & $\begin{array}{l}\text { Per cent. } \\
\text { I5.07 }\end{array}$ & $\begin{array}{l}\text { Per cent } \\
8 \cdot 60\end{array}$ & $\begin{array}{l}\text { Per cent. } \\
\mathbf{I}_{4^{\circ}} 53\end{array}$ \\
\hline B & $\begin{array}{l}\text { Phosphates, Potash, and } 2 \text { cwt. } \\
\text { Nitrate of Soda }\end{array}$ & $14 \cdot 30$ & $9 \cdot 20$ & I6.59 & $8 \cdot 83$ & I5.09 \\
\hline $\mathrm{C}$ & $\begin{array}{c}\text { Phosphates, Potash, and } 4 \mathrm{cwt} \text {. } \\
\text { Nitrate of Soda }\end{array}$ & $I_{4} .06$ & $9 \cdot 04$ & $15 \cdot 87$ & $9 \cdot 27$ & $\mathrm{I}_{4} 4^{4} 6$ \\
\hline $\mathrm{D}$ & $\begin{array}{l}\text { Phosphates, Potash, and } 6 \text { cwt. } \\
\text { Nitrate of Soda }\end{array}$ & 13.57 & $8 \cdot 60$ & $I_{4} \cdot 90$ & $8 \cdot 70$ & $\mathrm{I}_{3} \cdot 46$ \\
\hline $\mathbf{E}$ & $\begin{array}{c}\text { Phosphates, Potash, and } 8 \mathrm{cwt} \text {. } \\
\text { Nitrate of Soda }\end{array}$ & I 4 . II & $8 \cdot 85$ & $\mathrm{I}_{4} \cdot 49$ & $8 \cdot 96$ & $13 \cdot 30$ \\
\hline $\mathbf{F}$ & $\begin{array}{l}\text { Phosphates, Potash, and ro } \\
\text { cwt. Nitrate of Soda }\end{array}$ & $12 \cdot 21$ & $7 \cdot 91$ & 15.47 & $9 \cdot 4 \mathrm{I}$ & $12 \cdot 77$ \\
\hline $\mathrm{X}$ & 30 loads ( $5_{5}$ tons) London Dung & I3.93 & $8 \cdot 66$ & $14 \cdot 92$ & $8 \cdot 80$ & $14 \% 78$ \\
\hline $\mathrm{S}$ & $\begin{array}{l}\text { Rest of Field-I5 cwt. Basic } \\
\text { Slag, I ton Fish Guano, and } \\
4 \text { cwt. Nitrate of Soda }\end{array}$ & 13.03 & $8 \cdot 30$ & -. & •. & . \\
\hline S & $\begin{array}{l}\text { Rest of Field-2o loads Dung, } \\
6 \text { cwt. Superphosphate, and } \\
6 \text { cwt. Nitrate of Soda }\end{array}$ & .. & .. & $14 \cdot 26$ & $8 \cdot 43$ & •• \\
\hline S & $\begin{array}{l}\text { Rest of Field-2o loads Dung } \\
\text { (mixed horse and cattle), } 6 \\
\text { cwt. Superphosphate, and } 3 \\
\text { cwt. Nitrate of Soda }\end{array}$ & .. & .. & •. & .. & $I_{4} \cdot 2 \mathrm{I}$ \\
\hline $\mathrm{S}$ & $\begin{array}{l}\text { Rest of Field-6 cwt. Super- } \\
\text { phosphate and } 3 \mathrm{cwt} \text {. Nitrate }\end{array}$ & & a & & & \\
\hline & $\begin{array}{llll}\text { of Soda } & \ldots & \ldots & \end{array}$ & $\cdots$ & -. & -. & $\cdots$ & -. \\
\hline $\mathrm{S}$ & $\begin{array}{c}\text { Rest of Field-2o loads rather } \\
\text { poor Farmyard Dung }\end{array}$ & .. & .. & .. & .. & $\cdots$ \\
\hline $\mathrm{S}$ & $\begin{array}{l}\text { Rest of Field-2o loads Farm- } \\
\text { yard Dung, } 8 \mathrm{cwt} \text {. Phosphatic } \\
\text { Guano, } 3 \mathrm{cwt} \text {. Nitrate of Soda }\end{array}$ & $\cdots$ & . & •. & .. & $=$ \\
\hline $\mathbf{S}$ & $\begin{array}{l}\text { Rest of Field-6 cwt. Super- } \\
\text { phosphate, I cwt. Sulphate } \\
\text { of Potash, } 3 \text { cwt. Nitrate of } \\
\text { Soda } . . \\
\text {. }\end{array}$ & $\cdots$ & $\cdots$ & $\cdots$ & $\cdots$ & 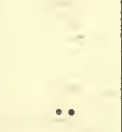 \\
\hline
\end{tabular}


Mr. ALFRED C. CHAPMAN, F.I.C.

\begin{tabular}{|c|c|c|c|c|c|c|c|c|}
\hline & \multicolumn{2}{|c|}{ I901. } & \multicolumn{2}{|c|}{1902.} & \multicolumn{2}{|c|}{ I903. } & \multicolumn{2}{|c|}{ I904. } \\
\hline $\begin{array}{c}\text { Soft } \\
\text { Resin. }\end{array}$ & $\begin{array}{l}\text { Total } \\
\text { Resin. }\end{array}$ & $\begin{array}{c}\text { Soft } \\
\text { Resin. }\end{array}$ & $\begin{array}{l}\text { Total } \\
\text { Resin. }\end{array}$ & $\begin{array}{c}\text { Soft } \\
\text { Resin. }\end{array}$ & $\begin{array}{l}\text { Total } \\
\text { Resin. }\end{array}$ & $\begin{array}{c}\text { Soft } \\
\text { Resin. }\end{array}$ & $\begin{array}{l}\text { Total } \\
\text { Resin. }\end{array}$ & $\begin{array}{c}\text { Soft } \\
\text { Resin. }\end{array}$ \\
\hline $\begin{array}{c}\text { Per cent } \\
8.90\end{array}$ & $\begin{array}{l}\text { Per cent. } \\
\text { I } 4.07\end{array}$ & $\begin{array}{c}\text { Per cent } \\
8.57\end{array}$ & $\begin{array}{c}\text { Per cent. } \\
1^{\circ} 57\end{array}$ & $\begin{array}{c}\text { Per cent } \\
8.59\end{array}$ & $\begin{array}{c}\text { Per cent } \\
\mathrm{I}_{4}{ }^{\circ} 53\end{array}$ & $\begin{array}{l}\text { Per cent } \\
8.92\end{array}$ & $\begin{array}{c}\text { Per cent. } \\
13^{\circ} 4^{2}\end{array}$ & $\begin{array}{c}\text { Per cent. } \\
9^{\cdot 25}\end{array}$ \\
\hline $8 \cdot{ }_{5} \mathrm{I}$ & $\mathrm{I} 4 \cdot 42$ & $8 \cdot 80$ & 14.59 & $9 \cdot 34$ & $\mathrm{I}_{4} \cdot 04$ & $9 \cdot 74$ & $\mathrm{I}_{4} \cdot 70$ & 9.93 \\
\hline $8 \cdot I 6$ & 13.78 & $8 \cdot 74$ & 13.80 & $9 \cdot 30$ & 13.48 & $8 \cdot 28$ & $13 \cdot 12$ & 9.34 \\
\hline $7 \cdot 62$ & I $2 \cdot 9 \mathrm{I}$ & $8 \cdot 21$ & 13.09 & $8 \cdot 8 I$ & I3.07 & $7 \cdot 88$ & 13.23 & $8 \cdot 86$ \\
\hline $7 \cdot 18$ & 13.69 & $8 \cdot 47$ & $13 \cdot 82$ & $8 \cdot 98$ & 13.49 & 7.69 & I3.94 & 9.07 \\
\hline 6.77 & 13.99 & $8 \cdot 59$ & 13.50 & $8 \cdot 84$ & 12.99 & $7 \cdot 62$ & 14.79 & 9.71 \\
\hline $9 \cdot 07$ & 13.77 & $8 \cdot 46$ & $13.2 I$ & $8 \cdot 4 \mathrm{I}$ & ${ }^{1} 4 \cdot 15$ & 8.85 & 13.76 & $9 \cdot 60$ \\
\hline .. & .. & .. & .. & .. & .. & .. & .. & .. \\
\hline .. & .. & .. & .. & .. & .. & . & .. & $\bullet$ \\
\hline $7 \cdot 74$ & .. & .. & .. & .. & .. & .. & .. & .. \\
\hline .. & $I_{4} \cdot 46$ & $9.5 \mathrm{I}$ & .. & .. & .. & .. & .. & .. \\
\hline .. & .. & .. & I2.59 & $8 \cdot 27$ & .. & .. & .. & .. \\
\hline .. & .. & .. & .. & .. & $12 \cdot 26$ & $7 \cdot 63$ & .. & .. \\
\hline$\cdots$ & ・・ & .. & ・. & .. & .. & .. & $I_{4} \cdot 86$ & $10 \cdot 23$ \\
\hline
\end{tabular}




\begin{tabular}{|c|c|c|c|c|c|c|}
\hline \multirow{2}{*}{ Plot } & \multirow{2}{*}{ Annual Manuring per Acre. } & \multicolumn{2}{|c|}{$\begin{array}{l}\text { I898 } \\
\text { Valuation. } \\
\text { Per cwt. }\end{array}$} & \multicolumn{2}{|c|}{$\begin{array}{l}\text { r899 } \\
\text { Valuation. } \\
\text { Per cwt. }\end{array}$} & \multirow{2}{*}{\begin{tabular}{|c|}
$\begin{array}{r}\text { I900 } \\
\text { Valua- } \\
\text { Per }\end{array}$ \\
$\begin{array}{c}\text { Mr. } \\
\text { Chapman } \\
\text { (as to } \\
\text { brewer). }\end{array}$
\end{tabular}} \\
\hline & & $\begin{array}{l}\text { Mr. } \\
\text { Chapman } \\
\text { (as to } \\
\text { brewer). }\end{array}$ & $\begin{array}{l}\text { Factors } \\
\text { (as to } \\
\text { grower). }\end{array}$ & $\begin{array}{l}\text { Mr. } \\
\text { Chapman } \\
\text { (as to } \\
\text { brewer). }\end{array}$ & $\begin{array}{l}\text { Factors } \\
\text { (as to } \\
\text { grower). }\end{array}$ & \\
\hline A & Phosphates and Potash & ${ }^{*}{ }_{4}$ th & 1361 & $40 /$ & 351 & 1051 \\
\hline B & Phosphates, Potash, and 2 cwt. & & & & & \\
\hline $\mathrm{C}$ & $\begin{array}{c}\text { Nitrate } \\
\text { Phosphates, Potash, and } 4 \text { cwt. }\end{array}$ & $5^{\text {th }}$ & $142 /$ & $56 /$ & 4 이 & I02/ \\
\hline & Nitrate $\quad$.. $\quad$. & 3 rd & I42/ & $50 /$ & 421 & $97 /$ \\
\hline D & Phosphates, Potash, and $6 \mathrm{cwt}$. & & & & & \\
\hline & $\begin{array}{llll}\text { Nitrate } & \cdots & \cdots & \cdots\end{array}$ & 6th & 1421 & $54 /$ & $44 !$ & 951 \\
\hline $\mathbf{E}$ & Phosphates, Potash, and $8 \mathrm{cwt}$. & & & & & \\
\hline & $\begin{array}{llll}\text { Nitrate } & \cdots & \ldots & \end{array}$ & $7^{\text {th }}$ & 136/ & 521 & $50 /$ & under 95/ \\
\hline $\mathbf{F}$ & $\begin{array}{c}\text { Phosphates, Potash, and Io } \\
\text { cwt. Nitrate.. }\end{array}$ & 8 th & I36/ & $60 /$ & 461 & under 95/ \\
\hline $\mathrm{X}$ & 30 loads London Dung $\quad$.. & Ist & 1421 & $5 \mathrm{I} /$ & 381 & 1051 \\
\hline S & $\begin{array}{c}\text { Rest of Field-Basic Slag, Fish } \\
\text { Guano, and } 4 \text { cwt. Nitrate }\end{array}$ & 2nd & I38I & •. & $\cdots$ & -. \\
\hline $\mathrm{S}$ & $\begin{array}{l}\text { Rest of Field-Dung, Super- } \\
\text { phosphate,and } 6 \mathrm{cwt} \text {.Nitrate }\end{array}$ & $\cdots$ & $\cdots$ & $58 /$ & $48 /$ & $\cdots$ \\
\hline $\mathrm{S}$ & $\begin{array}{l}\text { Rest of Field-Dung, Super- } \\
\text { phosphate,and } 3 \text { cwt. Nitrate }\end{array}$ & $\cdots$ & $\cdots$ & $\cdots$ & $\cdots$ & $99 /$ \\
\hline S & $\begin{array}{l}\text { Rest of Field - Superphos- } \\
\text { phate and } 3 \text { cwt. Nitrate .. }\end{array}$ & $\cdots$ & $\bullet$ & $\bullet$ & $\bullet$ & $\cdots$ \\
\hline S & Rest of Field-Farmyard Dung & $\cdots$ & $\cdots$ & $\cdots$ & $\cdots$ & $\because$ \\
\hline S & $\begin{array}{l}\text { Rest of Field - } 20 \text { loads Farm } \\
\text { Dung, } 8 \text { cwt. Phosphatic } \\
\text { Guano, } 3 \text { cwt.Nitrate of Soda }\end{array}$ & $\cdots$ & $\cdots$ & $\cdots$ & $\cdots$ & 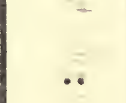 \\
\hline S & 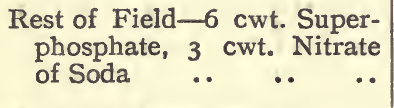 & $\cdots$ & $\cdots$ & $\cdots$ & $\cdots$ & $\cdots$ \\
\hline
\end{tabular}

In $1898 \mathrm{Mr}$ Chapman "placed" the samples in order of value, without assigning money figures. 


\begin{tabular}{|c|c|c|c|c|c|c|c|c|}
\hline \multirow{2}{*}{$\begin{array}{l}\text { tion. } \\
\text { cwt. } \\
\text { Factors } \\
\text { and Mer- } \\
\text { chants } \\
\text { (as to } \\
\text { grower). }\end{array}$} & \multicolumn{2}{|c|}{$\begin{array}{c}\text { Igor } \\
\text { Valuation. } \\
\text { Per cwt. }\end{array}$} & \multicolumn{2}{|c|}{$\begin{array}{c}1902 \\
\text { Valuation. } \\
\text { Per cwt. }\end{array}$} & \multicolumn{2}{|c|}{$\begin{array}{c}\text { r903 } \\
\text { Valuation. } \\
\text { Per cwt. }\end{array}$} & \multicolumn{2}{|c|}{$\begin{array}{c}1904 \\
\text { Valuation. } \\
\text { Per cwt. }\end{array}$} \\
\hline & $\begin{array}{c}\text { Mr. } \\
\text { Chapman } \\
\text { (as to } \\
\text { brewer). }\end{array}$ & $\begin{array}{c}\text { Factors } \\
\text { and Mer- } \\
\text { chants } \\
\text { (as to } \\
\text { grower). }\end{array}$ & $\begin{array}{c}\text { Mr. } \\
\text { Chapman } \\
\text { (as to } \\
\text { brewer). }\end{array}$ & $\begin{array}{l}\text { Factors } \\
\text { and Mer } \\
\text { chants } \\
\text { (as to } \\
\text { grower). }\end{array}$ & $\begin{array}{c}\text { Mr. } \\
\text { Chapman } \\
\text { (as to } \\
\text { brewer). }\end{array}$ & $\begin{array}{c}\text { Factors } \\
\text { and Mer- } \\
\text { chants } \\
\text { (as to } \\
\text { grower). }\end{array}$ & $\begin{array}{c}\text { Mr. } \\
\text { Chapman } \\
\text { (as to } \\
\text { brewer.) }\end{array}$ & $\begin{array}{l}\text { Factors } \\
\text { and Mer- } \\
\text { chants } \\
\text { (as to } \\
\text { grower). }\end{array}$ \\
\hline $99 /$ & 581 & $39 /$ & I I6/ & Iro/ & 1251 & го3/ & x 7 이 & I5O/ \\
\hline $99 /$ & 641 & 371 & Ir 81 & Iro/ & $123 /$ & I02/ & I75I & I53/ \\
\hline $95 /$ & 671 & 381 & I20/ & rog/ & II 7 & $99 /$ & I681 & I $54 /$ \\
\hline $96 /$ & $50 /$ & $3^{81}$ & II 4 / & I07I & II $4 /$ & 102/ & I65I & I53/ \\
\hline 921 & $6 \mathrm{I} /$ & 371 & III I & I07I & I2O/ & 103/ & I68I & I $55 /$ \\
\hline 9I/ & 521 & 351 & Irol & I06/ & Irol & I03/ & 1721 & I $53 /$ \\
\hline Iool & 551 & 371 & $\mathrm{II}_{3} /$ & 105/ & $125 /$ & 105/ & I68/ & I $53 /$ \\
\hline$\cdots$ & $\cdots$ & $\cdots$ & . & .. & $\cdots$ & $\cdots$ & 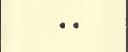 & $\cdots$ \\
\hline . & .. & . & . & . & $\cdots$ & $\cdots$ & $\cdots$ & $\cdots$ \\
\hline $9 \mathrm{I} /$ & $\cdots$ & $\cdots$ & . & $\cdots$ & $\cdots$ & $\cdots$ & $\cdots$ & $\cdots$ \\
\hline . & $70 /$ & 371 & $\cdots$ & . & . & $\cdots$ & •. & $\cdots$ \\
\hline$\cdots$ & $\cdots$ & $\cdots$ & II2/ & ro5l & . & . & . & •. \\
\hline$\cdots$ & $\because$ & $\cdots$ & $\cdots$ & • & II2/ & го3/ & $\cdots$ & $\bullet$ \\
\hline$\cdots$ & $\cdots$ & •. & $\cdots$ & $\cdots$ & •. & . & I 751 & I53/ \\
\hline
\end{tabular}

He reported that there was little difference between any of the first five samples in order of merit. 
The valuations made by Mr. Chapman of the samples referred to in the preceding table may now also be given in tabular form together with those arrived at by the factors, or (in the case of the last five years) by the factors and the merchants, who examined the corresponding duplicate samples. Where the samples were examined both by factors and merchants, the mean of their independent valuations has been taken-the difference between them, it may be added, being in no case of much moment.

It is seen throughout that the valuation of Mr. Chapman is higher than the market valuation, and it should, therefore, be borne in mind that the market valuation represents the price payable to the grower, while Mr. Chapman's figures represent the value to the brewer; the difference including merchants' profits, cost of intermediate warehousing, \&c.

It should also be noted that Mr. Chapman's valuations were not usually made on the same day as the valuations made by the merchants and factors, but some time later, when he had completed his chemical analyses; and also that the price of hops "as to grower" fluctuates rapidly, according to momentary supply and demand.

The produce of plot $\mathrm{S}$, although included in the foregoing table, cannot, except for the separate individual years, be compared with that of the other plots, as its manuring has varied. It is of interest, however, to examine the average comparative quality of the samples from the other plots.

From an examination of Mr. Chapman's valuations, arrived at jointly from chemical composition and physical characteristics, it appears that in different years both the highest and the lowest places have been taken by the plot (A) receiving mineral manures only; and that, while the dunged plot (X) has also twice occupied the place of honour, it has on two occasions been near the bottom of the list. The highest position in one year was accorded to the sample from plot $F$, which received no less than ro cwt. of nitrate of soda per acre; while this plot on three occasions took the last place. The sample grown with $4 \mathrm{cwt}$. of nitrate of soda per acre (plot C) was twice in the front rank and once in the second as regards quality. 
If the value assigned by $\mathrm{Mr}$. Chapman to the best sample in each of the four seasons in which he made a money valuation be taken as Ioo, and the valuation of the produce of each plot be expressed relatively to this for each year and then averaged, the following figures are obtained, which may be taken as expressing the average relative value of the various samples to the brewer :-

Average relative value to brewer (as percent-

Plot. Annual Manuring per Acre. age of Mr. Chapman's highest valuation) over 6 years (I899-r904).

B. Phosphates, Potash and 2 cwt. Nitrate of Soda ... 97

C. Phosphates, Potash and 4 cwt. Nitrate of Soda ... 94

X. 30 loads (I 5 tons) London Dung $\quad \ldots \quad$... $\quad \ldots .93$

E. Phosphates, Potash and 8 cwt. Nitrate of Soda $\ldots \quad 92$

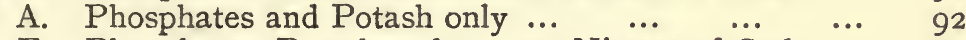

F. Phosphates, Potash and Io cwt. Nitrate of Soda ... 9 I

D. Phosphates, Potash and $6 \mathrm{cwt}$. Nitrate of Soda ... 90

It seems probable that the brewing value of the hops has been more affected by accidental influences incidental to picking and drying than by the mode of manuring. At any rate, it appears that, on the whole, the hops grown with mineral manures and nitrate of soda have not been inferior for brewing purposes to those grown with dung alone; indeed, the evidence tends to be in the contrary direction, for in individual years the dunged plot, for brewing quality, has been twice beaten by plot $F$, twice by plot $C$, twice by plot $\mathrm{D}$, twice by plot $\mathrm{E}$, and four times by plot $\mathrm{B}$.

If the valuations made by the factors and merchants are taken in the same way and stated in average percentages of the highest values assigned in the individual years, we get the following results :-

Plot. Annual Manuring per Acre.

Average relative value to grower (as percentage of factors' and merchants' highest valuation) over 6 years (r899-r904).

E. Phosphates, Potash and $8 \mathrm{cwt}$. Nitrate of Soda ... 97

B. Phosphates, Potash and 2 cwt. Nitrate of Soda ...

C. Phosphates, Potash and 4 cwt. Nitrate of Soda ... 96

D. Phosphates, Potash and 6 cwt. Nitrate of Soda ...

F. Phosphates, Potash and ro cwt. Nitrate of Soda ...

A. Phosphates and Potash only ... $\quad$... $\quad$... $\quad$...

X. 30 loads (I 5 tons London Dung) $\quad \ldots \quad \ldots \quad \ldots$ 
The conclusion here seems to be that, as far as regards physical characteristics, unaided by analytical information, there is on the average, very little difference between the produce of the various plots, and that certainly nitrate of soda, even in heavy dressings, produces no deleterious effect on the market value of the hops.

The average economy of the various manurial dressings, from the grower's point of view, is perhaps best seen from a statement of

\begin{tabular}{|c|c|c|c|c|c|c|c|c|c|c|c|}
\hline \multirow{2}{*}{ Plot } & \multirow{2}{*}{$\begin{array}{c}\text { Annual Manuring } \\
\text { per Acre. }\end{array}$} & \multicolumn{8}{|c|}{$\begin{array}{l}\text { Valuation of Crops per Acre } \\
\text { at Factors' Quotations. }\end{array}$} & \multirow{2}{*}{ 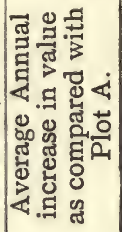 } & \multirow{2}{*}{$\begin{array}{c}\text { Average } \\
\text { Annual } \\
\text { Cost of } \\
\text { Manure } \\
\text { per } \\
\text { Acre. }\end{array}$} \\
\hline & & 1898 & I899 & 1900 & IgOT & 1902 & 1903 & I904 & 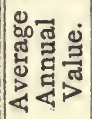 & & \\
\hline A & Phosphates and Potash & $\underset{56}{E}$ & $\frac{1}{35}$ & $t$ & $\underset{38}{t}$ & 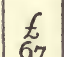 & $E$ & $£$ & $t_{8}$ & $£$ & $£$ s. d \\
\hline B & Phosphates, Potash and & & נד & & & & & & & $\cdots$ & \\
\hline C & $\begin{array}{l}2 \text { cwt. Nitrate of Soda } \\
\text { Phosphates, Potash and }\end{array}$ & 73 & 45 & 48 & 44 & 80 & 61 & 73 & 60 & 12 & 3 Io \\
\hline $\mathrm{D}$ & $\begin{array}{l}4 \text { cwt. Nitrate of Soda } \\
\text { Phosphates, Potash and }\end{array}$ & 89 & $4^{8}$ & 52 & $4^{8}$ & 86 & 64 & 96 & 69 & $2 \mathrm{I}$ & 4 I0 0 \\
\hline $\mathbf{E}$ & $\begin{array}{l}6 \text { cwt. Nitrate of Soda } \\
\text { Phosphates, Potash and }\end{array}$ & 92 & 50 & 50 & 46 & 82 & 65 & 92 & 68 & 20 & 5100 \\
\hline $\mathbf{F}$ & $\begin{array}{l}8 \mathrm{cwt} \text {. Nitrate of Soda } \\
\text { Phosphates, Potash and }\end{array}$ & 104 & 59 & $5 \mathbf{I}$ & $4^{8}$ & 87 & 78 & 95 & 74 & 26 & 6 Iо \\
\hline $\mathrm{X}$ & $\begin{array}{l}\text { Io cwt. Nitrate of Soda } \\
\text { 3o loads ( } 5 \text { tons) London }\end{array}$ & IO2 & 56 & $4^{8}$ & 44 & $8 \mathbf{I}$ & 78 & 92 & 72 & 24 & 7 Io \\
\hline & Dung $\quad \ldots \quad \ldots$ & 69 & 47 & 54 & 49 & 84 & 72 & 90 & 66 & I8 & 60 \\
\hline
\end{tabular}

the value of the crop, based on the acreage yield and the price put upon the samples in the market, for the seven years in which the valuation was made.

On the whole the most profitable results from the farmer's point of view, during these last seven years, have been on the average produced by the large dressing of $8 \mathrm{cwt}$. of nitrate of soda per acre. Such large dressings as this, however, would not be given where dung and other miscellaneous nitrogenous fertilisers are used from time to time.

The experiments of the German Hop Growers' Society, carried out under the direction of Professor WAgner, of Weihenstephan, have 
given results very similar in effect to those obtained at Hadlow, allowing for the fact that the crops grown in Germany are on the average much smaller than ours.

The German experiments have been carried out for several years running, on a similar plan, on twenty-one different hop plantations in various parts of the hop growing districts. The results for the three years (1900-1902) are shown in the following table, in which the original figures (which, according to Continental custom, are stated in kilogrammes per hectare) have been calculated into their equivalents in cwts. per English acre :-

RESUlts of EXPERIMENTS DURING THREE YEARS (I900-IgO2) ON twenty.one Hop Farms in Germany, comprising in alL sixty-three Experimental Crops.

\begin{tabular}{|c|c|c|c|c|}
\hline \multirow{2}{*}{ Annual Manuring per Acre. } & \multicolumn{4}{|c|}{$\begin{array}{l}\text { Yield of Hops per } \\
\text { English Acre. }\end{array}$} \\
\hline & I900. & I90I. & I 902. & $\begin{array}{l}3 \text { yrs. } \\
\text { avrge. }\end{array}$ \\
\hline 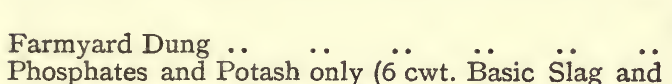 & $\begin{array}{l}\text { cwt. } \\
8 \frac{1}{4}\end{array}$ & cwt. & $\begin{array}{c}\text { cwt. } \\
7 \frac{1}{2}\end{array}$ & cwt. \\
\hline $\begin{array}{l}3 \text { cwt. } 40 \text { per cent. Potash Salts)... } \\
\text { Phosphates, Potash, and } 3 \frac{1}{4} \text { cwt. Nitrate of Soda } . .\end{array}$ & $\begin{array}{l}7 \frac{3}{4} \\
8 \frac{1}{2}\end{array}$ & $\frac{51}{6}$ & $6 \frac{1}{2}$ & $6 \frac{1}{2}$ \\
\hline 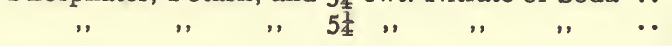 & $9 \frac{2}{4}$ & 7 & $8 \frac{1}{8}$ & $8 \frac{1}{8}$ \\
\hline
\end{tabular}

It should be stated that both of the nitrate of soda plots above mentioned were in every experiment duplicated, one-third of the nitrate in one case being supplied in the autumn, while in the other case all the nitrate has been applied in the spring. On the whole a slight advantage is shown by giving a part of the nitrate in the autumn, but it is to be remembered that nitrate so applied is in danger of being lost during a wet winter.

In this German investigation the quality of all the samples grown at the various centres in each year appears to have been carefully examined, the result being to show that on the average the best samples were those grown on the plots giving the heaviest yieldsnamely, those manured with phosphates, potash salts, and $5 \frac{1}{4} \mathrm{cwt}$. of nitrate of soda per acre. 
As to the practical limits of safety to be laid down for the use of nitrate of soda, the joint experience of Mr. SHRIVELL and the writer up to the present time does not materially modify the conclusions expressed some years ago-namely, that even when the soil is otherwise liberally manured by autumn or winter dressings of dung or of rape dust, fish guano, \&c., 4 cwt. of nitrate of soda per acre, applied early in the season, may be regarded as a thoroughly safe dressing for hops, even in a season which turns out to be wet. This, however, is a dressing which it would, under these circumstances, be best not to exceed in the case of the more delicate varieties of hops. If neither dung nor any of the other ordinary nitrogenous fertilisers has been recently applied, there appears to be no reason to anticipate that 6 cwt. of nitrate per acre would be otherwise than safe; while for freely growing and heavily cropping varieties as much as $8 \mathrm{cwt}$. per acre might be used. But a more general manuring, including a smaller quantity of nitrate of soda than this, will probably in the end commend itself to most growers.

Large dressings of nitrate of soda should be divided into separate applications of not more than $2 \mathrm{cwt}$. per acre each, with an interval of some weeks between the different dressings. The most favourable time for application on soils of medium consistency is probably April or May. For stiff or not readily permeable soils we should regard this as the latest time at which, under normal conditions of weather, nitrate should be applied, and we are inclined to prefer April to May for the final application.

But once again it should be borne in mind that neither nitrate of soda nor any other nitrogenous manure can be relied upon to produce a healthy growth and a heavy crop unless at the same time the soil is kept abundantly supplied with some form of readily available phosphatic manure, and also of potash, except on those soils on which it may have been experimentally ascertained that the latter is superfluous. 


\section{THE COLD STORAGE OF HOPS.}

By Lawrence Briant, F.C.S., F.R.M.S. THE alterable character of hops needs no proof. From the time they, under normal conditions, undergo continuous alteration, which is for the most part deterioration also. When picked, the moisture present in hops varies according to the weather, and ranges between 50 and 80 per cent. In such a condition they change with much rapidity. On the English system of drying, however, the hops are taken direct from the poles to the kiln. With Continental hops this does not occur. They are allowed to air-dry, and the curing is in some cases postponed for some time, in which case very rapid alteration takes place with considerable and sometimes most serious loss in soft resins, for it is recognised that the sooner hops are cured after they are picked the better the quality, and the expression "Season Cured," as applied to foreign hops, indicates the early withdrawal of moisture by kilning.

In drying in the oast house the moisture is generally reduced to a percentage varying from 3 to 6 , but by subsequent exposure on the packing floor the moisture quickly rises to 7 to 12 per cent., varying according to the humidity of the air at the time, the length of exposure, and other conditions. When placed in the pocket the normal percentage of moisture will lie between 8 and I I per cent. A sample of hops which contains any notably smaller proportion than the lower limit will be brittle and liable to powder when handled, and there is risk of loss of condition. If containing above the limit named the hops are slack and do not keep well. 
The proportion of water present in hops undoubtedly exerts a considerable influence upon their keep. In a number of experiments made some years back, the results of which were published at the time, samples from the same kiln of hops were stored under similar conditions, containing differing quantities of moisture. It was found the lower the proportion of moisture the slower was the deterioration of the hops. The reduction of moisture percentage may therefore be fairly regarded as an important factor in determining the keeping power of a hop; and this, rather than "curing" in the same sense as that word is applied to malt, is the object of the drying of hops on kiln. All we are able to do in this direction is to reduce the moisture to a fairly low proportion, to pack the hops without delay, and as tightly as possible.

But though the moisture is reduced to the limit of, say, 8 or 9 per cent, we know from experience that hops stored at ordinary temperatures undergo continuous alteration. The cause of this alteration is not as yet fully worked out, but there is reason to believe that the action both of zymes and enzymes is largely responsible for the changes which take place. These changes were at one time attributed to oxidation by exposure to air ; but experiments made with hops stored in exhausted chambers showed that no postponement in deterioration thereby resulted. It is, of course, impossible to secure a perfect vacuum, and the hops were merely stored relatively out of contact with the air, but inasmuch as the amount could only have been something less than $\frac{1}{1000}$ of that originally present, it is reasonable to assume that had air been the factor determining the deterioration, some marked difference would have been shown between the quality of hops stored in vacuo and those stored in the ordinary manner, and this was not the case.

Some experiments* have been recently described in one of the Trade journals, showing the effect of storage in a relatively perfect vacuum, and hops subjected to these conditions have been stated to retain their resin value, their aroma and colour to a remarkable extent. The writer has had no opportunity of making personal

* "Hops and their Storage," Brewers' Journal, pp. 6, 7, 8. Igor. 
enquiries into this process, but his experience above referred to does not lead him to anticipate much success from such a system.*

In other cases, the air has been replaced with gases such as pure nitrogen, carbon dioxide, and sulphur dioxide. No material postponement of change occurred in either of the experiments, though in that with sulphur dioxide the hops came out of the cylinder in a curiously green condition, but were not found to be superior in flavour or in resin value to those stored under ordinary conditions.

If, as the writer believes, the assumption is correct that the action of ferments is mainly responsible for deterioration, then an explanation is afforded of the undoubted success of cold storage. If we reverse the process, and hops are stored at relatively high temperatures, the effect of temperature is still more markedly shown. The writer some years ago made experiments with pockets of consecutive numbers of the same growth of hops, placing the pockets in stores, the temperatures of which were respectively $55^{\circ}$ (this being taken as a standard), $65^{\circ}, 75^{\circ}$, and $83^{\circ} \mathrm{F}$.t The deterioration which occurred may be stated as follows: In three months the pocket stored at $83^{\circ}$ had undergone as much deterioration as that stored at $55^{\circ}$ in a year. In five and

* Since this article was published, the writer has had an opportunity of personally examining the system of storage in vacuum referred to. Hops are placed in iron cylinders (the size most convenient appearing to be one sufficient to hold a pocket or bale) subjected to a high vacuum and stored in an ordinary warehouse. Hops were examined which had been thus stored for some five years. On opening, the result was somewhat disappointing, the hops having acquired a peculiar rancid odour, having lost their rub, and were in a condition such as no brewer could regard as superior to an old-old. This experience does not however necessarily prove the failure of the system, for the cylinder had been opened for the purpose of sampling and inspection several times in the course of three or four years, and the hops almost certainly must have been damaged by that cause. Certain samples of hops had been placed in glass tubes which were vacuumized and sealed, and the examination of these would be far more conclusive than of a sample which, although under vacuum, had been on several occasions exposed to the air for short periods. Assuming, however, the success of the vacuum system to be demonstrated, it remains to be seen whether in practice it would be so economical as cold storage. The cost of the cylinders is considerable, and their weight would be a very serious matter in a store holding some hundred pockets of hops. On the other hand the actual cost of working would be confined to vacuumizing in the first instance, and possibly raising the vacuum had it fallen on storage. It is sufficient to say that the vacuum system does not show any very apparent advantages over the proved and thoroughly successful system of cold storage.

† The temperature was not constant, and occasionally fluctuated between $80^{\circ}$ and $90^{\circ}$. Such variation would not, however, materially affect the actual temperature of the hops themselves. 
a half months that stored at $75^{\circ}$ had undergone slightly greater deterioration than had the standard sample in a year. The other pocket, stored at $65^{\circ}$ and examined at the same time, showed a deterioration about midway between the standard and that kept at $75^{\circ}$.

The following table* gives figures showing the influence of temperature on the amount of soft resin present :-

\section{RESINS EXPRESSED ON DRY HOPS.}

Date of Analyses. Soft. Hard. Total.

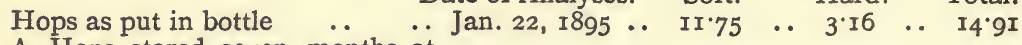
A. Hops stored seven months at

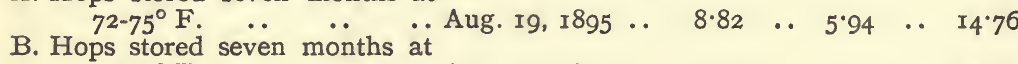

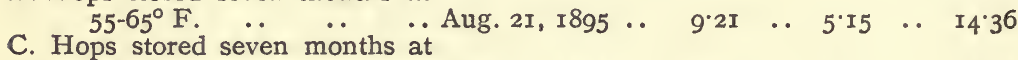

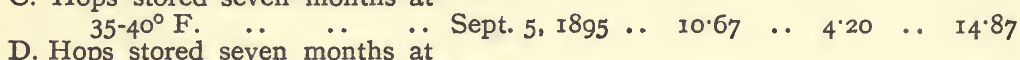

$\begin{array}{cccccccccc}\begin{array}{c}\text { D. Hops stored seven months at } \\ \text { below } 32^{\circ}\end{array} & \text { F. } & \ldots & \text {.. Aug. } 26, \text { I } 895 & \ldots & \text { II'IO } & \text {.. } & 3.57 & \text {.. } & \text { I } 4.67\end{array}$

These figures demonstrate at once the injurious influence of high and the beneficial effect of low temperatures. For practical purposes storage at any temperature below $40^{\circ}$ is effective, but in actual working it is found more convenient to reduce the temperature to below the freezing point of water, thereby insuring the contact of hops with moisture-free air. If the hops are stored at $40^{\circ}$, some steps have to be taken to withdraw the moisture from the air, though if this is done there should of course be an economy by the reduced cooling power required. In the early days of hop storage the writer, in conjunction with Mr. MEAcham, proposed the adoption of a system based on these lines; but it is only proper to say that the experience of some four or five years has modified these views, and though hops can be, and still are, very satisfactorily stored on such a system, the economy which was anticipated has not been realised in actual practice. The system, therefore, of storage at temperatures below $32^{\circ}$ may be fairly stated to hold the field as that best adopted for the preservation of hops.

Two systems of cold storage have been used: One in which the brine pipes are placed in the cold storage chamber and act upon

* "'Hops," Briant \& Meacham : Journal of the Federated Institutes of Breving. Vol. XI., No. 6, p. 4I4. 
practically quiescent air, the other in which a battery of brine pipes is placed outside the store, which is cooled by a current of air drawn over these pipes and circulating through the room. It is no doubt an advantage to have the pipes outside the storage chamber, thus preventing any drip should the temperature rise considerably through stoppage of machinery; but there is the drawback that circulation of air may mean withdrawal of essential oils, and the writer has satisfied himself that such does to a small extent occur, though its importance is lessened by the fact that the same air is continuously used for circulation.

When adopting the last-named system care must be taken that the pockets are so stacked as will permit of the free circulation of air between them, otherwise very considerable differences of temperature are observable.

From an examination of a number of hops stored on the two systems the writer gives the preference to that with quiescent air, though undoubtedly the other system also gives very good results.

It is interesting to inquire to what extent such cold storage does preserve. Statements have been made that all hops placed in cold store remain absolutely unchanged, even after the expiration of seven to ten years. Such a statement is not, however, accurate. Cold storage reduces, but it does not always entirely arrest change. For practical purposes, however, a cold stored hop, if of good quality, undergoes very little deterioration in the course of one or two years, and it is not necessary for commercial reasons to go much beyond this period.

The behaviour of hops when cold stored varies considerably. Some hops will, as above mentioned, remain practically unchanged, except for slight alteration in the oil, for a long period of time, but other hops undergo distinct deterioration despite cold storage; though, in every case, the deterioration is very much less than would occur under ordinary storage conditions. The results of the examination of a number of samples made by the writer with a view to gaining information upon this point, seem to point to the fact that hops placed in cold store containing a considerable amount of 
moisture undergo greater deterioration than those normal in this respect; but cases have occurred when hops which were extremely slack dried have nevertheless kept very well when cold stored, and hops actually damaged by water have when placed in cold store undergone no perceptible alteration. Of course a high proportion of moisture in a hop may be due either to the sample never having been properly dried, or it may be due to its having been cold bagged-that is, to its having absorbed an excessive quantity of moisture on the floor after leaving the kiln and prior to bagging. It is not possible at the present time to say which of these two conditions is most unfavourable to the preservative power of the hop, but the writer hopes to be in a position to publish some information on this point later.

That, given a good hop, cold storage is capable of deferring for a very long time any alteration of the resins and tannin is clearly shown by many practical observations. It may be of interest to give the figures obtained from the examination of samples of hops which have been cold stored for over six years. These were Kent Goldings of good quality. They were analysed when placed in cold store in 1895 . The bulk was used during the next year, but a pocket was kept for experimental purposes until Christmas I9or, when it was taken out and examined. The hops at the time of analysis maintained their bright colour almost unimpaired, but had to a considerable extent lost the bouquet which they originally possessed. The resins and tannin had, however, undergone very slight alteration, as is shown by the following figures :-

Hops when placed in cold store. I895.

Per cent.

Soft Resin*

Hard Resin

Total Resins

Tannin
I I. 45

$3 \cdot 34$

$14 \cdot 79$

$2 \cdot 79$
Hops taken out of cold store. rgor.

Per cent.

I I 20

3.40

$14 \cdot 60$

* The resins were in each case determined with the same quality of petroleum ether, a supply of which has been retained for the purpose, and the same apparatus was used and extractions conducted in duplicate. The tannin was determined by Loewenthal's method. 
The deterioration which takes place in the normal storage has been estimated by experienced judges at 25 to 33 per cent. This represents a very great monetary loss. Let us try to estimate what this avoidable loss means.

The approximate value of the English hop crop of 1902 may be stated at $£ \mathrm{I}, 900,000$. Assuming that one-third of these hops will be used before substantial deterioration has occurred, there remains two-thirds, representing a money value of $£^{\mathrm{I}, 260,000 \text {, which, with }}$ ordinary storage, will undergo deterioration, varying in degree according to the time at which they are used, but which we may average at $12 \frac{1}{2}$ per cent., representing the very considerable sum of $£^{158,000 .}$

Against this saving we must place the cost of cold storage. This has probably been very considerably overstated, for warehouse room, labour, \&c., have in many cases been included, ignoring the obvious fact that hops must be stored somewhere, and that although the hop merchant does in some cases charge for storage, yet actually the bulk of the hop crop is stored by the merchant without:any direct charge to the brewer. In such cases, however, as when storage is charged the ordinary rate may be taken at 2 d. per pocket per week from September to March I, and at Id. per pocket per week from March I to September I, which corresponds with a charge of $6 \mathrm{s.} 6 \mathrm{~d}$. per pocket per year, equivalent to about $4 \mathrm{~s}$. per $\mathrm{cwt}$.

The usual charge for cold storage is on one of two bases: (I) A charge of 6s. per cwt. for a period of one year, commencing January $\mathrm{I}$, or at the same rate for any part of the year ; (2) Eight shillings per cwt. for nine months, and Is. per cwt. per month afterwards.* We thus see that whilst ordinary storage costs $4 \mathrm{~s}$. per cwt., cold storage costs 6s., or in exceptional cases. 8s. The actual cost of cold as against ordinary storage may therefore be stated at $2 \mathrm{~s}$. to $2 \mathrm{~s}$. $6 \mathrm{~d}$. per cwt., and the extra cost of cold storage of two-thirds of the I 902 crop would amount to $£ 26$,ooo, whilst the saving in deterioration would amount to $£ 158$, oco, giving a net saving of $£_{132}$, o00.

* This charge is, of course, much higher than in No. $I$, but is the rate charged by the Dock Companies. 
The writer has made enquiries of the cost of the cold storage of hops in breweries, and if the cold store is on a scale of sufficient size it seems clear that the actual cost need not exceed 2s. $6 \mathrm{~d}$. a cwt., thus corresponding closely to the extra charge made by hop merchants.

But the advantage of cold storage is not merely a financial one, though the above figures will show how considerable is the advantage to be derived in that direction.

Under the old régime, new hops were unobtainable at one of the most critical periods of the year. During the late summer and early autumn, at a very trying period of brewing, the brewer was reduced to using hops which were practically yearlings. By cold storage he is able to employ hops possessing their maximum preservative power just at the period when he stands in most need of the assistance which these afford both in flavour and stability. Apart therefore from any economy, the fact that a brewer now has it in his power to use a new hop whenever he chooses, gives him an advantage of the greatest importance; whilst in view of the superior preservative value of a new hop, it is in many cases possible to reduce the actual quantity employed, or rather to avoid the increase in hopping which practice has in the past generally shown to be necessary toward the end of the summer.

But whilst we do well to avail ourselves of the retention of preservative power secured by cold storage, we must not overlook the fact that yearling hops possess special qualities of their own, and it is an undoubted fact that, particularly for certain classes of beer, the employment of a proportion of a yearling hop is desirable from the consideration of flavour. Indeed, there are some types of hops, such as many Californians, the flavour of which when new is too pronounced to be agreeable, and which, despite the deterioration they have suffered in resin value, are actually more useful to the brewer as yearlings than when new. Further than this, some amount of maturing is generally desirable before placing in cold store, and it is better to arrange for one or two months' storage at ordinary temperature prior to placing in cold store. The occurrence of hop-resin haze in beer has been attributed in some cases o hops which have been placed in cold store 
too early. In the writer's experience it is more often due to the use of unripe hops or to hops which have been badly dried.

It is necessary to refer again to the character of hops which are placed in cold store. All hops do not keep equally well under such conditions, and low class, badly managed, poor hops are often better used up at once in the copper rather than placed in store, for it is precisely these hops which do badly. Without doubt they will keep much better in cold store than out of it, but the policy of depending on such hops for summer use is very questionable.

The defrosting of hops was in the early days of cold storage regarded as a matter of very serious importance, and special precautions were in some cases taken to allow the hops to regain their normal temperature in a chamber containing perfectly dry air. Such a precaution has not, however, proved to be necessary. Indeed, hops have been taken direct from cold store and placed into copper within a few minutes without any apparent evil result, but it is no doubt a wise precaution to withdraw hops from store one, two, or-in the winter - three days before they are to be used. This period of time generally elapses where hops are despatched by the hop merchant to his customer by rail, but even those brewers who have their own hop stores are agreed in allowing a certain period of time to elapse between the withdrawal of the hops from the cold chamber and their use in brewing, though they no longer resort to any special means of defrosting.

When hops have been withdrawn from cold store they necessarily at once commence to deteriorate. The speed of this deterioration varies not only with the temperature and humidity of the place in which the hops are stored but with their original character. In practice there is no need to use hops older than a fortnight or three weeks out of store, and certainly during this time no very considerable deterioration takes place under any normal storage conditions. In the case of hopping down hops in a small brewery the position may be different, for a pocket of, say, fine Worcesters or of British Columbians used only for the hopping down of an I.P.A., might remain in the brewery a month or six weeks before it was used. This, of course, is unavoidable, but a brewer has 
the alternative of employing the later portion of the pocket as a copper hop should his brewing storage determine rapid deterioration, rejecting the sample for hopping down so soon as he detects any serious alteration in character.

When, early in 1896 , as the result of several years' experiments, the writer, in conjunction with another, first advocated the use of cold as the only preservative for hops, many doubts were expressed, not merely by brewers but by hop merchants of long experience, as to the practicability or even the efficacy of the system. The day has now long past since cold storage became a recognised system as applied to hops. Its success is established both as regards the quality of the article and commercial practicability, and the erection of large hop cold stores not only in London but in the provinces, and the fact that these cold stores are constantly increasing in number and are frequently taxed to their utmost capacity, dispels any shadow of doubt which may have once possessed the minds of brewers and merchants. Largely as cold storage is now adopted, it will be even more employed in the future, and the loss of many thousands of pounds which has for a long time past occurred each year will no longer be tolerated; but all hops of fair quality which are not immediately required by the brewer will certainly in the near future be retained in cold store until used. 


\section{THE ESSENTIAL OIL OF HOPS.}

By Alfred C. Chapman, F.I.C., F.C.S. $T_{\text {from ripe hop strobiles by mechanical means, constitutes, as is }}^{\text {HE yellow powder, or "lupulin," which is so readily separated }}$ well known, by far the most valuable part of the plant from the brewing point of view. The "rubbing-down" test is, in fact, a recognition of the truth of this, for the commercial value of a sample of hops is known to depend largely on the amount of lupulin or "condition" present, and this can be roughly judged by the degree of stickiness experienced when the strobiles are rubbed between the fingers. This yellow powder, if examined with a low magnifying power, will be found to consist of small capsules of definite structure, which are in reality superficial glands occurring on the external coating of the seeds, and at the bases of the bracts or " petals." This is present to very varying extents in different samples; in old hops it may be as low as 3 per cent., whilst in new and rich hops it may occur to the extent of 15 per cent. or even more. This " condition" or "hop flour," as it is sometimes called, contains the essential oil, resins, wax, bitters, and perhaps one or more alkaloids, but in this paper I propose to concern myself with the first-mentioned constituent alone. The essential oil, although boiling at temperatures much above the boiling point of water, is nevertheless readily volatile with steam, and can therefore be obtained from the hop strobiles (or from the separated lupulin itself) by boiling with water in a still, the essential oil passing over with the steam, and being condensed by suitable means. Owing to its very slight solubility in water, it is found floating on the surface of the distillate, and may be recovered either by mechanical separation or by 
extraction with a suitable solvent. In this way a yield of 0.2 to 0.5 per cent. is usually obtained. Of all the constituents of the hop cone probably none has been the subject of so many misstatements and of so much misconception as the volatile oil. Not only were the early statements in regard to its composition incorrect in nearly every respect, but the vôle it plays in the brewing process was for long entirely misunderstood.

The oil obtained by the above method is a colourless or pale yellow mobile liquid, possessing a fragrant and characteristic odour, and a slightly burning taste. It is almost insoluble in water (to which, however, it communicates its smell), and is only slightly soluble in dilute alcohol. It appears to have been first studied by PAYEN and Chevallier in I822, who obtained it by distilling the lupulinic grains with water.

In I853, WAGNER submitted the oil to examination, and stated that it contained "a terpene" and an oxygenated constituent "valerol." In I854, PERSONNE endeavoured to obtain information in regard to the nature of the constituents of this oil by fractionally distilling it, but without much success. In I883, Ossipow studied the oxidation products yielded when chromic acid is allowed to act on the oil and identified acetic and isovaleric acids.

All the above investigations were made by highly competent chemists, but it was in the nature of things impossible that much exact information should be gained by them owing to the fact that most of the compounds occurring in essential oils were then unknown, that great and important branch of organic chemistry which deals with the terpenes and their derivatives being of quite recent birth. The admirable and masterly contributions made to this department of chemical science by WALLACH and his colleagues induced me some years ago to undertake a study of the essential oil of hops in the light of this modern knowledge, and with the help of the more refined methods which are now at our disposal. In the course of this investigation, the completion of which has, owing to unforeseen circumstances and the pressure of other affairs, been considerably delayed, I have worked with seven different samples of oil, and it 
may be of interest to give briefly their histories and their physical constants :-

\begin{tabular}{|c|c|c|c|c|c|c|c|}
\hline & & & $\begin{array}{l}\text { Sp.Gr. } \\
5_{5} \% / 5^{\circ}\end{array}$ & & $\begin{array}{l}\text { Sp.Gr. } \\
20^{\circ} / 20^{\circ}\end{array}$ & & ${ }_{\mathrm{D}}^{[\mathrm{a}]^{2}} 20^{\circ}$ \\
\hline No. I & $\ldots$ & $\ldots$ & 0.8802 & & 0.8776 & ....... & $+0.41^{\circ}$ \\
\hline No. 2 & $\ldots$ & $\ldots$ & $0.86 \epsilon_{2}$ & & 0.8636 & ...... & $+0.58^{\circ}$ \\
\hline No. 3 & $\ldots$ & ... & 0.8771 & & 0.8739 & ...... & $+0.50^{\circ}$ \\
\hline No. 4 & $\ldots$ & $\ldots$ & 0.8743 & $\cdots \cdots$ & 0.8716 & ...... & 一 \\
\hline No. 5 & $\ldots$ & ... & 0.8676 & & 0.8645 & ...... & +0.3 \\
\hline No. 6 & $\ldots$ & $\ldots$ & 0.8639 & & $0.86 \mathrm{Io}$ & ...... & $-0.20^{\circ}$ \\
\hline No. 7 & ... & $\ldots$ & 0.8403 & $\ldots$ & 0.8357 & ....... & -0.08 \\
\hline
\end{tabular}

No. I sample I prepared myself by the steam distillation of about 80 kilograms of mixed hops, some grown in Burgundy, some in Alsace, and the remainder in Kent and Sussex.

No. 4 was also prepared by me and was obtained from mixed hops: of English and foreign growth.

The remaining five samples were distilled for me by Messrs. Schimmel \& Co., of Miltitz, near Leipzig-four from fine quality Bavarian hops of different years, and one from Californian hops grown in I899, which I had purchased in this country, and sent to the abovementioned firm for distillation. It will be seen, therefore, that the oils which have passed through my hands represented the produce of different countries and of different years, and that their genuineness. was in all cases entirely above suspicion.

These samples were then submitted to prolonged fractional distillation under greatly reduced pressure for the purpose of separating their constituents as completely as the differences in their boiling points would allow. Without going into details in regard to the methods employed (full particulars of which may be found in the Transactions and Proceedings of the Chemical Society), I may say that practically the same results were obtained in the case of all the samples of oil dealt with, and one account of the constituents will therefore suffice.

The Fraction of Lowest Boiling Point. - This was found to consist of a hydrocarbon having the formula $\mathrm{C}_{10} \mathrm{H}_{16}$. Although this is the 
general formula for the terpene hydrocarbons (of which ordinary American or French turpentine may be cited as typical examples) a closer examination of this substance showed that it was clearly not a terpene. It had a specific gravity of $0.8046^{\circ}$ at $15^{\circ} / 15^{\circ}$ and 0.8020 at $20^{\circ} / 20^{\circ}$. Its boiling point was $166^{\circ}-168^{\circ} \mathrm{C}$. under atmospheric pressure, and it exerted no action on the plane of a ray of polarised light. It was a colourless and very mobile liquid, having a penetrating but not unpleasant odour, somewhat suggesting yet quite distinct from that of the hop oil itself. A study of its chemical and physical characters showed it to be an unsaturated, open-chain hydrocarbon, and a careful comparison of its properties with those of myrcene, a hydrocarbon first obtained by POWER and KLEBER from bay oil, proved it to be identical with that substance. In all the samples of oil with which I worked myrcene was present to the extent of 40 to 50 per cent., although for the reason given below it will be seen that this is liable to considerable variation. It is well known that when hops are kept for a long time at ordinary temperatures, their aroma suffers marked deterioration, and their "stickiness" when rubbed between the fingers greatly diminishes. It is also known that when hop oil is stored in such a way (e.g., in an ordinary partially filled bottle) that air has access to it, the oil becomes more and more viscous and its solubility in alcohol diminishes. These phenomena, which are of considerable technical importance are due to the change of the myrcene present, for this compound possesses in a very marked degree the property of absorbing oxygen from the air, and of becoming quickly converted into a hard colourless resinous mass, polymerisation changes taking place at the same time. I shall allude a little later to the bearing of this fact on the brewing process.

The Second Fraction.--This was very small, and from 600 c.c. of oil (the largest quantity with which I worked at one time) only amounted to a few cubic centimetres. It was a colourless and very fragrant liquid, having a sp.gr. $=0.857$ I at $20^{\circ} / 20^{\circ}$, and a composition corresponding with the formula $\mathrm{C}_{10} \mathrm{H}_{18} \mathrm{O}$. It had a very slight lævorotatory action on the plane of a ray of polarised light, and evidently consisted of inactive linalool, an alcoholic body occurring in the oil of linaloes and in some other essential oils. The slight optical 
activity is probably due to the presence of a trace of some active substance.

The Third Fraction.-This consisted of a derivative of the above alcohol, namely, linalyl isononoate, and was a colourless liquid with a marked though less fragrant odour than that of the linalool itself.

The Fraction of Highest Boiling Point.-This fraction consisted of a nearly colourless liquid of much less mobility than any of the preceding, and boiling at $263^{\circ}-266^{\circ} \mathrm{C}$. under atmospheric pressure. Its sp. gr. $=0.900 \mathrm{I}$ at $\mathrm{I}^{\circ} / 15^{\circ}$ and its analysis and vapour density determinations showed it to have the formula $\mathrm{C}_{15} \mathrm{H}_{24}$. This sesquiterpene, for which I suggested the name humulene, is a well characterised substance, readily forming a number of crystalline derivatives, which have been described in a paper communicated to the Chemical Society, and published in the Transactions of that body. It occurred to the extent of about 40 per cent. in the majority of the samples of oil which I examined.

Humulene, when pure, has very little odour, and does not undergo much change when exposed to the air. It has, therefore, but little effect on those properties of the oil which are of chief technological importance, and may be regarded rather in the light of a diluent. The oil of hops, therefore, contains the following compounds :- Myrcene, humulene, linalool, linalyl-isononoate, probably traces of some ester of geraniol, and a small amount of a diterpene. In all the freshly distilled samples of oil with which I worked the hydrocarbons myrcene and humulene were present to the extent of 80 to 90 per cent.

It is well known that marked differences exist between the aroma of hops grown in different parts of the world, and that these are resident in the essential oils. No one, for example, relying on the sense of smell alone could mistake Californian for Bavarian hops, or the latter for the produce of Kent. It is interesting in this connection to note that these variations, readily recognised as they are by the nose, yet correspond with such slight differences in chemical composition that the methods available for the separation 
of the constituents are altogether insufficient for the purpose of detecting them. The Californian oil "No. 6" for example, yielded the same compounds as the Bavarian and English oils, and the differences in their odour must have been due, partly perhaps, to the different proportions in which the above constituents existed; but also, probably, to the presence of very small quantities of other fragrant substances, the separation of which in a state of purity was rendered impossible by the nearness of their boiling points, and by the great expense attending work with large quantities of the oil. We now come to the important question: What part does the essential oil play in brewing procedure? By the older authorities it was stated that the oil acted both as a flavouring and as a preservative agent, and that its rôle was consequently a most important one. With the latter point I propose to deal shortly, and will first discuss the question of flavour. As was pointed out at the commencement of the paper, the oil of hops is freely volatile with steam, and consequently little or none can remain in the wort at the end of the boiling period. The fragrant odour of the air for a considerable distance around a brewery when the wort is being boiled is sufficient proof of this escape of oil. On this point the following experiment may be of interest :-

Small quantities of oil were added to brewery wort which was boiled for periods varying from half an hour to two hours in large glass flasks. Extraction experiments made at the end of this period showed that even after half an hour 80 per cent. or more of the oil had volatilised with the steam, and that the great bulk of the remaining 20 per cent. had become converted into a sticky resinous mass. It may, therefore, be regarded as certain that little or no unchanged volatile oil can possibly remain in the copper at the end of boiling.

Even when a portion of the hops are added, as is often done about half an hour before turning out, it is practically certain that none of the volatile oil is left; and, it may be asked, to what, then, is the hop flavour due? It has already been pointed out that the oil readily oxidises and polymerises when exposed to the air, becoming viscous and resinous. This resin (which must not be 
confounded with the bitter, preservative resins) possesses in a marked degree the aroma of the oil itself, and is slightly soluble in the boiling wort, and not, of course, volatile with the steam. To this is chiefly due the hop flavour communicated to the wort during boiling, but some experiments which I have made render it not improbable that there are also present in the hop cones solid, nonvolatile substances which have their share in the communication of flavour. Of course, in the process of dry hopping, the oil plays a more obvious part, a little of it passing directly into solution in the beer. It may be added that the resinification of the oil is somewhat retarded, but not prevented, by cold storage, being much more dependent on the presence or absence of air. Formerly it was asserted that hops owed their preservative property to the essential oil, but this is now known to be largely, if not entirely, resident in the so-called "soft resins." A few years ago, in conjunction with Mr. H. E. Burgess, I made a number of experiments on this point, using malt wort, beef-extract solution and beer as nutrient media, and we found that neither the oil itself nor any of its separated constituents exerted any appreciable inhibitory action on the growth of any of those bacteria which are chiefly responsible for disease changes in beer.

The Oxidation of the Oil.-The well known "cheesy" odour which most hops develop on storage, has been almost invariably stated to be due to the production of valeric acid from the oil by oxidation. In 1883 , Ossipow investigated the action of certain chemical oxidising agents on the oil, and identified isovaleric acid among the acid products of the reactions; whilst WAGNER thirty years before had expressed his opinion that this acid was derived from one of the oxygenated constituents of the oil.

It may be at once said that valeric acid is never formed as a product of the aevial oxidation of hop oil, for the author has in his possession numerous samples of oil which have been exposed to the air for years, and whilst they have become more viscous, or in some cases completely resinised, no trace of valeric acid, judging from the smell, has been produced in any instance. As has been pointed out above, the oil contains linalyl isononoate, and possibly a little of 
some valeric ester, and it is far from improbable that these esters, under the conditions of ordinary hop storage (that is, exposed to the combined action of moisture and air), may undergo slight hydrolysis with liberation of traces of the two fatty acids, isovaleric and isononoic, which have very similar odours, resembling old cheese or rancid butter. Experiments made with the "soft resins" extracted from the hops by means of light petroleum showed that isovaleric acid in quantity was formed when these were submitted to the action of an alkaline solution of potassium permanganate or to other oxidising agents. Although there is no evidence that these resins can give rise to isovaleric acid under the ordinary condition of aerial oxidation, it is possible that they may, to some slight extent, contribute to the cheesy odour, and the same may be true of the bitter principle described by BUNGENER.

Numerous experiments were made, in which the oil was submitted to the action of such chemical oxidising agents as chromic acid, potassium permanganate and nitric acid, the oxidation products being separated, purified and identified. In this way acetic, valeric, unsymmetrical dimethyl succinic, succinic and isononoic acids were obtained when chromic acid was employed, whilst with potassium permanganate all the above oxidation products were yielded except dimethyl succinic acid, and oxalic acid was found in considerable quantity when dilute nitric acid was used.

From the experiments of which a brief outline has been given in this paper it will be seen that the essential oil of hops plays a less important part in the brewing process than was supposed by earlier investigators and authors. It must not, however, be thought that for this reason the character of the essential oil, as indicated by the aroma of the hops, is a point which the brewer may neglect, since the non-volatile flavouring resin, to which reference has been made above, develops to a very considerable extent the peculiarities of odour exhibited by the fresh oil itself. There is very little doubt that any unpleasantness in the oil will be communicated to the resin, and so in turn to the beer. It is, moreover, one of the surest guides to the general value of a sample of hops, where reliance is placed solely upon a physical examination. The short biblio- 
graphical table which follows contains references to the more important papers dealing with the chemistry of this essential oil.

\section{BibLIOGRAPHY.}

Payen \& Chevallier (1822), J. Pharm. 8, 214 and 533.

R. Wagner, J.pr. Chem., 58, 35I ; Dingl. pol. J., I28, 217 ; abstr. Chem. Centrbl., I853, 249.

Personne, Compt. vend., 38, 309; N. J. Pharm., 26, 24I and 329; 27, 22, Instit. 1854, 65; Chem. Centrbl., 1854, 228.

Chapman, Jown. Chem. Soc. Proc., 1893, 9, I77.

Chapman, Joum. Chem. Soc. Trans., I895, 67, 54 .

Chapman, Joum. Chem. Soc. Trans., I895, 67, 780.

Chapman \& Burgess, Brewers' Journal, 1896, 238.

Chapman, Journ. Fed. Inst. Brew., IV., No. 3, 224.

Chapman, Journ. Chem. Soc. Trans., I903, 83, 505. 


\title{
THE BITTER SUBSTANCES AND RESINS OF HOPS.
}

\section{A SHORT HISTORICAL REVIEW OF THE MOST} IMPORTANT PROPERTIES OF THESE BODIES.

\author{
By Dr. Georg Barth
}

(Consulting Chemist at the Wissenschaftliche Station für Brauerei at Munich).

$T \begin{gathered}\mathrm{HE} \text { great importance which hops enjoy in the brewing industry, } \\ \text { as well as from an agricultural standpoint, has induced investi- }\end{gathered}$ gators to undertake the examination of the chemical constituents of hops. The great variety of substances present in the hop flower, coupled with the ill.defined chemical character of some of them, have resulted in a whole series of communications ever containing fresh facts concerning the chemistry of the hop components ; but, unfortunately, this material is marred by many inconsistencies. If our knowledge in this domain were as extensive as its literature, the constituents of hops ought to be among those bodies best known to organic chemistry. Within recent years an extensive work on hops, by BRAUngarT, ${ }^{1}$ has appeared; but the subject matter is by no means well arranged. It is intended, therefore, in the following to consider briefly all past investigations relating to the bitter substance of the hop :-

Ives ${ }^{2}$ was the first to indicate that lupulin contains a bitter substance, soluble in water and alcohol. 
Pelletan, ${ }^{1}$ Payen, and Chevalier prepared this substance by treating an aqueous hop extract with lime and alcohol, evaporating the alcohol, extracting the residue with water, again evaporating and extracting with ether. The aqueous solution of this bitter substance (a yellowish white body, rather more soluble in warm than in cold water) exhibited neutral reaction, and was not decomposed by acids or alkalies.

In Doebereiners' 2 German Apothecaries' Manual a similar process for obtaining the bitter substance from an aqueous extract is described. The body is stated to be soluble in five parts of boiling water, more soluble in alcohol, and almost insoluble in ether. Further, that it is destroyed on heating, without formation of ammoniacal products.

PERSONNE ${ }^{8}$ claimed to have discovered a bitter substance of alkaloidal nature (precipitated by tannic acid, iodine in potassium iodide, \&c.), but was unable to effect its isolation in a pure state.

J. C. Leuchs ${ }^{4}$ made various experiments concerning the debittering of hop extracts, by treating aqueous solutions of the same, with freshly ignited wood charcoal, almond water, and almond paste. An extract of hops in boiling water was completely debittered on addition of acetic acid, or tartaric acid, lemon juice, sulphurous acid, aldehyde, or formic acid, and the same result obtained on prolonged exposure of the extract to air at $10^{\circ}-15^{\circ} \mathrm{R}$. $\left(54^{\circ} 5^{\circ}-65^{\circ} 75^{\circ} \mathrm{F}\right.$.).

VLAANDEREN ${ }^{5}$ attempted to obtain the resin by extracting lupulin with spirit. To this end, he repeatedly precipitated the alcoholic extract with water, redissolved the separated resin in alcohol, and again precipitated with water, thinking by this means to get rid also of the hop oil. The resin finally obtained was dark

1 Journal de Pharmacie, Tome 8, 209.

2 Deutsches A pothekerbuch, III, I847, 636 .

3 Comptes Rendus, 1854, 309.

4 Journal für Praktische Chemie, I867, 101, r37.

5 Scheikundige Verhandelungen en Onderzockingen, van G. T. Mulder, Deil II, Bladz 87, I858; abstracted in Jahresbericht für Chemie, I858, 448. 
brown, tasteless, almost free from ash, soluble in alcohol and in ether, and had the composition represented by the formula $\mathrm{C}_{54} \mathrm{H}_{35} \mathrm{O}_{11}+\mathrm{I}$ to $6 \mathrm{HO}(\mathrm{C}=6)$; i.e., $\mathrm{C}_{54} \mathrm{H}_{70} \mathrm{O}_{11}+\mathrm{I}$ to 6 $\mathrm{H}_{2} \mathrm{O}$, the quantity of water increasing according to the number of precipitations with water. From this resin various copper compounds were prepared: $\mathrm{C}_{54} \mathrm{H}_{35} \mathrm{O}_{11} \mathrm{CuO} ; \mathrm{C}_{54} \mathrm{H}_{35} \mathrm{O}_{11} \mathrm{CuO}$ and $\mathrm{C}_{54} \mathrm{H}_{38} \mathrm{O}_{14} \mathrm{CuO}$.

For the isolation of hop bitter, LERMER ${ }^{1}$ proceeded in quite a different fashion.

He extracted fresh hops with ether, treated the ether residue with 90 per cent. alcohol, in order to separate "Myricin" (wax), the latter remaining undissolved, and after removal of the alcohol, again dissolved the residue in ether. The ethereal solution was then repeatedly shaken with strong potash lye, whereby the bulk of the non-crystallisable resinous bodies was removed, passing into the aqueous layer. The ethereal solution, which exhibited strong alkaline reaction owing to the presence of potash, was repeatedly shaken up with water, when the hop bitter passed into the aqueous layer. From this the bitter substance was isolated by addition of copper sulphate solution, which produced a blueish precipitate, consisting of microscopically small needles, which could be washed with small quantities of ether. In larger quantities of ether the precipitate was completely soluble, a proof that it contained no cupric hydrate.

From this copper compound of the hop-bitter principle (it loses its fine blue colour rapidly when dried), LERMER separated the bitter substance itself by decomposition with hydrogen sulphide in ethereal solution. The ethereal solution so obtained, when evaporated in a current of carbon dioxide, leaves a brownish, syrupy residue, in which after 12-24 hours ray-shaped crystals begin to appear, and continually augment until the whole solidifies to a crystalline mass. The crystals are, however, still contaminated with more or less brownish resin, the separation of which presents great difficulties. There is only one solvent, nitro-benzene, which 
serves to dissolve the adherent brown syrup without attacking the crystals, and by its means LERMER finally obtained shining white crystals, which, however, in 12 hours exhibited some alteration, and gradually changed into a resinous, amorphous, yellow mass. In the pure state Lermer's "hop-bitter acid" is stated to be remarkable for its ready crystallisability.

According to LERMER the substance forms brilliant, rhombic, glass-like prisms, which are extremely brittle, and so insoluble in water that no bitter flavour can be detected when the crystals are placed whole, or crushed, on the tongue. A diluted alcoholic solution, however, exhibits a distinct bitter flavour. The crystals are very readily soluble in alcohol, ether, chloroform, carbon disulphide, benzene, turpentine, and similar solvents.

From the elementary composition of the copper compound Lermer endeavoured to deduce its empirical formula.

The analytical data for the copper salt point to the formula $\mathrm{CuO} \cdot \mathrm{C}_{32} \mathrm{H}_{35} \mathrm{O}_{7}(\mathrm{C}=6)$, and according to Lermer indicate a certain relationship with other bitter substances, such as Absynthiin and Jalapinolic acid. In addition, LeRmer refers to several other bodies obtained by him from hops, one of which forms felted, silky needles, melting at over $110^{\circ} \mathrm{C}$.

In his researches concerning hop-tannic acid, $\operatorname{ETrI}^{1}$, in conclusion, refers to hop bitter, which he prepares in the following manner :-

Hops are extracted with ether which dissolves ethereal oil, chlorophyll, a crystalline white, and an amorphous brown resin The white resin remains behind when the ether residue is taken up with alcohol. (This is Lermer's Myricin-a wax.)

The resin present in the alcoholic solution is separated from the bitter principle by addition of water, and settles out on standing (the turbid liquid passes through a filter) leaving the bitter in

${ }_{1}^{1}$ Dingler's Polyt. Journal, 1878, 228, 354; also Zeitschrift f. d. ges. Branwesen' 1878, 293 . 
solution. The latter, when evaporated in vacuo over strong sulphuric acid, deposits well-formed, colourless crystals; but if concentrated on the water bath yields an extract, and very few crystals.

The crystals, as also the syrup obtained on the water bath, possess a strong, bitter flavour, and are soluble in water, especially on warming to a bright solution. ETTI states that the precipitated resin, if repeatedly redissolved in water and reprecipitated, may be resolved completely into bitter substance and resin, the latter retaining no bitter flavour whatever.

In addition, EтTI distinguishes between the amorphous brown resin, and the bitter substance proper, regarding them as distinct substances.

ISSLEIB ${ }^{1}$ repeated these experiments as to the precipitation of the resin from alcoholic solution by water, but arrived at different results. He was the first to draw attention to the discordant nature of the statements, to be found in the literature of the subject, relating to the properties of hop bitter. He made use of the property of bone charcoal of absorbing certain bitter principles, for preparing hop bitter from aqueous decoctions of hops or of lupulin; and he describes the bitter substance and some of its reactions. He ascribes to this hop bitter the formula $\mathrm{C}_{29} \mathrm{H}_{46} \mathrm{O}_{10}$, based on the elementary composition, and particularly on the products of hydrolysis by dilute sulphuric acid-lupulieretin $\mathrm{C}_{10} \mathrm{H}_{18} \mathrm{O}_{4}$ and lupulinic acid $\mathrm{C}_{48} \mathrm{H}_{82} \mathrm{O}_{19}$.

IssLerb also gives the analysis of a barium salt of lupulinic acid, and of some other resinous compounds.

OTT, ${ }^{2}$ in general, confirms LERMER's findings concerning his hop-bitter acid, but detects some difference in the reactions of the ether soluble copper salt, which he finds readily decomposable by hydrogen sulphide, whilst LERMER affirms it to be stable.

Bungener's ${ }^{8}$ researches on hop-bitter acid marked a distinct

1 Archiv der Pharmacie, 1880, 216, 345-363.

2 Zeitschrift f. d. ges. Brauwesen, 1880, 201.

8 Bulletin de la Société Chimique de Paris, r886, 45, 487-496; also Zeitschrift . d. ges. Brauwesen, I884, 93. 
advance in the study of the components of hops. He obtained, by extraction of lupulin with light petroleum, a highly crystalline substance, very soluble in most organic solvents, but absolutely insoluble in water. Its alcoholic solution tasted intensely bitter. It melted at 92-93 ${ }^{\circ} \mathrm{C}$, and he assigned to it the formula $\mathrm{C}_{25} \mathrm{H}_{35} \mathrm{O}_{4}$. (This ought to be doubled, because of the uneven number of $\mathrm{H}$ atoms.) According to Bungener, the substance has the character of an aldehyde and of a weak acid; and he regards as not improbable the view that it is a condensation product of five groups of the amyl series, because, on oxidation, the substance yields valerianic acid. This last point was, however, not proved experimentally.

GRESHOFF $^{1}$ repeated Bungener's work, but was unable to obtain a crystallisable body from lupulin by extraction with petroleum-ether. Working on the assumption that hop bitter is an alkaloidal substance, he applied various methods (Stas-Otto, Dragendorff, \&c.) utilised in the isolation of alkaloids, but did not succeed in obtaining a crystalline bitter substance.

HAYDUCK $^{2}$ extracted hops with ether, and isolated three readily distinguishable resins, two of them bitter, the third tasteless. The former he designated $\alpha$ - and $\beta$-, the latter as $\gamma$-resin. Under suitable conditions microscopic crystals separate from the $\alpha$-and $\beta$-resins, being evidently related to them in the sense, as HAYDUCK supposes, that the resins are derived from the crystalline substances, the latter being the oft-found bitter substances of acid character. The tasteless $\gamma$-resin is possibly derived from the hop oil. The crystalline bodies from HAyDUCK's resins are described as $\alpha$ - and $\beta$-hop-bitter acids respectively.

Lintner and A. Bungener ${ }^{3}$ subsequently prepared the $\alpha$-resin by HAYDUCK's method, and isolated therefrom, by repeated precipitation and decomposition of the lead compound, the crystallisable $\alpha$-acid. In alcholic solution it was found to possess a strong, bitter flavour and acid reaction. The acid differs in composition and

1 Inaug. Dissert, Jena, I887, 36.

${ }^{2}$ Wochenschrift für Brauevei I888, 937 et seq .

${ }^{3}$ Zeitschrift f. d. ges. Brauwesen, I89r, 357. 
solubility from the bitter substance obtained by H. Bungener, the difference being particularly marked in the form of the crystals. The $\alpha$-acid crystallises in small rhomboids, whereas the $\beta$-acid $(\mathrm{H}$. BUNGENER's) forms long, massive prisms, or fine, felted needles.

SEYFFERT ${ }^{1}$ who also investigated the hop resins later on, slightly modified HAYDUCK's method, and gave some details concerning the ether-copper reaction of the $a$-acid, which he was able to obtain quite pure by means of ice-cold petroleum. He proposes the same solvent for the $\beta$-acid (crystals from the $\beta$-resin).

In addition, Seyffert refers to a crystalline body, which he obtained from the $\gamma$-resin, but gives no details as to its properties.

In continuation of these researches, and in collaboration with V. ANTROPOFF ${ }^{2}$, he proposed an improved method for the preparation of the $\beta$-hop-bitter acid, particular stress being laid on the exclusion of air (working in a current of carbon dioxide) and the avoidance of high temperatures.

The different preparations obtained by the above, as also by Bungener's method, all exhibited very ill-defined melting points, varying distinctly from that $\left(92-93^{\circ}\right.$ C.) founded by Bungener. Apart from this, the variations in the carbon and hydrogen percentages, indicated that impure substances were being dealt with. According to these investigators LERMER's bitter-acid is not identical with the $a$-acid, but the body described by them as the $a$-acid, although possessing faintly acid properties, to all appearances belongs to a very different class of substances. According to them the hop resins are a mixture of bodies undergoing continuous and increasing decomposition.

If we stop now to consider the results of the preceding investigations, several inconsistencies become apparent. The chemical nature of the bitter substances remains quite undecided, and not even the elementary composition and molecular weights of the bitter acids are known with any degree of precision. Only so much is certain, that

1 Zeitschrift f. d. ges. Brawwesen, 1892, Nos. 4, 5 and 6.

${ }^{2}$ Zeitschrift f. d. ges. Brauwesen, r8g6, Nos. I and 2. 
there are two crystallisable bitter substances of slightly acid character; further that hops contain at least three resins, of which two are bitter and one is tasteless. It is highly probable that the bitter resins are closely related to the crystallisable bitter acids, which, therefore, for the present, may be distinguished as the $\alpha$ - and $\beta$-acids. H. BungeneR's acid is the $\beta$ compound, and, in view of the thorough nature of his researches, the empirical formula assigned by him to the acid is in all probability correct. The $\alpha$ - and $\beta$-acids are undoubtedly dissimilar in composition.

This conclusion may be deduced from the work of LiNTNER and A. Bungener, also from that of H. Bungener, Seyffert, and ANTROPOFF.

Further, it appears fairly certain that LERMER's acid must be identical with the $\beta$-acid described by H. Bungener and Seyffert.

LINTNER, ${ }^{1}$ together with the author, instituted further researches on hop-bitter, operating on lupulin, and directed particularly towards the study of the $\alpha$-and $\beta$-acids. The method for preparing the $\beta$-acid was worked out so far, that it is now possible to obtain larger quantities of this body with relatively little trouble. Methyl alcohol was found to be a most useful solvent, and by its aid crystals up to I $\mathrm{cm}$. in length were obtained. The formula of lupulinic acid was found to be $\mathrm{C}_{25} \mathrm{H}_{36} \mathrm{O}_{4}$, and Bungener's formula $\mathrm{C}_{50} \mathrm{H}_{70} \mathrm{O}_{8}$ is, therefore, incorrect. Lupulinic acid, on exposure to air, develops an odour resembling that of fatty acids, and is converted into a yellow resin. That oxygen from the air plays a part in this change appears from the following experiments :-

Lupulinic acid was enclosed in small glass tubes, one of which was filled with hydrogen and sealed, the other left open at both ends. The tubes were then exposed to light, near a window, for several months. At the end of this time, the acid in the open tube had become quite yellow and "cheesy," whilst that in the sealed tube remained perfectly white. In another similar experiment, the tubes were preserved in a closed box. The result was the same, showing that light is not an essential factor in the change. The acid was 
found to keep particularly well at low temperatures; for which reason the cold storage of hops is also to be highly recommended. Lupulinic acid, when boiled with water, yields a bitter solution only when air is bubbled through the liquid during the boiling; evidently because, by slight oxidation, a water soluble bitter resin is formed. The acid does not, however, suffer any chemical change, but is polymerised in the resinification process. The resinous products obtained by VlaAnderen are, doubtless, identical with the author's $\beta$-resin. Whether the "hard" and "soft" resins described by BRIANT and MEACHAM ${ }^{1}$, belong to this class of resins, could not be decided; since it is questionable whether the products named are chemical entities, or mixtures of various resins with Chapman's hop oil. On oxidation lupulinic acid yielded valerianic acid; but by reduction no definite product could be obtained. As regards the salts of lupulinic acid, it was found impossible to prepare a copper salt of constant composition; although preparations were obtained agreeing very well in copper percentages with the copper resin compounds first described by VLAANDEREN-another proof that his resin was the $\beta$ variety. The experiments relating to the benzoylation of the acid, its behaviour towards acids and silver nitrate solution, and the action of alkaline iodine solution, being of purely chemical interest, may here be omitted. The action of sulphurous acid on lupulinic acid might be of greater interest, as having, possibly a bearing on the "sulphuring " of hops. It was found that sulphurous acid in all its forms is fixed by lupulinic acid. The combination is, however, of so unstable a nature that it is decomposed by water, recrystallisation from methyl alcohol, \&c., and for this reason the study of the compound would present great difficulties. It was hoped to obtain some idea of the constitution of the bitter acid by acting on the substance with bromine and iodine; the main result being to show the existence of double carbon linkings and of one methoxyl group. On prolonged boiling of lupulinic acid with potash-lye, the solution, when acidified, yielded fatty acids closely related to valerianic acid. The most useful indication of the nature of the hop-bitter acid was furnished on fusing it with potash, the results showing that lupulinic acid must be closely related to hop

1 Transactions of the Institute of Brewing, I893, I49; I894, II7. Journal of the Federated Institutes of Brewing, I896, 408. 
oil. Products were obtained identical with those prepared from hop oil by GreshofF ${ }^{1}$ and WAGNER ${ }^{2}$ and PERSONNE${ }^{8}$.

Further researches of the author's were made concerning the $a$-acid. This acid, although it yields a well-characterised lead salt, can be obtained quite pure only with great difficulty; consequently the results may be somewhat unreliable. The analytical data were confirmed by M. BAMBERGER and LANDSIEDL 4 , but these authors propose for the $a$-acid the formula $\mathrm{C}_{20} \mathrm{H}_{28} \mathrm{O}_{5}$ or $\mathrm{C}_{20} \mathrm{H}_{30} \mathrm{O}_{5}$, basing it on a determination of the molecular weight made with purer material. The action of melting potash on the $a$-resin indicated a relationship between that resin and hop oil, as also the $\beta$-acid. Like the latter, the $a$-acid is an unsaturated compound. When treated with potash-lye and sulphuric acid, the $a$-acid furnishes a body of acid character-the nat ure of this substance could not be determined owing to lack of sufficient material. Although the $a$-acid closely resembles the $\beta$-acid in many of its chemical properties, and apparently belongs to the same class of substances, it is distinguished by physical differences (melting point, solubility, crystalline form); by its elementary composition; and by the fact that it gives a crystalline decomposition product when acted upon by potash solution and sulphuric acid.

T. SchnelL ${ }^{5}$ has recently studied the $a$-acid, and his results furnish additional information as to its constitution. Two decomposition products are formed by the action of soda solution-an unsaturated oxyketonic acid $\left(\mathrm{C}_{15} \mathrm{H}_{24} \mathrm{O}_{4}\right)$ and valeric acid, which latter is also produced on the oxidation of the substance. The oxyketonic acid is not identical with the product obtained by the author in the same way, nor with that produced by IssLeis by the action of sulphuric acid.

From the decomposition products of the $a$-acid ScHNeLL ascribes to it the formula $\mathrm{C}_{20} \mathrm{H}_{32} \mathrm{O}_{5}$, which differs only by two hydrogen

1 Inangural Dissertation, Jena, I887.

2 Erdmann's Journal für Praktische Chenie, 58, 35 r.

8 Comptes Rendus, I854, 309.

4 Zeitschrift f. d. ges. Brauwesen, 1902, 46r.

5 Inaug. Diss. Tech. Hochs. Munich I904. Zeits. f. d. ges. Brauw, 1904, 666. 
atoms from that hitherto accepted; whilst, from its chemical nature, he is of opinion that it contains a lactone group and belongs to the class of pseudo-acids. These lactones, in aqueous or alcoholic solution, can be titrated by alkalies, exactly as can the acids, except that the reaction is slower. This peculiarity of the $a$-acid would account for the author having obtained equivalent weights of 345 and 337 by titration with $\frac{\mathrm{N}}{\mathrm{IO}}$ alcoholic potash, agreeing well with the theoretical value of 352 . The fact that this titration is possible proves that in neutralisation there is no further breaking down of the molecule but only a "rearrangement"; otherwise values varying largely from the theoretical would have been obtained.

Therefore, according to Schnell the $\alpha$-acid is most probably a lactone functioning as a pseudo-acid, and the name " $\alpha$-acid " might be replaced by "Humulone," and, correspondingly, the unsaturated oxyketonic acid formed on splitting up this "humulone" should be described as " humulinic acid."

Following upon these preliminary remarks concerning the general chemical properties of the bitter resin and the crystalline bitter principles present in hops, it remains to consider the distribution of these bodies in the hop-flour, and their bearing in practical brewing.

Lupulin must be regarded as the actual source of the bitter principles of hops.

Lupulin, or hop-flour, consists of small organised granules or lupulin grains. They form a part of the gland formation of the hop cone, and HolzNeR ${ }^{1}$ distinguishes-

I. Isolated glands.

2. Head glands.

3. Glandular scales.

The last form hop-flour or lupulin granules.

Under the microscope they appear like multicellular, shieldshaped scales, with conical or cup-shaped indentations, and 
resembling two cones placed base to base. During development of the gland, a secretion collects in the indented portions, and the upper cuticle breaks away and forms the tender, yellowish hood, forming the upper cone. By the increase of the secretion, the gland, as a rule, is burst open at the surface of contact of the two cones. The glandular scales easily break off the stalk by which they are attached to their bases; and so it comes about that in the preparation of hops for the market a part of the lupulin falls out. By lupulin, however, is also understood the secretory contents of the gland.

The name has also been applied to an unknown alkaloid recurring in hops. ${ }^{1}$

The contents of the lupulin granules do not consist of a single, definite, chemical compound, but are composed of a mixture of different bodies, the bitter substances predominating. The last it is proposed to consider at length.

Since very little is known concerning the chemical composition of lupulin, it may be of interest to give here the analysis of the raw material (commercial) employed by the author in his researches.

The lupulin was completely exhausted with ether, and the ether extract and the insoluble cellular residue separately examined.

Ioo g. lupulin (I8.27 per cent. total ash) yielded on the average :$63.93 \mathrm{~g}$. ether soluble extract. $36 \cdot 07 \mathrm{~g}$. lupulin cell walls.

The ether soluble extract comprised the following constituents:-

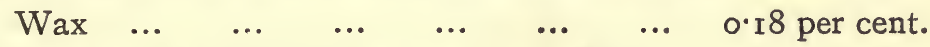
$a$-resin (by precipitation with lead salt-

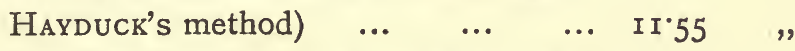
$\beta$-resin (by titration, the $\alpha$-resin being $\begin{array}{lllllll}\text { deducted) } . . . & \ldots & \ldots & \ldots & \ldots & 43 \cdot 3 \text { I } & \text {, }\end{array}$ $\begin{array}{lllllll}\text { Ether soluble ash }^{2} & \ldots & \ldots & \ldots & \ldots & \text { 0.17 } & \text {, }\end{array}$ Other constituents (fat, oil, $\gamma$-resin, \&c.) $\ldots \quad 8.72 \quad$,

1 Griessmayer. Dinglers' Polyt. Journal, 1874, 67; Zeitschrift für Analyt. Chemie, I880, ro5.

2 Mineral substances contained in the ether extract. 
The residue, insoluble in ether, comprised :-

Ash, insoluble in hydrochloric acid Ash, soluble in hydrochloric acid ... Albumenoids $(\mathrm{N} \times 6.25) \quad \ldots \quad \ldots$ Pentosans (Tollen's method) … Nitrogen-free extract substance, crude fibre, tannin and loss $\ldots \quad \ldots \quad \ldots \quad \ldots \quad 10.89 \quad$,

Extracts obtained by ether or petroleum-ether were always found to be free from nitrogen.

The proportion of sand present in lupulin is very variable and ranged in the samples examined from $10^{\circ} 9 \mathrm{I}$ to $20^{\circ} 24$ per cent. $\left(\mathrm{SiO}_{2}\right)$.

Older analyses similarly show that the composition of commercial lupulin is very variable.

For instance, Ives ${ }^{2}$ gives :-

Tannin, 5; extractive bodies, Io ; bitter substance, II ; wax, I2 ; resin, 36 ; fibre (lignin) 46 , in 120 parts.

Payen, $^{8}$ Pelletan ${ }^{8}$ and Chevalier ${ }^{8}$ find ethereal oil, 2 ; bitter substance, $10^{\circ} 3$; resin, 55 ; fibre, 32 , in Ioo parts.

AUBRY' gives :-

$\begin{array}{lrrrrr}\text { Ethereal extract } \quad \ldots & \ldots & \ldots & \ldots & 82.5 \\ \text { Extracted by ammonia } & \ldots & \ldots & \ldots & 7 \cdot 5 \\ \text { Lupulin cellular substance } & \ldots & \ldots & \ldots & 6.0 \\ \text { Ash, silica } \quad \ldots & \ldots & \ldots & \ldots & \ldots & 4 \cdot 0\end{array}$

Other analyses, to be found in the literature of the subject, are quite worthless.

Wimmer, ${ }^{4}$ for example, gives an analysis in which the constituents add up to III'I5 per cent., obviously based on some error.

\footnotetext{
1 Zeitschrift f. d. ges. Brauwesen, I898, 4I 3 .

2 American Journal of Science of Silliman II, 1820, 302.

${ }^{8}$ Journal de Pharmacie, 8, 209.

1 Lintner: Lehrbuch der Bierbrauevei, Braunschweig, 1878, 96 and 98.
} 
The great differences between the individual analyses may, no doubt, be ascribed to actual variations in the material examined. Lupulin, obtained by carefully brushing out the hop cones, contains far less ash than the rough lupulin collected as by-product during the preparation and handling of hops.

As regards the sub-division of the resins and decomposition products of the crystalline bitter principles into "hard" and " soft" resin, numerous observations have been communicated by BRIANT and Meacham, ${ }^{1}$ who examined hops of diverse origins. RemY investigated the same subject, and for separating the hard and soft resins proceeded as under :-

"Twenty-five grms. of hops were completely extracted with ether, and the ether residue treated with 90 per cent. alcohol to separate the wax. The alcohol soluble portion after evaporation to dryness, was again dissolved in ether, the solution repeatedly shaken out with dilute sulphuric acid ( 0.5 per cent.) in order to remove certain basic substances, evaporated, and the ether residue finally divided into hard and soft resins by treatment with petroleum ether (b.p. up to $60^{\circ}$ C.)."

Briant and Meacham's ${ }^{1}$ process is a good deal simpler than the preceding.

"Five grms. of hops are placed in a Soxhlet extracter, and completely exhausted with petroleum ether. The ether residue is freed from wax in the way already described, the alcohol evaporated, heated for six hours to $90^{\circ} \mathrm{C}$, and weighed as "soft " resin. The hard resin is then determined by exhausting the hops a second time with ordinary ether."

The analytical error in these methods is, as a rule, as much as I per cent. Nevertheless, the results serve to show that the better kind of hops, as a general rule, exhibit a higher proportion of soft resin, and a correspondingly higher percentage of total resins. According to REMY, the hops of the 1896 harvest were characterised by notably 
low content of soft resin. Certain experiments made by Remy as to the influence of kiln drying on hops, showed that a considerable proportion of the soft resin present in the fresh hops is converted into hard resin during drying in the air.

In the course of investigations made by LINTNER and the author, and relating to the bitter principles of hops, an attempt was made to estimate the $\beta$-bitter acid by titration of a hop extract. Since the resins are themselves acid in character, it might be possible by this method to find the total quantity of resin present.

LINTNER ${ }^{1}$ gives the following details:- Io grms. of hops are placed in a $\frac{1}{2}$-litre flask, graduated at 505 c.c. ( 5 c.c. is the volume of the hops), and extracted for eight hours with 300 c.c. of petroleum ether (b.p. $30-50^{\circ}$ C.) under an inverted condenser. The time of extraction-eight hours-was fixed upon as necessary from the result of special experiments, although the bulk of the resin is extracted in two hours. The flask is then filled up to the 505 c.c. mark with petroleum ether at $175^{\circ} \mathrm{C}$., and the liquid filtered as rapidly as possible so as to prevent solution of the $a$-resin. Ioo c.c. of the extract are titrated with $\frac{\mathrm{N}}{\mathrm{IO}}$ potassium hydrate. As the alcoholic potash does not mix with the petroleum ether, 8 o c.c. of strong alcohol must be added before titration, together with Io drops of phenolpthalein solution ( $\mathrm{I}$ in IOO) as indicator. A blank experiment must be made to determine the acid in the ether and alcohol, and a correction applied. Since one molecule of alkali neutralises one molecule of lupulinic acid (molecular weight 400), the volume of alkali consumed multiplied by $0 \cdot 4$ equals the weight of acid present.

Dr. Heim ${ }^{2}$ examined 5 different hops by LintneR's method, the samples being supplied by the firm of F. J. Barth \& Weigmann, in Lauf. With most varieties the results ranged within comparatively narrow limits, 14.6 per cent. and 12.7 per cent.; only one variety, the Auschaer hops, yielding notably lower figures, 9.80-7.04 per cent. On comparing these figures with the percentage of soft 
resin, which REMY ${ }^{1}$ determined in individual cases, a quite satisfactory agreement was observed.

In view of its simplicity of execution, LINTNER's method undoubtedly presents some advantages over the usual processes for determining resins.

The method received an interesting practical application at the hands of Remy, ${ }^{2}$ who endeavoured to judge the bittering and aromatic value of hops by chemical means. REMy determined not only the total quantity of bitter acids, but also the proportions of $\alpha$ and $\beta$-acid, by precipitation with lead acetate; and, as a matter of fact, a certain connection was traced between the relative proportions of the acids on the one hand, and the applicability of the hops on the other. The results, although undoubtedly requiring further investigation and confirmation, show that those hops, which in brewery practice are employed on account of their greater bittering power, uniformly contain a relatively large proportion of the $a$-acid; whereas with hops that are more particularly valued for mild beers, the $\beta$-acid predominates. Opinions, however, as to the value of hops, from the point of view of bittering power diverge so widely, that it would be rash to consider high content in $a$-acid either a good or bad indication. For most purposes a hop showing a high percentage of total bitter and a moderate proportion of the $a$-acid would probably be preferred. In Remy's experiments the total bitter acid ranged from II 0 to I8. 5 per cent., the $a$-acid from 3.5 to 6.6 per cent., and the $\beta$-acid from $7 \cdot 5$ to $12 \cdot 3$ per cent.

As has been already pointed out, the hop-resins are extraordinarily subject to changes which detract from the value of the hops; and it will be the endeavour of every brewer to prevent as much as possible these alterations, which, according to BRIANT and MEACHAM ${ }^{8}$ consist in a conversion of soft into hard resin. For this reason the cold storage of hops, which is strongly recommended by many scientists and practical men, is a step in the right direction.

1 Wochenschrift für Brauerei, $1897,513$.

2 Wochenschrift für Brauevei, I902, 6r4.

${ }^{8}$ Journal of the Federated Institutes of Brewing, 1897, 48r. 
For the benefit of those who do not care to erect a special store, it may be mentioned that the temperature of an ice cellar is quite low enough to preserve hops for some time, and to prevent changes in the resins.

This brings us to a portion of our subject, closely related to the employment of hops in the brewery; and it may be pertinent to ask: "Why are hops used in brewing?" Apart from the hop tannin, which is said to effect a readier coagulation of the albumenoids of the wort, it is particularly the hop resins that are to give the beer a pleasant flavour. But in addition to this function of flavouring agent, the hopping is a valuable means of increasing the stability of the beer, since the hop resins influence the development of bacteria.

HAYDUCK $^{1}$ was the first to prove the antiseptic action of the hop resins, in experiments made with lactic, butyric, and acetic bacteria, and the Pediococcus which forms lactic acid. Subsequently, RICHARDSON ${ }^{2}$ investigated the influence of aqueous hop decoctions on certain pathogenic organisms, and in nearly every instance observed a germicidal effect, and he ascribed this action mainly to the hop tannin. G. HARRIS MORRIS ${ }^{3}$ and Heron ${ }^{4}$ have also contributed to this subject. SchöNFELD ${ }^{5}$ was the first to follow up an observation of REICHARD's ${ }^{6}$ in his regearches on Sarcinæ. REICHARD found that cask hopping of beer was an effective means of checking sarcina diseases; and in consideration of this result, SснӧNFELD studied the influence of lupulin, and of soft resin on sarcinæ in beer. $\mathrm{He}$ concluded from his experiments that an alcoholic solution of the soft resins of hops may be regarded as an intense sarcina poison, and that the presence in beer of a sufficiency of dissolved soft resin will retard or check the development and virulence of the sarcina.

1 Wochenschrift für Brauerei, 1885, 268; r888, 945.

${ }^{2}$ Journal of the Federated Institutes of Brewing, I898, 128.

${ }^{3}$ Transactions of the Laboratory Club, 2, 26; 3, 24 .

4 Diary of the Brewing Room, 1899.

5 Wochenschrift für Brauevei, 1898, 292 ; 1899, 665.

${ }^{6}$ Zeitschrift f. d. ges. Brawwesen, 1894, 265. 
Following upon these experiments with the soft resin of hop, it was thought of interest to study the influence of the separate constituents of soft resin (at least $\alpha$-and $\beta$-resin) on various sarcinæ. For this purpose the author ${ }^{1}$ employed the crystallized $\alpha$ - and $\beta$-hop bitter acids. The experimental results show that :-

I. The $\alpha$ - and $\beta$-hop resins retard the reproduction of various sarcina organisms, the conditions as to stage of development being identical.

2. The $\alpha$-resin is less effective than the $\beta$-resin.

3. The $\beta$-resin may even exert a germicidal effect on certain species of sarcinæ.

4. The various species of sarcinæ (and Pediococci) are dissimilarly influenced by the hop resins.

The action of the individual constituents of the hop on various lower organisms having been considered, it remains to make some reference to their effect on higher organisms, and, more particularly, on warm-blooded animals. The earliest communication of the kind came from DRESER ${ }^{2}$, who employed in his experiments material supplied by Bungener. Owing to the fact that the $\beta$-hop-bitter acid is readily precipitated from alkaline solutions by weak acids, even carbonic acid being operative in this way, some difficulty was experienced when introducing the acid into the organism. It appears, however, that the acid, when administered internally, produced no abnormal effects on the animals experimented upon. Direct injection into the circulation resulted in an increase of the blood pressure, and restricted respiration. Resin isolated from beer, as also resin obtained from the crystallised bitter acid, was found to be quite indifferent.

Subsequently, FARKAS ${ }^{3}$ instituted similar experiments with the $\alpha$-acid, and found its action in many respects to resemble that of the $\beta$-acid, as reported by DReser. The main difference was that the $a$-acid attacks the central nervous system less and the peripheral

1 Zeitschrift f. d. ges. Brauwesen, I901, 333.

${ }^{2}$ Archiv fûr experimentelle Pathologie \& Pharmacologie, 1887, 129.

${ }^{3}$ Archiv fûr die gesammte Physiologie, 1902, 92, 6r. 
muscles more energetically, from which it appears that the lethal dose of the $a$-acid is distinctly higher for cold than for warm-blooded animals. When introduced by way of the stomach, the $\alpha$ - and $\beta$-acids, even when employed in large doses, are alike inoperative; and it may be concluded that the resinous components of hops may be disregarded, so far as concerns the beer in which they occur, for, as DRESER has shown, they are almost entirely converted into harmless derivatives.

The foregoing review of the present state of our knowledge relating to the bitter principles of the hop, although somewhat brief, is intended to give the reader a survey of the manifold views and investigations in this domain; and, in addition, to serve the experimenter as a guide to the extensive literature, the study of which must, of necessity, precede further researches. Let us hope that such researches, adding to this branch of our knowledge, may soon be undertaken, and prove of benefit, to the brewing industry. 


\section{HOP ALKALOIDS.}

By Philip Schidrowitz, Ph.D., F.C.S. $T_{\text {denote organic bases occurring in nature, and is sometimes }}^{\mathrm{HE} \text { term "Alkaloid" is nowadays generally understood to }}$ still further restricted to such organic bases as occur in plants. They are mostly of a markedly toxic nature. In addition to the resins, oil, wax, \&c., contained in the hop, there undoubtedly exist small quantities of bodies of a distinctly alkaloidal nature. These substances have not been studied as closely as some of the other hop constituents, but at least one of them has been fully identified. This is the well-known alkaloid morphine, to which further reference will be made below.

Historically Lermer (Chemisches Central-Blatt, I863, 78r) is apparently the first to have claimed the isolation of an alkaloid from hops. He obtained this substance, which, he affirmed, sublimes in fine needles, from an ethereal extract of hops, by a process which might reasonably be assumed to isolate alkaloidal substances if they were present. The substance had an alkaline reaction, and contained nitrogen, but was not further identified. 'Griessmayer (C. I874, 328) distilled an aqueous hop extract in the presence of potash. The distillate so obtained was saturated with hydrochloric acid, evaporated, the residue extracted with alcohol, the alcohol removed, and the remanent hydrochlorates decomposed by means of alkali in the presence of ether. He thus obtained an oil of a markedly alkaline nature, which gave a number of characteristic reactions, and had an odour strongly reminiscent of coniine. Griessmayer named this body "lupulin," and this has given rise to some confusion, as the term "lupulin" is usually employed to denote the hop "flour." The 
substance in question was stated by GRIESSMAYER not to be bitter. It is indeed questionable whether any appreciable part of the hop " bitter" is due to alkaloidal bodies, for the various bitter substances which have been isolated by different investigators have almost invariably been of an acid nature (cf. Breving Trade Review, I903, I7, 2 I6219). Personne indeed (Compt. Rend., r854, 309) claimed to have obtained an alkaloidal bitter from hops, but as he did not prepare the substance in question in anything approximating to a pure state, little weight can be attached to this assertion. Griessmayer obtained, in addition to "lupulin," considerable quantities of trimethylamine in the course of the distillation of the aqueous hopextract with potash or magnesia. This is of interest, inasmuch as it is in all probability a decomposition product of cholin, which was obtained from hops by Griess and Harrow (Ber. 18, 7I 7a). Cholin, in its turn, is probably not present as such in hops, but results from the splitting up of the more complicated base lecithin. As cholin has been shown to be present in unhopped wort in considerable quantities by KJELDAHL, this base (the term "alkaloid" is perhaps scarcely appropriate here) cannot be considered to be specifically introduced into beer by way of the hop.

Michel (Versuchstats. Ber. I4) claims to have isolated a nonvolatile liquid alkaloid, which he also terms "lupulin." It is not clear whether this substance is to be considered as identical with Griessmayer's alkaloid of the same name. Michel states that this alkaloid has been mistaken by analysts for coniine and colchicine. In this connexion it is of interest to recall Graham's (J. Chem. Soc., 5, 173) historical investigation, which resulted in completely dispelling the somewhat (at that time) prevalent idea that strychnine was used for the purpose of imparting additional bitterness to bitter ales. Williamson (Chemiker Zeit., I886, 20, 38, I47) extracted American hops with a solution of sugar, evaporated in a partial vacuum at a low temperature, and subsequently treated the extract so obtained with alcohol. The alcoholic extract yielded a residue which possessed powerful narcotic properties. This was further purified with dilute ammonia, ether, chloroform, benzene, and by recrystallisation. In this way Williamson obtained what he considered to be two new alkaloids, the one a 
crystalline solid, of a relatively insoluble character, the other a body of a somewhat more soluble nature. The former he considered to be isomeric with morphine, and he termed it "isomorphine," the latter he called "hopein." Williamson further states that these alkaloids occur in certain species of American wild hops to the extent of 0 I 5 per cent. They are only present in very small quantities in European hops.

LADEnBURG (Ber. 19, 783) proved beyond all manner of doubt that Williamson's "iso-morphine" is actually morphine, but he was unable to identify or to closely characterise the "hopein."

The presence of morphine in hops is extremely interesting, and may account for the well-known narcotic effects of some heavily-hopped beers-a narcotic effect which is admittedly not to be explained by the alcoholic contents alone. It is true that Wrlliamson could only find infinitesimal quantities of the alkaloids referred to in any hops other than certain American species, but the total number of specimens examined (in view of the great number of existing varieties) was relatively small.

Recently Koloman Farkas (Archiv. Physiol. I902, 92, 6I) has made some interesting pharmacological experiments with " hopein." He finds that when injected into the veins it acts as a strong cardiac poison, but that when administered by the mouth or into the blood (intra-venously) it is comparatively harmless. 


\section{THE PART PLAYED BY HOP TANNIN IN BREWING.}

THE tannin, or tannic acid, of hops formerly had a considerable reputation as an important contributor to the soundness of the wort; for Griessmeyer, having observed that the ordinary tannin of commerce, or gallo-tannic acid as it is frequently called, precipitated albuminoid matter from wort, concluded that the hop tannin had the same effect, and that such nitrogenous matter having been removed the ultimate beer would be by so much the sounder. This led to the use of tannin in the copper, and to this day in certain breweries there exist small pipes connecting the copper with the brewing room, which formerly served to convey the solution of tannic acid to the boiling wort at the proper time; and some brewers have not yet given up the addition of a small quantity of catechu (which contains about 50 per cent. of tannin) to the copper as a matter of routine.

Later work has conclusively proved that the amount of nitrogenous matter precipitated by the hop tannin is not only insignificant, but that no connection has been proved to exist between the percentage of nitrogen in beer and its stability. In this respect some of BRIANT and MEACHAM's work on hops may be quoted. In a paper published in 1894 (Institute of Bvewing, Vol. VII, p. 132) they give particulars of experiments made on the amount of nitrogenous matter precipitated from a wort by hops. A volume of wort running bright from the mash-tun was taken and carefully filtered at $150^{\circ} \mathrm{F}$, and the nitrogen in it was then determined by KJELDAHL's method; then two volumes of 500 c.c. each of this were taken and boiled for one hour, one being hopped at the rate of 
Io lbs. per quarter, the other left unhopped. The following results. were obtained calculated on the dry wort solids :-

Total soluble albuminoids in wort ... $\quad . .6$ 6.0 ro per cent.

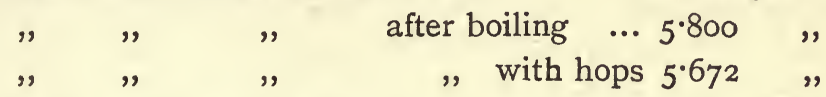

That is to say, of the total albuminoids present an apparent increase of only 2.13 per cent. $\frac{(0.128 \times 100)}{6.010}$ was precipitated by the addition of hops; and it does not follow that this was due to tannin, as there is another body known as phlobaphen, which is present in hops and is somewhat readily formed from tannin, and this body will likewise precipitate albuminoids. In connection with this subject another experiment of BRIANT and MEAcham (Institute of Bvewing, Vol. VI, p. I6o), is interesting. In it they estimate the total albuminoids in two brewery worts before and after boiling (a) with $8 \mathrm{lbs}$. of hops per quarter, and $(b)$ with $16 \mathrm{lbs}$. of hops per quarter. The amount precipitated in each case was practically the same-namely $(a)$, just at boiling 5.93 per cent. of soluble albuminoids, and after boiling 5.75 per cent., making a difference of 0.18 per cent., or 3.035 per cent. of the total albuminoid. In the case of $(b)$ the total albuminoid just at boiling was 6.01 per cent., and after boiling 5.83 , making again a difference of 0.18 or 2.995 per cent. on the total albuminoid present. The differences here are within experimental error, especially considering the practical difficulties under which the samples had to be taken in the brewery. As the first samples were taken just as the wort started boiling, it might be objected that some precipitation had taken place, but in answer to this it must be pointed out that tannin is not readily removed from hops, the authors saying that they have always found a considerable amount of tannin in the spent hops after one boiling in the copper. However, the experiments quoted are sufficient to prove that the value of tannin as an albuminoid precipitant is negligible, and this view is amply corroborated by the work of Hyde, Aubry, Heron, and others.

A later aspect of the tannin of hops is that it combines with certain albuminoid bodies of a peptone nature, and is therefore 
present in the finished beer as a " tanno-peptone." In reference to this Hayduck and Goldiner published some results in the Wochenschrift für Brawerei in 1894 (II, p. 409). The authors separated some tannin from hops and found that it precipitated albumin incompletely; elsewhere they state that it is soluble in boiling water, but almost insoluble in cold water, that some of this albumin tannin is still left in the clear and cooled wort, but that more comes out during fermentation, and only a trace remains in the finished beer; but the analyses they give show as much as ${ }^{\circ} 024$ per cent. in English ale, Munich and Berlin beer showing half as much. Now . 024 per cent. is really a large quantity; taking a pale ale of 23 lbs. gravity, hopped at the rate of ro lbs. per quarter, and dry-hopped with a pound per barrel, the hops containing 3 per cent. of tannin, and the malt giving 92 extract, then 90 per cent. of the tannin would have to go into the finished beer to give 024 per cent., and it is extremely doubtful if the whole of the tannin of the dry hops would be dissolved out of them. At this rate there would be no appreciable precipitation on the coolers. German beers are hopped far less than English beers, so that or 2 would be a high figure for the tannin in them also. But we can hardly consider it proved that the tannin is in chemical combination with the albuminoid matter, and MATHIEU's work referred to further on is highly suggestive.

The authors go on to say how the influence of hop tannin is shown in the much smaller quantity of soluble albumin present in strongly hopped English ale than in the much less hopped German beers. But here again no account is taken of the great differences in the processes of brewing English beer and German beer, especially in regard to the possible action of proteolytic enzymes in the decoction process; there are considerable differences also in the English and German malting processes, the latter being what we term highly forced, which would influence the amount and constitution of the nitrogenous bodies.

Heron (Fed. Inst. of Brew., I8g6, p. I6I) takes the "tannopeptone" view, and states (p. I77) "there is strong proof that tannin unites and forms a definite compound with certain nitro- 
genous matters derived from the malt, and which I have every reason to believe, from various tests which I have applied, to be peptone." Unfortunately, HERON does not give the tests which influenced his opinion, so that there is no evidence that such a compound exists. He goes on to say (boc. cit. p. I79) that he has reason to believe that this tanno-peptone is in many cases a cause of turbidity in beer, especially in cold weather, because the haze which will come on chilling a beer, and which disappears if the temperature is raised, is an extremely characteristic feature of tanno-peptone. If this were so one would expect the tanno-peptone body to be removed on prolonged chilling and filtering, such as takes place in certain modern methods of bottling beer, but it wil be found that these beers, which in some cases have been three weeks in cold store before filtering, still show the tannic acid reaction with ferric chloride. Moreover, the non-alcoholic "hop bitters" and "hop ales," whose basis is usually cane sugar, malt not entering into their composition, generally show the presence of tannic acid when tested. In this case any albuminoid matter present must have come from the sugars or saccharums employed, if they contain any, so can hardly be of a peptone nature.

On this point also a communication of MathieU to a congress of chemists at Rheims (Amrales de la Brasserie, 1904, p. II4) on various turbidities occurring in wine is à propos. In referring to a turbidity due to amorphous particles, he states that these give the reaction for tannoids, and also give off nitrogen by the action of soda-lime, thus indicating the presence of nitrogenous matter, but it does not follow that they are exclusively formed by a combination of tannin and albuminoids, and he thinks the existence of such combination in a chemical sense to be very doubtful. Thus, with aqueous or slightly alcoholic solutions of a tannin extracted from various parts of the grape, which had been purified with alcohol, and in which the absence of nitrogenous compounds had also been verified, deposits of insoluble resinous matter have been obtained (especially in the presence of light and oxygen) which present exactly the reactions obtained with tannoids observed in deposits of white wines obtained under similar conditions; but in this case there are certainly other substances. The author cites this fact of 
the apparently spontaneous precipitation of this tannin in order to show that it can be produced in wine without any albuminoid being necessarily present, and without requiring the formation of an insoluble compound with another substance. He adds that it appears to him impossible to consider these turbidities as due exclusively to combinations of tannin with albuminoids, either derived naturally or added with the finings.

We are inclined to the opinion that the tannic acid of hops plays a most insignificant part in the brewing of beer. We do not say that it plays no part, but whatever happens to it its power for good or evil is negligible.

On the other hand, looking at tannic acid from the point of view of its relationship to the hop, although we know but little we are on safer ground. For it may be considered more scientific to try first and ascertain what part may be assigned to the tannic acid in the hop plant, before hastening to the conclusion that as it is present in hops it is therefore necessary in beer.

There is a general consensus of opinionamong scientific experts that a high percentage of tannic acid denotes a good hop, but the figures obtained (and there are plenty of them) do not bear it out when the hop is valued commercially. We are inclined to agree with the opinion rather than the figures, for two reasons: first, because hops are seldom valued according to their real actual worth to the brewer as measured by their chief constituents, and secondly, because the various methods of estimating the tannic acid of hops leave a good deal to be desired on the score of accuracy. With respect to the first point, hops are valued nearly exclusively by the "nose" and the "rub," especially the former. We do not dispute the great importance of the "nose," as it certainly gives an indication of the final flavour of the beer in which the hops are used, in so far as the hops influence that flavour ; the " rub," too, is a qualitative test of the richness of the hop in resin. But to neither of these tests can any figure denoting measurement be applied, and they are so subject to the personal equation of the person testing that their value as tests is uncertain and indefinite. 
With respect to the second point, investigators are by no means agreed as to the best method of estimating the tannic acid in hops. Heron (loc. sit.) cites several methods, one depending on the absorption of tannic acid by "hide" powder, the decrease in weight being put down to tannic acid absorbed. Heron condemns this method, we think justly, on the score that "hide" powder is indefinite in its reaction and of greatly varying activity; it is certainly not the class of reagent which a chemist cares to deal with. In another process, generally known as LöwentHaL's method, the extract containing the tannin is titrated with permanganate of potash before and after treatment with "hide" powder, and this method certainly gives better results than the weighing method, but still introduces the objectionable reagent. The method which Heron finally used himself was a slight modification of that known as LöwenthaL's gelatin process. In this last case the tannic acid is precipitated with gelatin and titration made before and after with potassium permanganate. But HERON prefers to calculate his potassium permanganate into terms of oxalic acid, whereas by the usual method a titration of the standard potassium permanganate solution is made on a solution of tannin of known strength. This last method would appear to give results more in accordance with facts, the only objection that can be raised being in respect to the tannin employed for the solution. Instead of extracting his hops by successive boilings with water HERoN only digests them in the boiling water bath for one hour, and he gives figures to show that by this means he obtains the whole of the tannic acid. The very proper objection he raises to repeated boilings is that the tannic acid is liable to be partially converted into phlobaphen. There is yet another method of estimating tannin devised by Kokosinski, based on the property of tannic acid of absorbing iodine with great energy in the presence of alkaline carbonates. It is recommended by Moritz and Morris ("Text Book of the Science of Brewing," p. 497), but does not appear to have found favour with investigators.

Hence it will be seen, that with varying methods of varying degrees of accuracy there is great difficulty in basing any conclusive argument on figures as to the relative value of tannic acid; a 
reliable analytical method must first be agreed upon, and even then a more scientific method of valuing hops will also be necessary.

However, in respect to the part played by tannic acid in the hop plant, Beckenhaupt has made some remarkable observations. $\mathrm{He}$ says in regard to the proportion of tannin (Petit Journal du Brasseur, I903, p. 6I8) that it appears to correspond to a red colouration of the stalks, a colouration which characterises early hops. This colour must be attributed to the presence of anthocyanine, a substance in which KERNER thinks he distinguishes a protection for the protoplasm against too strong a light, and also a means of transforming the light rays into heat rays. It seems clear that anthocyanine protects the plant at the beginning of its vegetative career against inclement weather, and it is possible that it also protects the new-formed chlorophyll against the absorption of yellow rays. It is very interesting to remark that DeNNeRT considers this anthocyanine to be a derivative or product of the transformation of tannin, and by plunging green stalks of the hop into a solution of tannic acid, BECKENHAUPT has obtained a weak but undoubted colouration of anthocyanine. Also by the action of potassium carbonate on tannin solution the same colouration is obtained. This relationship, he says, between tannin and anthocyanine in early hops serves to explain the presence of large quantities of tannin in the cones, and at the same time is useful in appreciating the constitution of each variety, for there is no doubt that it is the tannin which has allowed the young hops to develop when placed under unfavourable food conditions. The plant requires certain organs to protect it against wet, mould, animals, and insects, but the means of defence vary according to the situation and dangers present, and the conditions under which the plant has to develop. There is reason to think that the lupulin or the resins protect it against premature wet, at the same time that the bitter acids and the strongly smelling essential oil protect it against insects and birds which would devour it. It is the tannin, on the other hand, which appears to prevent the cone from prematurely falling to pieces. One knows that the cones which develop freely, and which naturally contain much nitrogen, disintegrate readily; frequently it is sufficient only to shake the plant to cause them to 
fall. On the contrary, the fine varieties which contain much tannin are solidly fixed and drop less readily.

From these interesting remarks of BECKENHAUPT it would appear that the abundance of tannin is a good sign in a hop, but that its presence in moderately small quantities is not of necessity a bad sign, much depending on the variety and the season. However, it appears to us that at the present time tannin is a constituent of the hop which concerns the hop grower far more than the brewer; but when experiments in the hop garden have fully demonstrated its purpose and value, it is possible that its estimation may be useful to brewers as bearing a certain significance in respect to the quality of the hop. 


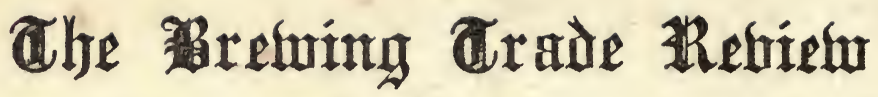

(The Official Organ of thr Brewbrs' Society.)

SUBSCRIPTION - - 20s. per Annum, post free

Published on the 1st of each month

BY

W. H. Phelp, at The Review Press, i3 Little Trinity Lane

Upper Thames Street, E.C.

\section{Dublications by The Review Dress 2 imited.}

\section{MALTING JOURNAL.}

By Charles F. Thatcher, Cork. Designed for the use of Maltsters, Brewers, Students, and Foremen, to facilitate the daily registration of all essential details during the manufacture of Malt. Supplied either as loose sheets or bound in books.

\section{THE FLOORING AND KILNING OF MALT.}

By T. Haynes, Jun. Price 2s., post free.

\section{PRACTICAL MANAGEMENT OF PURE YEAST.}

By Alfred Jörgensen. Price 5s.; by post 5s. $2 d$.

\section{A COST PRICE BOOK.}

A Book to be kept in the brewing room, enabling the brewer to tell at a glance the cost price per barrel of each brewing. Descriptive circular and specimen page will be sent post free on application to the publishers.

\section{Cellar management.}

A few practical instructions to Publicans. Sample card on application.

$$
\text { \&c., \&c. }
$$

13 Little Trinity Lane, Upper Thames Street, London, E.C. 
(

1

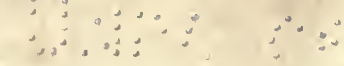

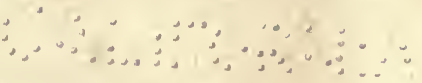

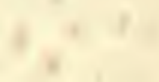

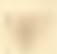

$\sqrt{2}$

x

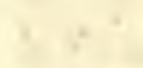

1

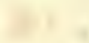




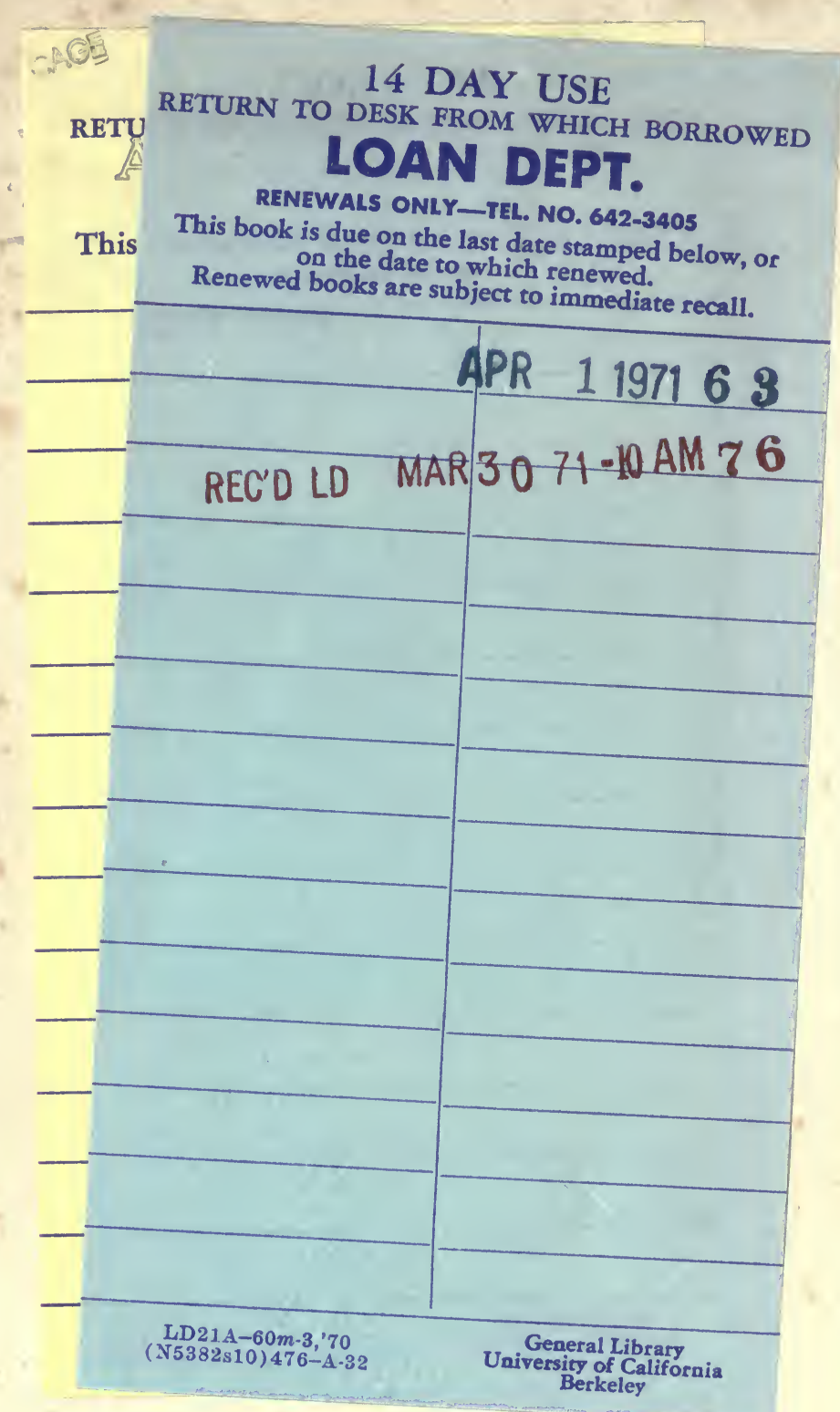




\section{YC 61914}

586540

UNIVERSITY OF CALIFORNIA LIBRARY 
